\title{
Cochrane
}

Library

Cochrane Database of Systematic Reviews

\section{Antiplatelet and anticoagulant agents for primary prevention of thrombosis in individuals with antiphospholipid antibodies} (Review)

Bala MM, Paszek E, Lesniak W, Wloch-Kopec D, Jasinska K, Undas A

Bala MM, Paszek E, Lesniak W, Wloch-Kopec D, Jasinska K, Undas A.

Antiplatelet and anticoagulant agents for primary prevention of thrombosis in individuals with antiphospholipid antibodies.

Cochrane Database of Systematic Reviews 2018, Issue 7. Art. No.: CD012534.

DOI: 10.1002/14651858.CD012534.pub2.

www.cochranelibrary.com

Antiplatelet and anticoagulant agents for primary prevention of thrombosis in individuals with antiphospholipid 
TABLE OF CONTENTS

HEADER 1

ABSTRACT

PLAIN LANGUAGE SUMMARY

SUMMARY OF FINDINGS

BACKGROUND

OBJECTIVES

METHODS

RESULTS

Figure 1.

Figure 2.

Figure 3.

DISCUSSION

AUTHORS' CONCLUSIONS

ACKNOWLEDGEMENTS

REFERENCES

CHARACTERISTICS OF STUDIES

DATA AND ANALYSES

Analysis 1.1. Comparison 1 Anticoagulant with or without ASA versus ASA only, Outcome 1 Thrombosis.

Analysis 1.2. Comparison 1 Anticoagulant with or without ASA versus ASA only, Outcome 2 Minor bleeding.

Analysis 2.1. Comparison 2 ASA only versus placebo, Outcome 1 Thrombosis.

Analysis 2.2. Comparison 2 ASA only versus placebo, Outcome 2 Bleeding.

Analysis 3.1. Comparison 3 ASA with LMWH versus placebo or IVIG, Outcome 1 Thrombosis.

Analysis 3.2. Comparison 3 ASA with LMWH versus placebo or IVIG, Outcome 2 Bleeding.

Analysis 4.1. Comparison 4 ASA + high-dose LMWH versus ASA + low-dose LMWH or UFH, Outcome 1 Thrombosis.

Analysis 4.2. Comparison $4 A S A+$ high-dose LMWH versus ASA + low-dose LMWH or UFH, Outcome 2 Major/excessive bleeding.

Analysis 4.3. Comparison 4 ASA + high-dose LMWH versus ASA + low-dose LMWH or UFH, Outcome 3 Subcutaneous bruises. ....

Analysis 5.1. Comparison 5 Sensitivity analyses anticoagulant with or without ASA versus ASA only, Outcome 1 Thrombosis best-worst scenario.

Analysis 5.2. Comparison 5 Sensitivity analyses anticoagulant with or without ASA versus ASA only, Outcome 2 Thrombosis worst-best scenario.

Analysis 6.1. Comparison 6 Sensitivity analyses ASA with LMWH versus placebo or IVIG, Outcome 1 Thrombosis best-worst scenario.

Analysis 6.2. Comparison 6 Sensitivity analyses ASA with LMWH versus placebo or IVIG, Outcome 2 Thrombosis worst-best scenario.

APPENDICES

CONTRIBUTIONS OF AUTHORS

DECLARATIONS OF INTEREST

SOURCES OF SUPPORT

DIFFERENCES BETWEEN PROTOCOL AND REVIEW

NOTES

INDEX TERMS

1

2

4

9

10

10

12

13

15

16

19

21

21

22

28

46

46

46

47

47

48

48

49

49

49

50

50 
[Intervention Review]

\title{
Antiplatelet and anticoagulant agents for primary prevention of thrombosis in individuals with antiphospholipid antibodies
}

\author{
Malgorzata M Bala1, Elżbieta Paszek², Wiktoria Lesniak ${ }^{3}$, Dorota Wloch-Kopec ${ }^{4}$, Katarzyna Jasinska ${ }^{5}$, Anetta Undas 6
}

1Chair of Epidemiology and Preventive Medicine; Department of Hygiene and Dietetics; Systematic Reviews Unit - Polish Cochrane Branch, Jagiellonian University Medical College, Krakow, Poland. 2Department of Interventional Cardiology, Jagiellonian University Medical College, Krakow, Poland. 32nd Department of Internal Medicine, Jagiellonian University Medical College, Krakow, Poland. ${ }^{4}$ Neurology Department, Jagiellonian University Medical College, Krakow, Poland. ${ }^{5}$ Students' Research Group, Systematic Reviews Unit-Polish Cochrane Branch, Jagiellonian University Medical College, Krakow, Poland. 6 Institute of Cardiology, Jagiellonian University Medical College, Krakow, Poland

Contact address: Malgorzata M Bala, Chair of Epidemiology and Preventive Medicine; Department of Hygiene and Dietetics; Systematic Reviews Unit - Polish Cochrane Branch, Jagiellonian University Medical College, Kopernika 7, Krakow, 31-034, Poland. gosiabala@mp.pl.

Editorial group: Cochrane Vascular Group.

Publication status and date: New, published in Issue 7, 2018.

Citation: Bala MM, Paszek E, Lesniak W, Wloch-Kopec D, Jasinska K, Undas A. Antiplatelet and anticoagulant agents for primary prevention of thrombosis in individuals with antiphospholipid antibodies. Cochrane Database of Systematic Reviews 2018, Issue 7. Art. No.: CD012534. DOI: 10.1002/14651858.CD012534.pub2.

Copyright @ 2018 The Cochrane Collaboration. Published by John Wiley \& Sons, Ltd.

\section{A B S T R A C T}

\section{Background}

Antiphospholipid syndrome (APS) is an autoimmune disease characterised by the presence of antiphospholipid (aPL) antibodies that have prothrombotic activity. Antiphospholipid antibodies are associated with an increased risk of pregnancy complications (recurrent miscarriage, premature birth, intrauterine growth retardation) and thrombotic events (both arterial and venous). The most common thrombotic events include brain ischaemia (stroke or transient ischaemic attack) and deep vein thrombosis. To diagnose APS, the presence of aPL antibodies in two measurements and at least one thrombotic event or pregnancy complication are required. It is unclear if people with positive aPL antibodies but without any previous thrombotic events should receive primary antithrombotic prophylaxis.

\section{Objectives}

To assess the effects of antiplatelet or anticoagulant agents versus placebo or no intervention or other intervention on the development of thrombosis in people with aPL antibodies who have not had a thrombotic event. We did not address obstetric outcomes in this review as these have been thoroughly addressed by other Cochrane Reviews.

\section{Search methods}

We searched the Cochrane Vascular Specialised Register (4 December 2017), the Cochrane Central Register of Controlled Trials (CENTRAL) (last search 29 November 2017), MEDLINE Ovid, Embase Ovid, CINAHL, and AMED (searched 4 December 2017), and trials registries (searched 29 November 2017). We also checked reference lists of included studies, systematic reviews, and practice guidelines, and contacted experts in the field.

\section{Selection criteria}

We included randomised controlled trials (RCTs) that compared any antiplatelet or anticoagulant agents, or their combinations, at any dose and mode of delivery with placebo, no intervention, or other intervention. We also included RCTs that compared antiplatelet or anticoagulant agents with each other or that compared two different doses of the same drug. We included studies performed in people of any age and with no history of thrombosis (as defined by APS Sapporo classification criteria or updated Sydney classification criteria), but with aPL antibodies confirmed on at last two separate measurements. The studies included both pregnant women who tested positive for 
aPL antibodies and had a history of recurrent obstetric complications, as well as non-pregnancy related cases with positive screening for antibodies, in accordance with the criteria mentioned above.

\section{Data collection and analysis}

Pairs of authors independently selected studies for inclusion, extracted data, and assessed the risk of bias for the included studies and quality of evidence using GRADE. Any discrepancies were resolved through discussion or by consulting a third review author when necessary. In addition, one review author checked all the extracted numerical data.

\section{Main results}

We included nine studies involving 1044 randomised participants. The studies took place in several countries and had different funding sources. No study was at low risk of bias in all domains. We classified all included studies as at unclear or high risk of bias in two or more domains. Seven included studies focused mainly on obstetric outcomes. One study included non-pregnancy-related cases, and one study included both pregnancy-related cases and other patients with positive results for aPL antibodies. The remaining studies concerned women with aPL antibodies and a history of pregnancy failure. Four studies compared anticoagulant with or without acetylsalicylic acid (ASA) versus ASA only and observed no clear difference in thrombosis risk (risk ratio (RR) $0.98,95 \%$ confidence interval (CI) 0.25 to $3.77 ; 4$ studies; 493 participants; low-quality evidence). No major bleeding was reported, but minor bleeding risk (nasal bleeding, menorrhagia) was higher in the anticoagulant with ASA group as compared with ASA alone in one study (RR 22.45, 95\% Cl 1.34 to $374.81 ; 1$ study; 164 participants; low-quality evidence). In one study ASA was compared with placebo, and there were no clear differences in thrombosis (RR $5.21,95 \% \mathrm{Cl} 0.63$ to $42.97 ; 1$ study; 98 participants; low-quality evidence) or minor bleeding risk between the groups (RR 3.13, $95 \% \mathrm{Cl}$ 0.34 to 29.01; 1 study; 98 participants; low-quality evidence), and no major bleeding was observed. Two studies compared ASA with low molecular weight heparin (LMWH) versus placebo or intravenous immunoglobulin (IVIG), and no thrombotic events were observed in any of the groups. Moreover, there were no clear differences in the risk of bleeding requiring transfusion (RR 9.0,95\% $\mathrm{Cl} 0.49$ to $164.76 ; 1$ study; 180 participants; moderate-quality evidence) or postpartum bleeding (RR 1.30, 95\% Cl 0.60 to 2.81; 1 study; 180 participants; moderatequality evidence) between the groups. Two studies compared ASA with high-dose LMWH versus ASA with low-dose LMWF or unfractionated heparin (UFH); no thrombotic events or major bleeding was reported. Mortality and quality of life data were not reported for any of the comparisons.

\section{Authors' conclusions}

There is insufficient evidence to demonstrate benefit or harm of using anticoagulants with or without ASA versus ASA alone in people with aPL antibodies and a history of recurrent pregnancy loss and with no such history; ASA versus placebo in people with aPL antibodies; and ASA with LMWH versus placebo or IVIG, and ASA with high-dose LMWH versus ASA with low-dose LMWH or UFH, in women with aPL antibodies and a history of recurrent pregnancy loss, for the primary prevention of thrombotic events. In a mixed population of people with a history of previous pregnancy loss and without such a history treated with anticoagulant combined with ASA, the incidence of minor bleeding (nasal bleeding, menorrhagia) was increased when compared with ASA alone. Studies that are adequately powered and that focus mainly on thrombotic events are needed to draw any firm conclusions on the primary prevention of thrombotic events in people with antiphospholipid antibodies.

\section{PLAIN LANGUAGE SUMARY}

\section{Anticoagulant and antiplatelet drugs, or both, for reducing the risk of blood clots in susceptible individuals}

\section{Background}

Anitiphospholipid (aPL) antibodies are proteins produced by the immune system in some people that are directed against components of their own cells. The presence of such antibodies may increase the risk of developing blood clots (thrombosis) in the blood vessels or pregnancy-related complications (such as recurrent miscarriage, stillbirth, premature birth, or serious illness of a pregnant woman). Blood clots within arteries can cause strokes, resulting in brain damage or reversible neurological symptoms. Blood clots in veins are associated with a buildup of fluid in the limbs (oedema) and pain, and if moved or translocated, may cause a blockage in a major vessel in the lung (pulmonary embolism).

In individuals who have previously had a thrombotic event, two types of drugs are commonly used to prevent recurrent thrombotic events: anticoagulants and antiplatelet agents. Anticoagulants prevent clots (thrombus) formation by interfering with the activity of proteins involved in blood clotting (clotting factors), while antiplatelets, usually aspirin, prevent platelet aggregation and impair clot formation. The most common side effect of anticoagulant or antiplatelet treatment is a tendency to bleed. However, little is known about the benefits and harms of using anticoagulants and antiplatelets in people who have aPL antibodies but have not previously had any thrombotic event.

\section{Review question}

This review aimed to establish the potential benefits and harms of using anticoagulants and antiplatelet drugs for preventing thrombotic events, in people who are susceptible but have not as of yet had any thrombotic event.

\section{Study characteristics}


The evidence is current as of December 2017. We searched for studies that randomly allocated people with aPL antibodies and without any previous thrombotic event to different treatments, including anticoagulants, antiplatelet drugs, or both. We identified nine studies involving 1044 participants. The studies took place in several different countries. One study was multicentred and had a variety of funding sources. In two studies aspirin was compared with placebo (dummy treatment). Four studies compared an anticoagulant with or without aspirin with aspirin alone. The remaining studies compared combinations of antiplatelet agents, anticoagulants, other treatments, or two different doses of the same drug. The majority of the studies concerned women with aPL antibodies and a history of pregnancy failure. One study included non-pregnancy-related cases, and one study included pregnancy-related cases and other patients with positive results for aPL antibodies.

\section{Key results}

We summarised the effects of the treatments using the following comparisons: aspirin only versus placebo, anticoagulant only or with aspirin versus aspirin only, aspirin with anticoagulant versus placebo or other treatment. We found no clear differences in the number of individuals with thrombotic events in the compared groups. One study revealed an increased risk of minor bleeding (such as nasal bleeding or intensified menstruation) in participants receiving aspirin and anticoagulant. All other analyses did not show any meaningful differences in the number of participants with bleeding. None of the studies reported on risk of death or quality of life. We found no clear difference between the groups in any of the comparisons for unwanted effects other than bleeding, where this information was reported; the more common of these effects included mild gastrointestinal symptoms in the aspirin group and allergic reactions in the aspirin with anticoagulant group.

\section{Quality of the evidence}

We assessed none of the studies as at low risk of bias because of methodological concerns or reporting of the results. We judged the overall quality of evidence to be low to moderate, it was downgraded due to unclear or high risk of bias, small number of studies and imprecise results. 


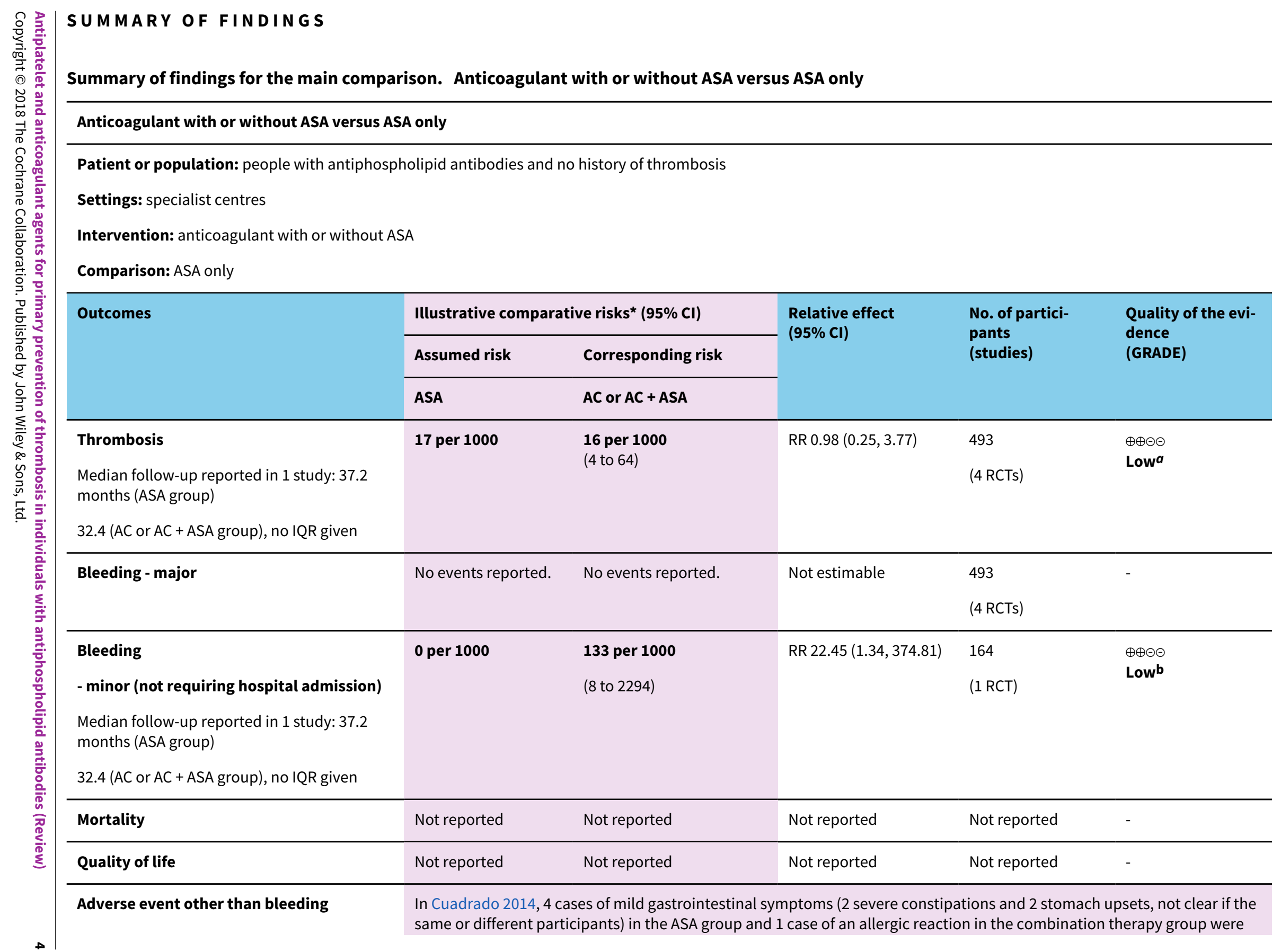


*The basis for the assumed risk (e.g. the median control group risk across studies) is provided in footnotes. The corresponding risk (and its $95 \%$ confidence interval) is based on the assumed risk in the comparison group and the relative effect of the intervention (and its $95 \% \mathrm{Cl}$ ).

AC: anticoagulant; ASA: acetylsalicylic acid; CI: confidence interval; IQR: interquartile range; RCT: randomised clinical trial; $\mathbf{R R}$ : risk ratio

GRADE Working Group grades of evidence

High quality: Further research is very unlikely to change our confidence in the estimate of effect.

Moderate quality: Further research is likely to have an important impact on our confidence in the estimate of effect and may change the estimate.

Low quality: Further research is very likely to have an important impact on our confidence in the estimate of effect and is likely to change the estimate.

Very low quality: We are very uncertain about the estimate.

aDowngraded by one level due to unclear or high risk of bias in more than one domain in all studies and one level due to wide $95 \% \mathrm{Cl}$ for both benefit and harm.

bDowngraded by one level due to wide $95 \% \mathrm{Cl}$ and one level due to the presence of only one study with a small number of participants.

\section{Summary of findings 2 . ASA versus placebo}

\section{ASA versus placebo}

Patient or population: people with antiphospholipid antibodies and no history of thrombosis

Settings: university department and 3 unspecified centres

Intervention: ASA

Comparison: placebo

\begin{tabular}{|c|c|c|c|c|c|}
\hline \multirow[t]{3}{*}{ Outcomes } & \multicolumn{2}{|c|}{ Illustrative comparative risks $(95 \% \mathrm{Cl})$} & \multirow{3}{*}{$\begin{array}{l}\text { Relative effect } \\
(95 \% \mathrm{Cl})\end{array}$} & \multirow{3}{*}{$\begin{array}{l}\text { No. of partici- } \\
\text { pants } \\
\text { (studies) }\end{array}$} & \multirow{3}{*}{$\begin{array}{l}\text { Quality of the evi- } \\
\text { dence } \\
\text { (GRADE) }\end{array}$} \\
\hline & Assumed risk & Corresponding risk & & & \\
\hline & Placebo & ASA & & & \\
\hline $\begin{array}{l}\text { Thrombosis } \\
\text { Mean follow-up } 2.3+/-0.95 \text { years }\end{array}$ & 20 per 1000 & $\begin{array}{l}105 \text { per } 1000 \\
(13 \text { to } 860)\end{array}$ & RR $5.21(0.63,42.97)$ & $\begin{array}{l}98 \\
(1 \mathrm{RCT})\end{array}$ & $\begin{array}{l}\oplus \oplus \ominus \ominus \\
\text { Lowa }\end{array}$ \\
\hline Bleeding - major & No events reported. & No events reported. & Not estimable & $\begin{array}{l}98 \\
(1 \mathrm{RCT})\end{array}$ & - \\
\hline Bleeding - minor & 20 per 1000 & 63 per 1000 & RR $3.13(0.34,29.01)$ & 98 & $\oplus \oplus \ominus \odot$ \\
\hline
\end{tabular}




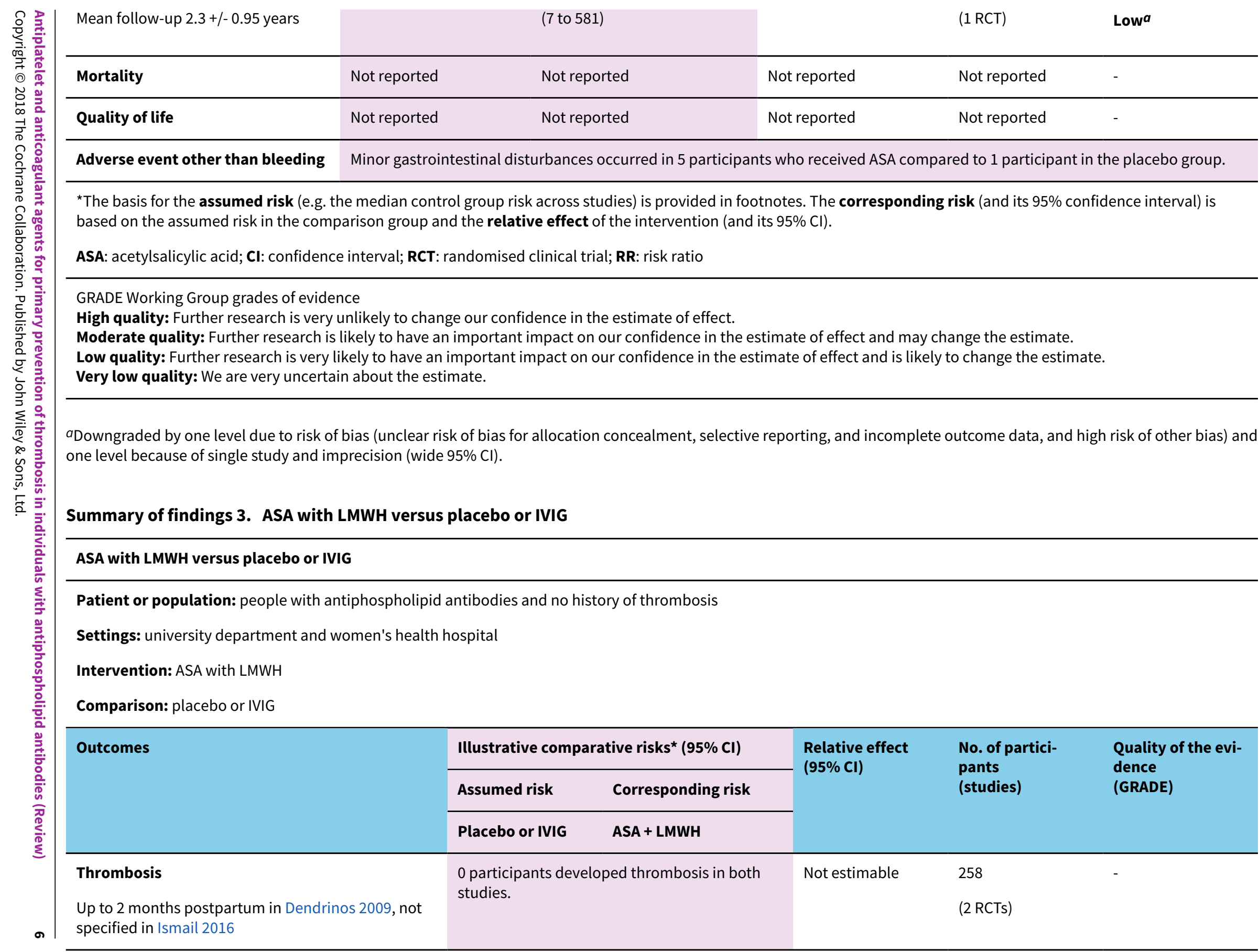

High quality: Further research is very unlikely to change our confidence in the estimate of effect.

Moderate quality: Further research is likely to have an important impact on our confidence in the estimate of effect and may change the estimate.

Low quality: Further research is very likely to have an important impact on our confidence in the estimate of effect and is likely to change the estimate.

(low quality: We are very uncertain about the estimate.

aDowngraded by one level due to risk of bias (unclear risk of bias for allocation concealment, selective reporting, and incomplete outcome data, and high risk of other bias) and Summary of findings 3. ASA with LMWH versus placebo or IVIG

\section{ASA with LMWH versus placebo or IVIG}

Patient or population: people with antiphospholipid antibodies and no history of thrombosis

Settings: university department and women's health hospital

Intervention: ASA with LMWH

Comparison: placebo or IVIG

specified in Ismail 2016 


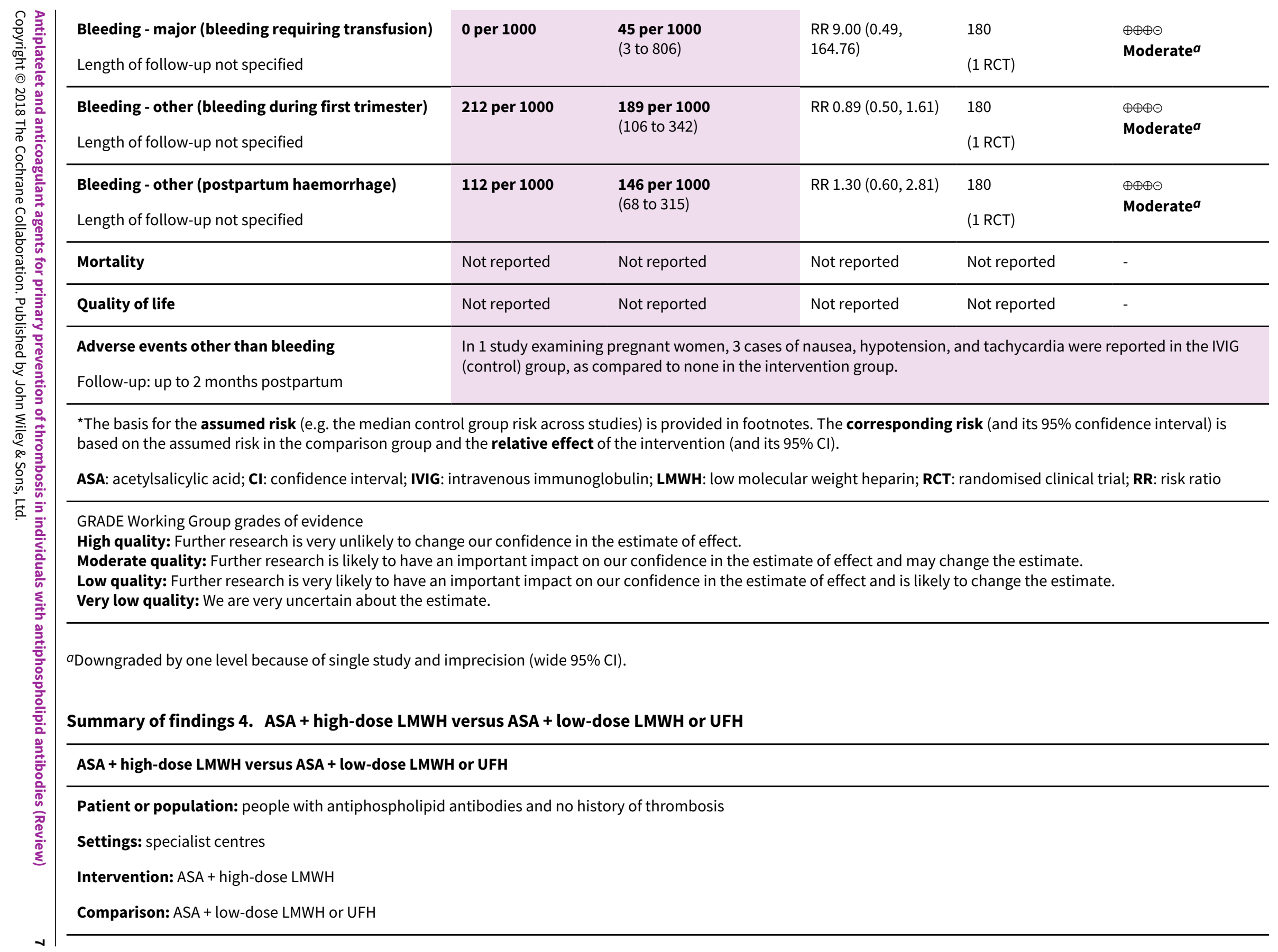




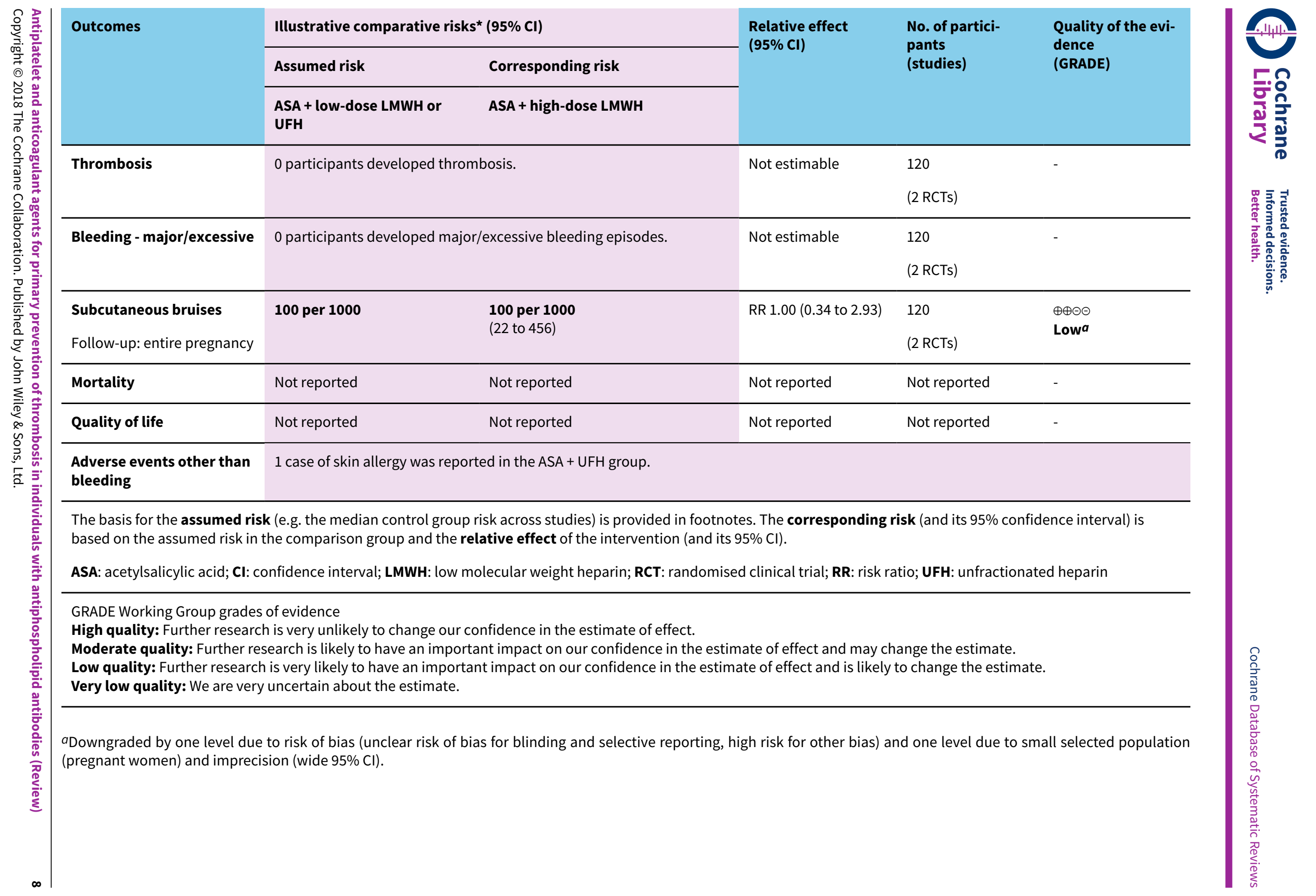




\section{B A C K G R O U N D}

\section{Description of the condition}

Antiphospholipid syndrome (APS), also known as Hughes syndrome, is an autoimmune condition triggered by antiphospholipid (aPL) antibodies that have prothrombotic activity. The aPL antibodies are a heterogeneous group of antibodies directed against certain proteins in blood, such as protein C (Chen 2010), and on platelet cell membranes (annexin V) (Rand 2008), tissue factor and other (Chen 2010). The risk of prothrombotic activity varies depending on the type of antibodies, which include: anticardiolipin ( $\mathrm{aCL}$ ) antibodies, anti-beta2glycoprotein I (anti- $\beta_{2} \mathrm{GPI}$ ) antibodies, and lupus anticoagulant (LA) (Sebastiani 1999). According to the literature, aPL antibodies are found in approximately $1 \%$ to $5 \%$ of the general population; $6 \%$ (interquartile range (IQR) $2 \%$ to $13 \%$ ) of women who present with pregnancy complications; $9 \%$ of women with spontaneous abortion; 9.5\% (IQR 5.3\% to $13.8 \%$ ) of individuals with deep vein thrombosis; $11 \%$ (IQR $4 \%$ to $23 \%$ ) of individuals with myocardial infarction; and $13.5 \%$ (IQR $6.8 \%$ to $23.3 \%$ ) of individuals with ischaemic stroke (Amengual 2015; Andreoli 2013; Gomez-Puerta 2014). The aPL antibodies can be detected in people diagnosed with various conditions, such as autoimmune diseases, and most commonly systemic lupus erythematosus (SLE) (Abu-Shakra 1995), or during diagnostic processes that investigate foetal deaths, premature births, and recurrent spontaneous abortions (Miyakis 2006). The isolated presence of aPL antibodies is insufficient to diagnose APS. According to the modified criteria by Miyakis 2006, a person is required to meet at least one clinical criterion related to either vascular thrombosis or an obstetric complication, as well as the presence of one or more specified aPL antibody on two or more occasions, at least 12 weeks apart. It is unclear if individuals who have aPL antibodies present in their circulating blood but who have not experienced any thrombotic clinical events should receive primary antithrombotic prophylaxis. Empson 2005 conducted a Cochrane Review addressing this issue in pregnant women with prior miscarriage and aPL antibodies, and showed that combined unfractionated heparin (UFH) and acetylsalicylic acid (ASA) may reduce pregnancy loss by $54 \%$. More recently, another systematic review, Amengual 2015, assessed the effect of ASA in asymptomatic women who were positive for aPL antibodies and who had no history of recurrent miscarriage or intrauterine foetal death. Amengual 2015 did not find evidence of the superiority of prophylactic treatment with ASA compared to placebo or usual care to prevent obstetric complications in otherwise healthy women with aPL antibodies during their first pregnancy.

\section{Description of the intervention}

Antiplatelet drugs inhibit platelet function, mostly platelet aggregation, which reduces the probability of thrombus formation (Depta 2015; Weitz 2012). The most commonly used antiplatelet agent is acetylsalicylic acid (ASA), which is also known as aspirin. Anticoagulants are agents that interfere with blood coagulation and thereby reduce fibrinogen polymerisation and blood clot formation.

In standard practice, antiplatelet agents (ASA, clopidogrel, prasugrel, and ticagrelor) are used in people with coronary artery disease (Montalescot 2013; Roffi 2016; Windecker 2014), or peripheral artery disease (Alonso-Coello 2012), to prevent thrombus formation.
Anticoagulant agents (vitamin $\mathrm{K}$ antagonists (VKA): warfarin, acenocoumarol) and non-vitamin $\mathrm{K}$ antagonists, which are known as direct oral anticoagulants (DOAC) (dabigatran, rivaroxaban, apixaban, edoxaban) (Ageno 2012; Kearon 2016), are used to prevent thrombus formation in people with atrial fibrillation (Lip 2014). Vitamin $\mathrm{K}$ antagonists are also used after implantation of an artificial heart valve (Whitlock 2012), to treat venous thromboembolism (Kearon 2016; Weitz 2016), and in the primary prevention of thromboembolic complications in people with knee or hip replacement surgery (Gomez-Outes 2012).

Low molecular weight heparins (LMWHs) and, less often, UFH are also used to treat and prevent thrombotic events (Garcia 2012; Vandvik 2012), for example in individuals who are immobilised because of a medical condition, Kahn 2012, or surgery, Douketis 2012, in people with cancer (Farge 2016), or in pregnant women with thrombophilia (Bates 2012).

\section{How the intervention might work}

The presence of aPL antibodies is associated with an increased risk of thrombus formation with all its consequences (Giannakopoulos 2007; Giannakopoulos 2013). People who have had a thrombotic event and who meet APS criteria are recommended to receive anticoagulation (Ruiz-Irastorza 2011). The benefits of antiplatelet (ASA) use in the context of primary prevention of cardiovascular events have been shown (Guirguis-Blake 2016), and anticoagulants have been examined in the primary prevention of several prothrombotic conditions (MRCGPRF 1998; Rasmussen 2012). It is therefore assumed that antiplatelet and anticoagulant agents may decrease the incidence of thrombus formation based on their mechanism of action (Cuadrado 2014; Erkan 2007). Acetylsalicylic acid, a commonly used antiplatelet agent, acts through inhibition of platelet cyclooxygenase 1 (COX-1), which leads to blockage of the production of thromboxane A2 (TXA2) (Warner 2011), while clopidogrel, another commonly used antiplatelet agent, acts through the blockage of $\mathrm{P} 2 \mathrm{Y}$ receptors on platelets, thus impairing their function (Wijeyeratne 2011). Unfractionated heparin and LMWHs are administered intravenously or subcutaneously and form complexes with antithrombin molecules, which leads to the neutralisation of factor $\mathrm{Xa}$ and deactivation of thrombin (Garcia 2012). Additionally, UFH directly inhibits thrombin activity. Vitamin $\mathrm{K}$ antagonists are oral antagonists of vitamin $\mathrm{K}$. They reduce the production of coagulation factors II, VII, IX, and X and proteins $C$ and S (Ageno 2012). Among DOAC, there are direct thrombin inhibitors (dabigatran), which block the catalytic site or the substrate recognition site in the thrombin molecule, and factor Xa inhibitors (rivaroxaban, apixaban, edoxaban), which cause factor Xa inhibition that is not mediated by antithrombin (Ageno 2012).

The administration of all anticoagulants is generally associated with a high risk of bleeding. Vitamin $\mathrm{K}$ antagonists are potentially teratogenic and require regular international normalised ratio (INR) monitoring (Torbicki 2008). Important UFH side effects are heparininduced thrombocytopenia (HIT) and osteopenia (Linkins 2012; Rajgopal 2008). Low molecular weight heparins, for which the most common complications are bleeding, allergic reactions, and injection site reactions, are associated with a lower risk of HIT (Junqueira 2012; Martel 2005), and some studies also indicate a lower risk of major bleeding compared to UFH (Alikhan 2014). 


\section{Why it is important to do this review}

The issue of secondary prevention of thrombosis in people with APS has been or will be addressed by other Cochrane Reviews. Two Cochrane Reviews have thoroughly addressed obstetric outcomes: one review included people with aPL antibodies or lupus anticoagulant (Empson 2005), while the other included people with unexplained recurrent miscarriage with or without inherited thrombophilia (de Jong 2014). One Cochrane Review protocol considers using antiplatelets or anticoagulants to prevent recurrent peripheral vascular thrombosis (Islam 2016). We have also published a Cochrane Review on secondary prevention of recurrent thrombosis, particularly ischaemic stroke, in people with APS (Bala 2017a). However, we have not identified any Cochrane Review that addresses the issue of primary prevention of thrombosis in individuals with aPL antibodies, while at least one randomised controlled trial (RCT) has investigated this issue (Erkan 2007). Two recently published systematic reviews addressed this issue in part (Arnaud 2014; Qushmaq 2014). Arnaud 2014 assessed the effect of ASA and included all types of study designs (RCTs and observational studies, both prospective and retrospective), and Qushmaq 2014 considered all primary prophylactic interventions but included all types of study designs and excluded studies published in languages other than English. This Cochrane Review presents a broader scope of studies, including those that assess antiplatelet agents other than acetylsalicylic acid, as well as anticoagulants.

\section{O B JECTIVES}

To assess the effects of antiplatelet and anticoagulant agents versus placebo or no intervention or other intervention on the development of thrombosis in people with aPL antibodies who have not had a thrombotic event.

\section{METHODS}

\section{Criteria for considering studies for this review}

\section{Types of studies}

Randomised controlled trials (RCTs).

\section{Types of participants}

People of any age with no history of thrombosis (as defined by APS Sapporo classification criteria (Wilson 1999), or updated Sydney classification criteria (Miyakis 2006)), but with aPL antibodies confirmed on at least two separate measurements (time period between measurement as defined in the criteria current when the study was done), including LA, anti- $\beta_{2} \mathrm{GPI}$ antibodies, and $\mathrm{aCL}$ antibodies (all detected using the assays recommended at the time when the study was conducted). We also included studies that addressed pregnant women with a history of recurrent pregnancy loss and positive $\mathrm{aPL}$ antibodies.

\section{Types of interventions}

We included studies that compared any antiplatelet or anticoagulant agents, or their combinations, at any dose and administered using any mode of delivery with placebo, no intervention, or other intervention (such as hydroxychloroquine). We also included studies that compared antiplatelet or anticoagulant agents with each other or that compared two different doses of the same drug.

\section{Types of outcome measures}

\section{Primary outcomes}

1. Any acute arterial or venous thrombosis diagnosed based on the APS Sapporo classification criteria (Wilson 1999), or updated Sydney classification criteria (Miyakis 2006), which would be confirmed by objectively validated methods, including (but not limited to) deep vein thrombosis, pulmonary embolism, myocardial infarction, ischaemic stroke, transient ischaemic attack, peripheral thromboembolism.

2. Bleeding based on definitions of minor or major bleeding (Schulman 2005).

3. Total mortality.

We planned to analyse any acute arterial and venous thrombosis events combined and separately by the type of event (such as myocardial infarction, deep vein thrombosis, etc.). However, the numbers of each type of events were very low per study, and one study did not report the type of events by participant randomised. We therefore decided not to perform analyses by the type of event.

In our protocol we planned to analyse obstetric failure among thrombotic events, however as this outcome was thoroughly addressed by other Cochrane Reviews (de Jong 2014; Empson 2005), we did not analyse this outcome.

\section{Secondary outcomes}

1. Quality of life as measured by a validated questionnaire.

2. Adverse event other than bleeding, e.g. gastrointestinal disturbances, urticaria, other allergic reactions, dizziness, peptic ulcers, insomnia, or headache.

\section{Search methods for identification of studies \\ Electronic searches}

The Cochrane Vascular Information Specialist (CIS) first searched the following databases for relevant trials (15 February 2017):

- the Cochrane Vascular Specialised Register (15 February 2017);

- the Cochrane Central Register of Controlled Trials (CENTRAL; 2017, Issue 1) via the Cochrane Register of Studies Online.

See Appendix 1 for details of the search strategy used to search CENTRAL.

The Cochrane Vascular Specialised Register is maintained by the $\mathrm{CIS}$ and is constructed from weekly electronic searches of MEDLINE Ovid, Embase Ovid, CINAHL (Cumulative Index to Nursing and Allied Health Literature), AMED (Allied and Complementary Medicine Database), and through handsearching of relevant journals. The full list of databases, journals, and conference proceedings searched, as well as the search strategies used, are described in the Specialised Register section of the Cochrane Vascular module in the Cochrane Library (www.cochranelibrary.com).

The CIS also searched the following trial registries for details of ongoing and unpublished studies (15 February 2017):

- ClinicalTrials.gov (www.clinicaltrials.gov);

- World Health Organization International Clinical Trials Registry Platform (www.who.int/trialsearch);

- ISRCTN Register (www.isrctn.com/). 
See Appendix 2 for details of the search strategy used.

The CIS subsequently performed a follow-up search of the Cochrane Vascular Specialised Register (4 December 2017), the Cochrane Central Register of Controlled Trials (CENTRAL) (last search 29 November 2017), MEDLINE Ovid, Embase Ovid, CINAHL, and AMED (searched 4 December 2017), and trials registries (searched 29 November 2017). See Appendix 3 for details of the search strategies used.

\section{Searching other resources}

We checked the references of included studies, systematic reviews, health technology assessments, and practice guidelines relevant to the topic of this review. We contacted experts in the field, including PL Meroni (Milan), MA Khamashta (London), PG de Groot (Utrecht), P de Moerloose (Geneva), and V Pengo (Padova), and manufacturers of the brand-name drugs (mainly direct oral anticoagulants (DOAC)) for additional studies (Bristol-Myers Squibb-Pfizer, Pfizer Europe, Boehringer Ingelheim International, Aspen Pharma, Eli Lilly, Bayer Pharma AG, Alfasigma).

\section{Data collection and analysis}

\section{Selection of studies}

We used Covidence software for abstract and full-text screening (Covidence 2017). We eliminated duplicate records of the same study using appropriate software. We divided work between two pairs of review authors (EP, KJ, DWK and MMB or WL). In each group, one of the review authors is a medical student involved in research work and trained in methodology or an active clinician and the other is an experienced review author (it is not possible to identify specific pairs when using Covidence software). The review authors in the above-mentioned pairs independently screened the titles and abstracts of the search results against the eligibility criteria. Any discrepancies were resolved by discussion between the review author pair, with a third review author (MMB, WL, AU) acting as an arbiter when necessary. We retrieved the full-text articles of studies that appeared to fulfil the inclusion criteria and selected studies for inclusion. Any discrepancies were resolved by discussion between the review author pair, with a third review author (MMB, WL, AU) acting as an arbiter when necessary. We screened the gathered reports for multiple publications of the results of the same study. We assessed the following aspects: time, location, the study authors, the number of participants, the baseline data, the doses and frequencies of drug administration. If necessary, we contacted the authors of the reports or studies, or both, to clarify or add any important information. We included studies based on the data we collected in the described process. We listed all studies excluded after full-text assessment in a 'Characteristics of excluded studies' table. We displayed the study selection process in a PRISMA study flow diagram.

\section{Data extraction and management}

We collected data on study design and methods, population intervention, outcomes, and results of the included studies. We planned to use and prepare the Cochrane Vascular data extraction template in Covidence if sufficient form adjustment options were available (Covidence 2017), however as the adjustment in Covidence was insufficient, we prepared a data extraction form on the basis of the Cochrane Vascular data extraction template in Microsoft Excel and used Covidence for the 'Risk of bias' assessment. We first pilot-tested a data collection form to check if we needed to add, erase, or rephrase some additional fields or options. In the case of multiple reports being available for the same study, we extracted data from all of the reports into a single data collection form.

Two pairs of review authors independently extracted the data as outlined above. Any disagreements were discussed between the review author pair, and when necessary by asking a third review author (MMB, WL, AU) for their opinion. If we were unable to resolve a disagreement, we planned to describe this in the review.

\section{Assessment of risk of bias in included studies}

We used the Cochrane 'Risk of bias' assessment tool, as outlined in Chapter 8 of the Cochrane Handbook for Systematic Reviews of Interventions (Higgins 2011). Pairs of review authors (formed from EP, KJ, MMB, DWK, and WL) independently applied the tool to each included study. Any disagreements were resolved by discussion or by consulting a third review author (AU) when necessary. In addition, one review author checked all numeric results against the original reports (MMB).

We assessed risk of bias for the following domains (Higgins 2011).

1. Random sequence generation.

2. Allocation concealment.

3. Blinding of participants and personnel.

4. Blinding of outcome assessment.

5. Incomplete outcome data.

6. Selective outcome reporting.

7. Other bias.

We graded the risk of bias as high, low, or unclear for each domain and included a justification for our judgement in the 'Risk of bias' tables. We judged a trial as at low risk of bias if it was at low risk of bias in each of the 'Risk of bias' domains; we judged all other trials as at high risk of bias. We took the 'Risk of bias' assessment into account in our interpretation of the data.

\section{Measures of treatment effect}

We calculated the risk ratio (RR) and 95\% confidence interval (CI) for all the primary endpoints available (any thrombosis, bleeding), and planned to do this for the secondary endpoints described as adverse events other than bleeding (e.g. gastrointestinal disturbances or allergic reactions). However, adverse events other than bleeding were reported in such a way that prevented pooling, and therefore were summarised narratively. For the quality of life indicators, we planned to determine the mean difference (MD) or standardised mean difference (SMD) values and $95 \% \mathrm{Cls}$, depending on whether the same or different scales were used in the included studies.

\section{Unit of analysis issues}

The participants were the unit of analysis. If an included study had a mixture of units of analysis, we planned to adjust them to one common unit. We discussed any unusual issues within the review author team and planned to adjust the methods outlined in the published protocol accordingly. If any cross-over studies met the inclusion criteria of the review, we planned to include only the first period of such studies in our analyses. 


\section{Dealing with missing data}

For one study with missing data, we contacted the authors of the original report for the missing data or for the reasons for exclusion of the data. For data missing at random, we analysed only the available data. We analysed the potential impact of missing data on the results using sensitivity analyses, and discussed this in the review.

\section{Assessment of heterogeneity}

Since we assessed the effects of the introduction of several different drugs, we expected clinical diversity. We planned to estimate statistical heterogeneity visually (overlap of $\mathrm{Cls}$ derived from single studies) and by using the $\mathrm{Chi}^{2}$ test, with a significance level of $\mathrm{P}=$ 0.10 . We also planned to calculate the percentage of variability that stemmed from heterogeneity ( 12 statistic).

\section{Assessment of reporting biases}

In order to minimise reporting bias, we planned to search multiple sources (see the Search methods for identification of studies section). We planned to visually assess funnel plots to screen for small-study effects if at least 10 studies were included in a metaanalysis (Higgins 2011).

\section{Data synthesis}

As mentioned in the Assessment of heterogeneity section, we expected heterogeneity to be significant. We therefore planned to perform meta-analyses using a random-effects model. If we were unable to pool the data due to considerable heterogeneity, as defined in the Cochrane Handbook for Systematic Reviews of Interventions (Higgins 2011), we planned to summarise the findings in the form of tables, figures, and text. We used Review Manager 5 to perform the analyses (RevMan 2014).

\section{Subgroup analysis and investigation of heterogeneity}

We planned to analyse the effect of the antiplatelet and anticoagulant agents separately. Provided the number of studies included in the analysis was sufficient (at least 10 included studies), we planned to analyse the effects of the interventions in relation to different subgroups of antiplatelet agents and anticoagulants and, if the information was available, the presence of additional risk factors of thrombosis (e.g. smoking, the use of contraception/ hormone replacement therapy, obesity, neoplasms, and heart failure). If possible, we planned to analyse the effects in subgroups according to the type of antibodies present as well as the number of types of antibodies present (i.e. one, two, or three types of antibodies). We did not have a sufficient number of studies per comparison to perform subgroup analyses.

\section{Sensitivity analysis}

We planned to assess the following.

1. The impact of risk of bias on study results: we planned to analyse the results of studies at low risk of bias versus studies at high risk of bias (see the Assessment of risk of bias in included studies section). However, as none of the studies was assessed as at low risk of bias, we could not perform this analysis.

2. The impact of missing data: we performed analyses by 'bestcase scenario' (when all participants with missing data in the intervention group were assumed to have had a good outcome, and all participants with missing data in the control group were assumed to have had a poor outcome) and by 'worstcase scenario' (when all participants with missing data in the intervention group were assumed to have had a poor outcome, and all participants with missing data in the control group were assumed to have had a good outcome) and compared the results of trials that had no missing data with trials that had missing data.

\section{'Summary of findings' tables}

Two review authors independently assessed the quality of the evidence using the GRADE approach, as specified by the Cochrane Handbook for Systematic Reviews of Interventions (Higgins 2011), and by Atkins 2004. We summarised the quality of the evidence in 'Summary of findings' tables (separately for anticoagulants and antiplatelets) using GRADEpro Guideline Development Tool (GDT) (GRADEpro GDT 2015). In the 'Summary of findings' tables we included all of the prespecified outcomes (primary and secondary, see the Types of outcome measures section). In case of composite outcomes, we planned to present results for the composite and also for the individual components of the composite.

\section{RES U LTS}

\section{Description of studies}

\section{Results of the search}

We performed our last searches on 4 December 2017 and identified 418 records after the removal of duplicates (Figure 1). Of these, 79 were retrieved and their full texts checked. We excluded 66 records due to: wrong study design (33 records of reviews, guidelines, comments, etc. and 5 records not an RCT); wrong population (18 records); wrong intervention ( 2 records); and wrong outcomes (i.e. obstetric failure only or coagulation activation only) (8 records). The reasons for exclusion are reported in the Characteristics of excluded studies table. We finally included nine studies that fulfilled our inclusion criteria, reported in 12 references (Alalaf 2012; Cuadrado 2014; Dendrinos 2009; Erkan 2007; Farquharson 2002; Fouda 2010; Fouda 2011; Ismail 2016; Rai 1997). In addition, we identified one ongoing trial reported as a record in ClinicalTrials.gov (NCT03100123). 


\section{Figure 1. Study flow diagram.}

92 additional records identified
from additional search of
systematic reviews, studies
considered in other systematic
reviews

426 records identified from searches of databases, trials registries, and Specialised Register

reviews

339 records not relevant

33 full-text articles excluded as not a study (i.e. reviews, guidelines, comments, etc.)

28 studies ( 33 records) excluded for other reasons, as follows:

- 13 studies (18 records): wrong patient population

- 8 studies (8 records): wrong outcomes (obstetrical failure only or coagulation activation only)

- 5 studies (5 records): wrong study design - not RCT

- 2 studies (2 records): wrong

79 full-text articles assessed for eligibility intervention 


\section{Included studies}

The nine included studies were all randomised clinical trials that were performed between 1993 and 2013. One study was described as double-blind (Erkan 2007); in one study there was no information about blinding (Ismail 2016); and the remaining studies were not blinded.

Detailed information on each study is presented in the Characteristics of included studies table.

\section{Participants}

The studies included 1044 randomised individuals with no history of thrombosis as defined by APS Sapporo classification criteria (Wilson 1999), or updated Sydney classification criteria (Miyakis 2006), but who were tested positive for aPL antibodies on at least two separate measurements (time period between measurement as defined in the criteria current when the study was done), including LA, anti- $\beta_{2} \mathrm{GPI}$ antibodies, and $\mathrm{C} C \mathrm{~L}$ antibodies. Additionally, in eight studies with 714 individuals recurrent pregnancy losses was the main inclusion criterion or one of the inclusion criteria (Alalaf 2012; Cuadrado 2014; Dendrinos 2009; Farquharson 2002; Fouda 2010; Fouda 2011; Ismail 2016; Rai 1997).

\section{Location}

Three of the studies were performed in Egypt (Fouda 2010; Fouda 2011; Ismail 2016), Farquharson 2002 and Rai 1997 were performed in the UK, Alalaf 2012 in Iraq, and Dendrinos 2009 in Greece. Cuadrado 2014 was a multicentre study performed in several European countries and in Mexico. In Erkan 2007 the country where the study was performed and where follow-up took place was not specified; only a co-ordinating centre in the USA was mentioned.

\section{Setting}

Farquharson 2002 and Rai 1997 were based in miscarriage clinics. Dendrinos 2009, Fouda 2010, and Fouda 2011 took place at university hospitals. Alalaf 2012 and Ismail 2016 were performed at a maternity teaching hospital and a women's health hospital, respectively. Cuadrado 2014 was based in 14 tertiary hospitals and one district hospital. In Erkan 2007 the type of medical units where the study was performed was not specified.

\section{Interventions}

In two studies an intervention was compared with a placebo (Erkan 2007; Ismail 2016); in Erkan 2007 the intervention was $81 \mathrm{mg} \mathrm{ASA}$, and in Ismail 2016 it was $81 \mathrm{mg}$ ASA combined with $40 \mathrm{mg}$ enoxaparin. Alalaf 2012 compared $100 \mathrm{mg}$ ASA with 2500 IU bemiparin. In Dendrinos 2009 the intervention group was given $75 \mathrm{mg} \mathrm{ASA}$ and $4500 \mathrm{IU}$ heparin, whereas the control group received $400 \mathrm{mg} / \mathrm{kg}$ intravenous immunoglobulin (IVIG). In three studies all participants received ASA (75 mg), and the intervention group additionally received anticoagulant (in Farquharson 2002 this was 5000 IU of LMWH subcutaneously, in Rai 19975000 IU of UFH subcutaneously, in Cuadrado 2014 warfarin with the target international normalised ratio (INR) 1.5 with a range of 1.3 to 1.7 ). In Fouda 2010 two doses of enoxaparin were compared (20 mg versus $40 \mathrm{mg}$ ), with both groups additionally given $75 \mathrm{mg}$ of ASA. In Fouda 201140 mg enoxaparin was compared with UFH 5000 IU subcutaneously, twice daily; all participants were given 75 mg ASA.
In some of the studies concomitant treatment was used: folic acid in Alalaf 2012; prenatal vitamins, oral calcium, and vitamin D in Fouda 2010 and Fouda 2011; and hydroxychloroquine, steroids, and nonsteroidal anti-inflammatory drugs (NSAIDs) in 57\%, 33\%, and $40 \%$ of participants, respectively in Erkan 2007.

\section{Outcomes}

The primary outcome in Alalaf 2012, Farquharson 2002, Dendrinos 2009, Fouda 2010, Fouda 2011, Ismail 2016, and Rai 1997 was live birth, whereas in Cuadrado 2014 it was a documented thrombosis (which included deep vein thrombosis in venography or ultrasonography, pulmonary embolism in a computed tomography (CT) scan, radionuclide lung scan, or angiography, thrombosis in intracerebral vessels on magnetic resonance imaging (MRI), retinal thrombosis in ophthalmological examination and angiography, peripheral or mesenteric arterial thrombosis in arteriography; myocardial infarction, amaurosis fugax, and transient ischaemic attack as per standard definitions), and in Erkan 2007 the primary outcome was acute thrombosis (defined as a stroke confirmed by neuroimaging, deep vein thrombosis by Doppler ultrasonography, pulmonary embolism in CT scan, myocardial infarction).

In Alalaf 2012 the secondary outcomes included maternal and foetal complications (specified as embolic events, pre-eclampsia, ecchymosis, and preterm labour). In Cuadrado 2014 secondary outcomes were defined as clinical and serological risk factors for thrombosis, medication side effects, and death of any cause. In Dendrinos 2009 secondary outcomes included haemorrhages, pregnancy-associated hypertension, fractures during pregnancy or up to two months postpartum, reduced maternal bone mineral density, and death.

Fouda 2010 and Fouda 2011 included the following secondary outcomes: bleeding/haemorrhages, neonatal bleeding, thrombocytopenia, intrauterine growth restriction, intrauterine foetal death, preterm delivery, congenital anomalies, preeclampsia, spontaneous osteoporotic fractures, and thrombotic events.

In Ismail 2016 the secondary outcomes were first- and second-trimester spontaneous abortion, vaginal bleeding during pregnancy, pre-eclampsia and pregnancy-induced hypertension, intrauterine growth restriction, abruptio placentae, and preterm delivery. The last was the only secondary outcome mentioned in Rai 1997. In Erkan 2007 transient ischaemic attack was classified as a secondary outcome; gastrointestinal disturbances and minor and major bleeding episodes were reported as "other outcomes".

\section{Excluded studies}

Reasons for exclusion are provided in the Characteristics of excluded studies table.

\section{Risk of bias in included studies}

Details for each included study are presented in the Characteristics of included studies table. The overall risk of bias in each domain for the included studies is shown in Figure 2. Risk of bias by trial is presented in Figure 3. 
Figure 2. Risk of bias graph: review authors' judgements about each risk of bias item presented as percentages across all included studies.

\begin{tabular}{|r|} 
Random sequence generation \\
Allocation concealment \\
Blinding of participants and personnel: All outcomes \\
Blinding of participants and personnel: Death \\
Blinding of participants and personnel: Bleeding \\
Blinding of participants and personnel: Thromboembolic events \\
Blinding of participants and personnel: Adverse events \\
Blinding of outcome assessment: All outcomes \\
Blinding of outcome assessment: Death \\
Blinding of outcome assessment: Bleeding \\
Blinding of outcome assessment: Adverse events \\
Incomplete outcome data \\
Selective reporting \\
Other sources of bias \\
\hline Low risk of bias
\end{tabular}


Figure 3. Risk of bias summary: review authors' judgements about each risk of bias item for each included study.

\begin{tabular}{|c|c|c|c|c|c|c|c|c|c|c|c|c|c|c|c|}
\hline & 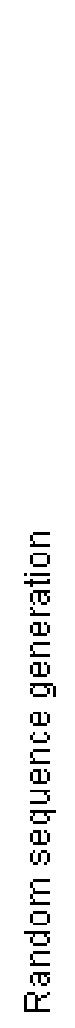 & 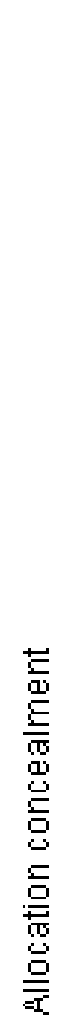 & 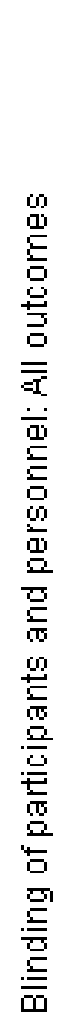 & 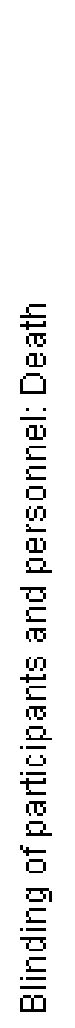 & 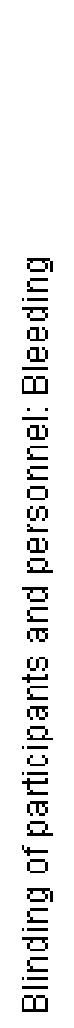 & 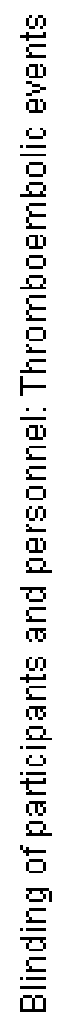 & 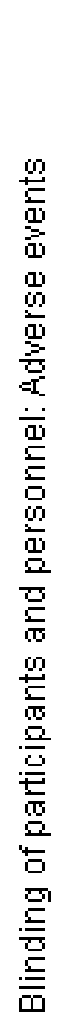 & 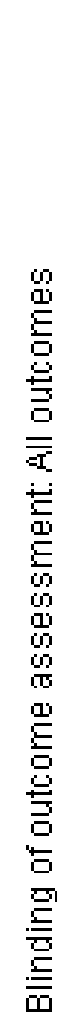 & 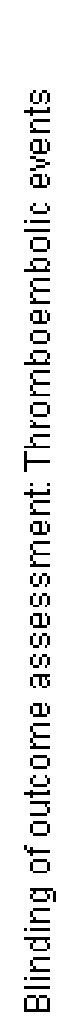 & 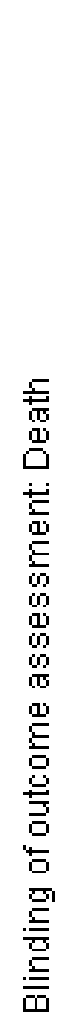 & 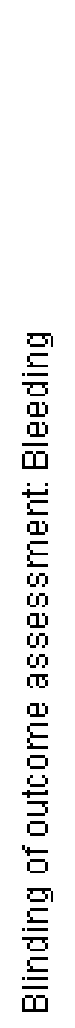 & 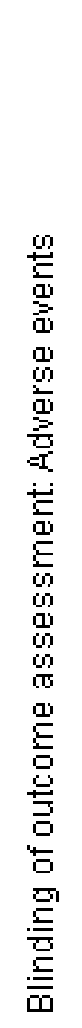 & 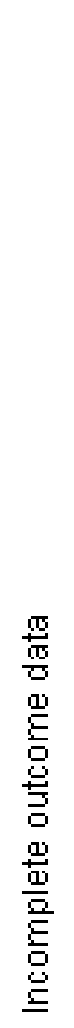 & 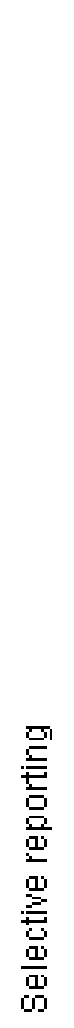 & 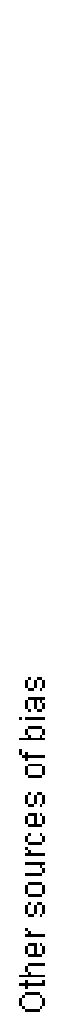 \\
\hline Alalaf 2012 & & - & $?$ & & & & & $?$ & & & & & + & - & \\
\hline Cuadrado 2014 & $\oplus$ & + & & + & $?$ & + & - & & + & + & $?$ & - & & + & \\
\hline Dendrinos 2009 & + & $?$ & & + & & $?$ & $?$ & & $?$ & + & & $?$ & & $?$ & 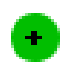 \\
\hline Erkan 2007 & + & $?$ & + & & & & & + & & & & & $?$ & $?$ & \\
\hline Farquharson 2002 & + & + & & & & $?$ & & & $?$ & & & & + & $?$ & \\
\hline Fouda 2010 & $\Psi$ & + & & & $?$ & $?$ & $?$ & & $?$ & & $?$ & $?$ & + & $?$ & \\
\hline Fouda 2011 & $\uplus$ & + & & & + & $?$ & $?$ & & $?$ & & 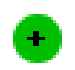 & $?$ & + & $?$ & \\
\hline Ismail 2016 & $\oplus$ & + & + & & & & & & $?$ & & + & + & + & $?$ & + \\
\hline Rai 1997 & + & + & $?$ & & & & & $?$ & & & & & + & $?$ & + \\
\hline
\end{tabular}

All of the included studies were published as full articles, and no single study was at low risk of bias in all domains.

\section{Allocation}

For one study we judged the risk of bias for the random sequence generation and allocation concealment domains as high, since the explanation of random allocation of the procedure suggested an alternate allocation with changed ratios of allocation (Alalaf 2012).
The other eight studies presented clear information about sequence generation and were judged as at low risk of bias (Cuadrado 2014; Dendrinos 2009; Erkan 2007; Farquharson 2002; Fouda 2010; Fouda 2011; Ismail 2016; Rai 1997). In six studies computer-generated randomisation was used (Erkan 2007; Farquharson 2002; Fouda 2010; Fouda 2011; Ismail 2016; Rai 1997), in one study a random number table (Dendrinos 2009), and in one study minimisation protocol (Cuadrado 2014). 
The risk of bias for the allocation concealment domain was unclear in two studies because no detailed information was provided (Dendrinos 2009; Erkan 2007). We judged the risk of bias for allocation concealment as low for the other six studies because they used opaque, sealed envelopes (Fouda 2010; Fouda 2011; Ismail 2016), allocation was by an independent individual not involved in the trial (Cuadrado 2014; Rai 1997), or a telephone randomisation (Farquharson 2002).

\section{Blinding}

In the analysed studies outcomes were reported and measured in different ways. We therefore assessed blinding either for all outcomes together (if the influence was the same) or for main groups/types of outcomes separately.

We assessed the blinding of participants, personnel, and outcome assessors in three studies for all outcomes together (Alalaf 2012; Erkan 2007; Rai 1997). For one study we judged the blinding of participants, personnel, and outcome assessors for thromboembolic events, adverse events, and death (Dendrinos 2009); for one study we judged the blinding of participants, personnel, and outcome assessors for thromboembolic events, bleeding, adverse events, and death (Cuadrado 2014), and one study reported only information about thromboembolic events, so we judged blinding only for this outcome (Farquharson 2002). In two studies the blinding of participants, personnel, and outcome assessors was reported for thromboembolic events, adverse events, and bleeding (Fouda 2010; Fouda 2011). In one study we assessed the blinding of participants and personnel for all outcomes together, but analysed the blinding of outcome assessors for thromboembolic events, adverse events, and bleeding separately (Ismail 2016).

For one study we judged the risk of bias related to the blinding of participants, personnel, and outcome assessors as low for all outcomes (Erkan 2007). We assessed the study by Ismail 2016 to be at low risk of bias for blinding of participants and personnel for bleeding and adverse events, but not for thromboembolic events, which we judged to be at unclear risk of bias because no clear information about this outcome definition or verification was provided.

In two studies participants and personnel were not blinded and clear definitions of outcomes were not provided, so it was not possible to assess if the lack of blinding could have influenced the outcomes (Alalaf 2012; Rai 1997). We therefore assessed the risk of bias for these studies as unclear for all outcomes.

In Cuadrado 2014 participants and personnel were not blinded, but thromboembolic events were verified by objective methods, and in our judgement the lack of blinding did not influence this outcome and the outcome of death. We therefore judged the risk of bias for these two outcomes as low. However, adverse events were not objectively verified in this study, and as the lack of blinding was likely to influence this outcome, we judged the risk of bias for adverse events as high. For the outcome bleeding the definition was unclear, therefore we judged the risk of bias for bleeding as unclear.

Dendrinos 2009 did not provide any information about blinding, so we judged the risk of bias for thromboembolic events and adverse events as unclear, and the risk of bias for death as low because the lack of blinding probably did not influence this outcome.
Farquharson 2002 did not provide any information about blinding, so the risk of bias was unclear for this study.

In Fouda 2010 participants and personnel were not blinded, and clear definitions of the analysed outcomes were not provided. The risk of bias for this study was unclear for every outcome because it was not possible to assess whether the lack of blinding could have influenced the outcome assessment.

In Fouda 2011 participants and personnel were not blinded, but we judged the risk of bias for bleeding as low because this outcome was clearly defined and objectively verified and the lack of blinding was unlikely to influence this outcome assessment. Definitions were not provided for thromboembolic events and adverse events, and we could not judge if the lack of blinding could have influenced outcome assessment, therefore we judged the risk of bias for these two outcomes as unclear.

\section{Incomplete outcome data}

We assessed six studies as at low risk of bias for incomplete outcome data because there were either no missing outcome data or there was a low and similar number of missing participants (Alalaf 2012; Farquharson 2002; Fouda 2010; Fouda 2011; Ismail 2016; Rai 1997).

We judged Cuadrado 2014 as at high risk of bias due to the difference in the number of participants followed up between the experimental and control groups.

We assessed Dendrinos 2009 as at high risk of bias because participants were excluded from the analysis after randomisation. The trial described an analysis of a primary outcome (live births) as intention-to-treat, but in our judgement what was meant by that was not clearly explained or if it was applied to other outcomes as well.

We assessed Erkan 2007 as at unclear risk of bias for incomplete outcome data because insufficient information about the analysis of lost to follow-up data of participants was provided.

\section{Selective reporting}

We assessed the risk of selective reporting in Cuadrado 2014 as low because we could access the protocol, and all prespecified outcomes were reported and well described.

We judged the risk of bias for selective reporting in Alalaf 2012 as high because the protocol was not available, and the side effects described in the methods section were not completely reported.

We assessed the risk of bias for selective reporting for the remaining seven studies as unclear as protocols for these studies were not available (Dendrinos 2009; Erkan 2007; Farquharson 2002; Fouda 2010; Fouda 2011; Ismail 2016; Rai 1997). Dendrinos 2009 and Fouda 2011 did report all outcomes prespecified in the methods section.

\section{Other potential sources of bias}

We did not identify any other potential sources of bias in three studies (Dendrinos 2009; Ismail 2016; Rai 1997). Erkan 2007 was sponsored by Bayer, which we identified as a potential risk for favouring the ASA group. 
Five studies were underpowered and recruited fewer participants than had been calculated as their sample size: the estimated sample size in Fouda 2011 was 1447, and only 60 were recruited the estimated sample size in Fouda 2010 was 410 participants, but the analysed number of participants was only 60; the planned sample size in Cuadrado 2014 was 443 participants in each arm, and the analysed number of participants was a total of 166; the planned sample size in Farquharson 2002 was 220, and the study included 98 participants; the initially planned sample size in Erkan 2007 was 110 per group; after interim analysis it was estimated that 30,363 participants in each arm would be needed to test the original hypothesis that ASA had a beneficial effect; the study included a total of 98 participants. Due to this low recruitment rate, we judged all five studies as at high risk of bias.

We assessed Alalaf 2012 as at high risk of bias because the intervention in one of the groups was introduced before pregnancy, while in the other group it was introduced after the confirmation of pregnancy. In addition, no details on the structure of the groups in terms of diabetes and no sample size calculation were provided.

\section{Effects of interventions}

See: Summary of findings for the main comparison Anticoagulant with or without ASA versus ASA only; Summary of findings 2 ASA versus placebo; Summary of findings 3 ASA with LMWH versus placebo or IVIG; Summary of findings 4 ASA + highdose LMWH versus ASA + low-dose LMWH or UFH

We summarised the effects of interventions in four comparison groups, as follows.

1. Anticoagulant with or without acetylsalicylic acid (ASA) versus ASA only in women with a history of recurrent pregnancy loss and in people with no such history (Alalaf 2012; Cuadrado 2014; Farquharson 2002; Rai 1997).

2. ASA only versus placebo in people with positive aPL antibodies (Erkan 2007).

3. ASA with low molecular weight heparin (LMWH) versus placebo or IVIG in women with recurrent pregnancy loss (Dendrinos 2009; Ismail 2016).

4. ASA with high-dose LMWH versus ASA with low-dose LMWH or unfractionated heparin (UFH) in women with recurrent pregnancy loss (Fouda 2010; Fouda 2011).

We reported the results for these comparisons for each outcome.

We planned to conduct a sensitivity analysis regarding risk of bias. However, there were almost no differences in the risk of bias between the studies, and none of the studies was considered to be at low risk of bias.

To assess the impact of missing data we performed an analysis of the worst-best and best-worst case scenarios for Cuadrado 2014 and Dendrinos 2009.

\section{Outcome: any arterial or venous thrombosis}

\section{Comparison: anticoagulant with or without ASA versus ASA only}

All studies in this group assessed this outcome. However, only Cuadrado 2014, which included a mixed population of women with a history of recurrent pregnancy loss and people with no such history, reported thrombotic events: four cases in both the intervention and the control groups. In the meta-analysis there was no clear difference in risk of this outcome (risk ratio (RR) $0.98,95 \%$ confidence interval (CI) 0.25 to 3.77 ; 4 studies; 493 participants; lowquality evidence; Analysis 1.1).

Since the dropout rate was quite high in Cuadrado 2014 (at least one year of follow-up was completed only in 69 out of 83 participants in the intervention group and 75 out of 81 participants in the control group), we performed a sensitivity analysis. The results of the bestworst case scenario analysis did not differ from the main analysis (RR 0.39, 95\% Cl 0.13 to 1.19; 4 studies; 493 participants; Analysis $5.1)$.

In the simulation where all missing participants in the intervention group were assumed to develop thrombosis and none in the control group (worst-best case scenario), ASA with anticoagulant was associated with a higher risk of any thrombosis (RR 4.39, 95\% Cl 1.55 to 12.42; 4 studies; 493 participants; Analysis 5.2).

\section{Comparison: ASA only versus placebo}

In Erkan 2007, which included people with positive aPL antibodies, one case of thrombosis in the control group versus five cases in the intervention group (cases of transient ischaemic attack included) were reported. There was no clear difference between the groups, with an RR of 5.21 and a considerably wide $95 \% \mathrm{Cl}$ from 0.63 to 42.97 (1 study; 98 participants; low-quality evidence; Analysis 2.1).

\section{Comparison: ASA + LMWH versus placebo or IVIG}

In Dendrinos 2009 and Ismail 2016, which included women with a history of recurrent pregnancy loss, no thrombotic events were observed in either the intervention or the control group, therefore the effect was not estimable (Analysis 3.1). There were no significant differences in the results of the sensitivity analysis performed to assess the impact of missing data (Analysis 6.1; Analysis 6.2).

\section{Comparison: $A S A+$ high-dose $L M W H$ versus $A S A+$ low-dose LMWH or UFH}

In both Fouda 2011 and Fouda 2010, which included women with a history of recurrent pregnancy loss, no thrombotic events occurred, so the effect of the intervention was not estimable (Analysis 4.1).

\section{Outcome: bleeding}

\section{Comparison: anticoagulant with or without ASA versus ASA only}

In this comparison only Cuadrado 2014, which included a mixed population, explicitly reported bleeding episodes, as 11 minor bleeding episodes defined as not requiring hospital admission (one nasal and 10 menorrhagia) in the intervention group (ASA + warfarin) compared to none in the control group, indicating a higher risk of minor bleeding (RR 22.45, 95\% Cl 1.34 to 374.8; 1 study; 164 participants; low-quality evidence; Analysis 1.2) for treating with two drugs as compared with ASA only. Cuadrado 2014 reported no cases of major bleeding. Among other studies, which included women with a history of recurrent pregnancy loss, Farquharson 2002 reported no data on any type of bleeding, while Alalaf 2012 reported five cases of ecchymosis at the injection site in the bemiparin group, and Rai 1997 reported mild bruising at the injection site in participants receiving heparin without providing any details. 


\section{Comparison: ASA only versus placebo}

In Erkan 2007, which included participants with positive aPL antibodies, no major bleeding events and three minor bleeding episodes in the intervention group and one in the control group were reported. However, the difference between the groups was not significant (RR 3.13, 95\% Cl 0.34 to 29.01; 1 study; 98 participants; low-quality evidence; Analysis 2.2). In addition, two cases of easy bruising were reported in the intervention group and one case in the control group.

\section{Comparison: ASA + LMWH versus placebo or IVIG}

Both studies reported on women with a history of recurrent pregnancy loss. Dendrinos 2009 did not report on bleeding episodes.

In Ismail 2016, four major bleeding episodes (defined as requiring blood transfusion) in the treatment group and none in the placebo group were noted, with no clear difference between the groups (RR 9.0, $95 \% \mathrm{Cl} 0.49$ to 164.76 ; 1 study; 180 participants; moderatequality evidence; Analysis 3.2). Additionally, there were 17 (19\%) participants with bleeding in the first trimester of pregnancy in the intervention group and $19(21 \%)$ such cases in the control group (Analysis 3.2), and 13 (14\%) cases of postpartum haemorrhage in the intervention group and $10(11 \%)$ in the control group (Analysis 3.2), however no significant differences between the groups were reported for these outcomes.

Since there was no information on whether the cases of major bleeding, first-trimester bleeding, and postpartum haemorrhages concerned the same or different participants, we did not pool all of the above for the total bleeding event risk in any of the groups.

\section{Comparison: $A S A$ + high-dose $L M W H$ versus ASA + low-dose LMWH or UFH}

Both studies reported on women with a history of recurrent pregnancy loss. In Fouda 2010, no postpartum bleeding episodes were reported, and in Fouda 2011, no excessive bleeding episodes were reported (Analysis 4.2). In both studies three cases of subcutaneous bruising in each group were reported (RR 1.00, 95\% $\mathrm{Cl} 0.34$ to 2.93 ; 2 studies; 120 participants; low-quality evidence; Analysis 4.3).

\section{Outcome: total mortality}

None of the included studies assessed this outcome.

\section{Outcome: quality of life}

None of the included studies assessed this outcome.

\section{Outcome: adverse event other than bleeding}

\section{Comparison: anticoagulant with or without ASA versus ASA only}

In Cuadrado 2014, which included a mixed population, four cases of mild gastrointestinal symptoms were reported in the group of participants who received ASA (two severe constipations and two stomach complaints; it is not clear if these were the same or different participants). Moreover, one case of an allergic reaction in the group receiving the combination of drugs was reported. Among studies that reported on women with a history of recurrent pregnancy loss, there were no reports of adverse events other than bleeding or obstetric failure in Farquharson 2002 and Alalaf 2012. Rai 1997 reported that in both groups the interventions were well tolerated, and there were no cases of thrombocytopenia or vertebral fractures in the heparin group.

\section{Comparison: ASA only versus placebo}

In Erkan 2007, which reported on individuals with positive aPL antibodies, minor gastrointestinal disturbances occurred in five participants who received ASA compared to one participant in the placebo group.

\section{Comparison: ASA + LMWH versus placebo or IVIG}

Both studies reported on women with a history of recurrent pregnancy loss. Dendrinos 2009 reported nausea, hypotension, and tachycardia in three participants in the control (IVIG) group as compared to none in the intervention group.

In Ismail 2016, no cases of heparin-induced thrombocytopenia and no cases of allergies were reported.

\section{Comparison: ASA + high-dose $L M W H$ versus ASA + low-dose LMWH or UFH}

Both studies reported on women with a history of recurrent pregnancy loss. Fouda 2010 and Fouda 2011 reported no osteoporotic fractures or thrombocytopenia. Fouda 2011 reported one case of skin allergy in the ASA + UFH group.

\section{DISCUSSION}

\section{Summary of main results}

We identified four studies comparing anticoagulants (with or without ASA) versus ASA. In one of these studies that included a mixed population of women with a history of recurrent pregnancy loss and people with no such history, thrombotic events were reported in similar numbers in both treatment groups. However, the incidence rate of thrombosis was low, and therefore conclusions from this comparison are limited, especially given that the calculated sample size was not reached (low-quality evidence). The risk of minor bleeding episodes, which was explicitly reported in only one of the four studies, was higher in the group treated with anticoagulant and ASA as compared with ASA only (low-quality evidence). Three studies that included women with a history of recurrent pregnancy loss did not report any cases of thrombosis.

We identified one study comparing ASA with placebo in people with positive aPL antibodies, which showed no clear difference in the risk of both thrombotic and bleeding events. As the study was small and underpowered, we judged the quality of evidence to be low, and therefore were not able to draw any meaningful conclusions.

In two studies comparing ASA combined with LMWH versus placebo or IVIG in women with a history of recurrent pregnancy loss, no thrombotic events were reported, preventing us from drawing any conclusions about this outcome. However, in those studies, which focused mainly on obstetric outcomes, several episodes of major and minor bleeding were reported, with no clear differences between the groups (moderate-quality evidence).

We found two small studies comparing ASA combined with highdose LMWH versus ASA combined with low-dose LMWH or UFH, in women with a history of recurrent pregnancy loss, which also focused mainly on obstetric outcomes. No thrombotic events or major bleeding was reported, so any conclusions were not possible. 


\section{Overall completeness and applicability of evidence}

In studies comparing ASA combined with LMWH versus IVIG or placebo and ASA combined with high-dose LMWH versus ASA combined with low-dose LMWH or UFH that were performed in women with a history of recurrent pregnancy loss, no thrombotic events were reported. In one study comparing warfarin combined with ASA versus ASA alone in a mixed population, the number of thrombotic events was low, and the study was seriously underpowered (originally planned sample size 1000, included 232), with a higher dropout rate in the combined-treatment group (Cuadrado 2014). An increased number of minor bleeding episodes was reported in the warfarin group, but due to the abovementioned reasons, the evidence was of low quality (Cuadrado 2014). In the other study that reported thrombotic events, which compared ASA with placebo in people with positive aPL antibodies, the incidence of the events was also low, and the study was also underpowered (originally planned sample size 220, included 98) (Erkan 2007).

Most of the analysed studies recruited pregnant women (or women planning a pregnancy) and were focused on obstetric outcomes. In fact, only one study involved exclusively nonpregnancy-related cases (Erkan 2007). Cuadrado 2014 studied a mixed population of pregnancy-related and non-pregnancyrelated cases. The remaining studies included pregnant women with a history of obstetric complications. Most authors agree that in the case of women with aPL antibodies and recurrent miscarriage, the underlying cause is not solely thrombosis-related (Marchetti 2013; Meroni 2011; Sebire 2002; Shamonki 2007; Skrzypczak 2011), therefore these studies were eligible for inclusion. Still, it seems intuitive that the results of such studies cannot be applied to the general population. Clearly there is a need for further investigation in this field with respect to a broader population of people with aPL antibodies.

The proportion of participants with each type of antibody differed between studies, but due to the low number of studies and their heterogeneity we could not examine the influence of this issue on the effects of the studied interventions.

\section{Quality of the evidence}

We analysed data from nine studies involving 1044 participants with aPL antibodies. The studies were published between 1997 and 2016. We judged none of the included studies to be at low risk of bias in all domains. The most common problems included blinding of participants and personnel, which was at unclear or high risk of bias for at least one outcome in seven studies; blinding of outcome assessors, which was at unclear or high risk of bias for at least one outcome in eight studies; and selective outcome reporting, which was at unclear or high risk of bias in eight studies. We judged randomisation to be at high risk of bias in one study and allocation concealment to be at unclear or high risk of bias in three studies. We judged dealing with missing data to be at high risk of bias in two studies and unclear risk of bias in one study. Also, in many of the included studies the calculated sample size was not achieved. For most comparisons, either single studies provided results or single studies were included, therefore we did not assess heterogeneity. In meta-analyses where more than one study was included, we did not detect any heterogeneity between the results of the studies. However, all of the analyses provided imprecise results with wide confidence intervals. We could not assess publication bias due to the small number of studies.

We judged the quality of the evidence to be low for the following comparisons: anticoagulant with or without ASA compared to ASA; ASA compared with placebo; and ASA with high-dose LMWH compared with ASA with low-dose LMWH or UFH. We downgraded the quality of the evidence due to concerns regarding risk of bias and imprecision. We judged the quality of the evidence for the comparison ASA with LMWH versus placebo or IVIG to be moderate, downgrading by one level due to imprecision.

For further details, please see Summary of findings for the main comparison; Summary of findings 2; Summary of findings 3; Summary of findings 4.

\section{Potential biases in the review process}

Our searches, conducted by the Cochrane Vascular Group, were comprehensive and performed without any restrictions. We supplemented the searches by seeking additional systematic reviews and practice guidelines to check references. In addition, we checked included and excluded studies in three other Cochrane Reviews covering similar topics (Bala 2017a; de Jong 2014; Empson 2005). We sought additional information from experts and manufacturers. Our review identified more trials than the other two reviews addressing primary prevention in people with aPL antibodies (Arnaud 2014; Qushmaq 2014).

Since the number of studies included in each comparison was low, we did not produce funnel plots.

\section{Agreements and disagreements with other studies or reviews}

We identified seven recent reviews, meta-analyses, or practice guidelines that covered the topic of primary prevention of thrombosis in people with $\mathrm{PPL}$ antibodies.

Arnaud 2014 assessed the effect of ASA and included all types of study designs (RCTs and observational studies, both prospective and retrospective). It included only one RCT on ASA, which was also included in our review. The authors concluded that the risk of the first thrombotic event was reduced in people taking ASA (low-dose), but the effect was not significant in the analyses that included studies with the best methodological quality, therefore additional properly designed, high-quality RCTs are needed. The same authors requested individual patient data from 11 included cohort studies and obtained data from five of those studies (Arnaud 2015; two prospective and three retrospective studies). They aimed to assess the effect of ASA (low-dose) on the risk of first thrombotic event in people with aPL antibodies using individual patient-level data. After adjustment on several confounders, Arnaud 2015 concluded that risk of first thrombosis is significantly lower in aPL-positive patients treated with low-dose ASA.

Qushmaq 2014 addressed all primary prophylactic interventions but included all types of study designs and excluded studies published in languages other than English. It included only one RCT on ASA, which was also included in our review. The authors concluded that ASA and hydroxychloroquine reduced the frequency of thrombotic events in people with $\mathrm{PPL}$ antibodies and systemic lupus erythematosus (SLE), but this was mainly based on the results of observational studies. Four documents were practice 
guidelines (Andreoli 2017; Bates 2012; Erkan 2014; Ruiz-Irastorza 2011). Andreoli 2017 recommended, based on limited evidence, anticoagulation or antiplatelet therapy or both in family planning for women with SLE and/or antiphospholipid syndrome. Bates 2012 recommended the use of heparin (UFH in a prophylactic or intermediate dose or LMWH in a prophylactic dose) in combination with low-dose ASA in women with a history of recurrent pregnancy loss and who met laboratory criteria for aPL antibodies. RuizIrastorza 2011 recommended the use of hydroxychloroquine and low-dose ASA in people with SLE and lupus anticoagulant (LA) or anticardiolipin $(\mathrm{aCL})$ antibodies at medium and high titres, while they recommended long-term use of low-dose ASA in people without SLE with a high-risk aPL profile, and especially in the presence of other risk factors for thrombosis. Erkan 2014 reviewed the evidence on treatments other than traditional anticoagulants or antiplatelet agents and did not identify any completed studies of oral direct thrombin or anti-factor Xa inhibitors for primary prevention in people with aPL antibodies.

\section{AUTHORS' CONCLUSIONS}

\section{Implications for practice}

The evidence identified in this Cochrane Review was insufficient to draw any conclusions on the benefit of using anticoagulant with or without acetylsalicylic acid (ASA) versus ASA alone; ASA versus placebo; ASA with low molecular weight heparin (LMWH) versus placebo or intravenous immunoglobulin; and ASA with highdose LMWH versus ASA with low-dose LMWH or unfractionated heparin, for the primary prevention of thrombotic events in people with antiphospholipid antibodies, without previous thrombotic events. In people treated with anticoagulant combined with ASA, the incidence of minor bleeding (nasal bleeding, menorrhagia) was increased compared with treatment using ASA alone. Given the insufficient evidence for reduced thromboembolism and concomitant higher bleeding rates in the analysed clinical setting, the use of anticoagulant agents combined with ASA is generally unadvised. Introducing such a therapy may be considered in patients with additional thrombotic risk factors accompanied by a regular assessment of the balance of thrombosis against bleeding.

\section{Implications for research}

Studies that are adequately powered and focused mainly on thrombotic events, as well as that include participants other than women with a history of obstetric complications, are needed to enable the drawing of any meaningful conclusions on the primary prevention of thrombotic events in people with antiphospholipid antibodies, in particular those with persistently high levels of these antibodies.

\section{ACKNOWLEDGEMENTS}

We thank Mr Mateusz Swierz for help in preparing the Background section of the protocol of this review, Dr Karsten Juhl Jørgensen for comments on the draft protocol, and Ms Anna Witkowska for help in managing the references and obtaining full-text articles. We thank Prof Pier L Meroni, Prof Munther A Khamashta, Prof Vittorio Pengo, Prof Phillippe de Moerloose, and representatives of Eli Lilly, Boehringer Ingelheim International, and Aspen Pharma for help with checking for additional studies. 


\section{RE F E R E N C E S}

\section{References to studies included in this review}

\section{Alalaf 2012 \{published data only\}}

Alalaf S. Bemiparin versus low dose aspirin for management of recurrent early pregnancy losses due to antiphospholipid antibody syndrome. Archives of Gynecology and Obstetrics 2012;285:641-7.

\section{Cuadrado 2014 \{published data only\}}

Cuadrado MJ, Bertolaccini ML, Seed P, Tektonidou M, Aguirre A, Mico L, et al. Primary prevention of thrombosis in antiphospholipid antibodies positive patients: a prospective, multicenter, randomised, open trial comparing low dose aspirin with low dose aspirin plus low intensity oral anticoagulation. Arthritis and Rheumatism 2009;60:1285.

* Cuadrado MJ, Bertolaccini ML, Seed PT, Tektonidou MG, Aguirre A, Mico L, et al. Low-dose aspirin vs low-dose aspirin plus low-intensity warfarin in thromboprophylaxis: a prospective, multicentre, randomized, open, controlled trial in patients positive for antiphospholipid antibodies (ALIWAPAS). Rheumatology 2014;53(2):275-84.

\section{Dendrinos 2009 \{published data only\}}

Dendrinos S, Sakkas E, Makrakis E. Low-molecular-weight heparin versus intravenous immunoglobulin for recurrent abortion associated with antiphospholipid antibody syndrome. International Journal of Gynaecology and Obstetrics 2009;104:223-5.

\section{Erkan 2007 \{published data only\}}

Erkan D, Harrison MJ, Levy R, Peterson M, Petri M, Sammaritano $L$, et al. Aspirin for primary thrombosis prevention in the antiphospholipid syndrome: a randomized, double-blind, placebo-controlled trial in asymptomatic antiphospholipid antibody-positive individuals. Arthritis and Rheumatism 2007;56(7):2382-91.

\section{Farquharson 2002 \{published data only\}}

Farquharson FG, Quenby S, Greaves M. Antiphospholipid syndrome in pregnancy: a randomized, controlled trial of treatment. Obstetrics and Gynecology 2002;100(3):408-13.

\section{Fouda 2010 \{published data only\}}

Fouda UM, Sayed AM, Ramadan DI, Fouda IM. Efficacy and safety of two doses of low molecular weight heparin enoxaparin in pregnant women with a history of recurrent abortion secondary to antiphospholipid syndrome. Journal of Obstetrics and Gynaecology 2010;30:842-6.

\section{Fouda 2011 \{published data only\}}

Fouda UM, Sayed AM, Abdou AM, Ramadan DI, Fouda IM, Zaki MM. Enoxaparin versus unfractionated heparin in the management of recurrent abortion secondary to antiphospholipid syndrome. International Journal of Gynaecology and Obstetrics 2011;112:211-5.
Ismail 2016 \{published data only\}

Ismail AM, Hamed AH, Saso S, Abu-Elhasan AM, Abu-Elghar MM, Abdelmeged AN. Randomized controlled study of preconception thromboprophylaxis among patients with recurrent spontaneous abortion related to antiphospholipid syndrome. International Journal of Gynaecology and Obstetrics 2016;132:219-23.

\section{Rai 1997 \{published data only\}}

* Rai R, Cohen H, Dave M, Regan L. Randomised controlled trial of aspirin and aspirin plus heparin in pregnant women with recurrent miscarriage associated with phospholipid antibodies (or antiphospholipid antibodies). BMJ 1997;314:253-7.

Rai RS, Cohen H, Regan L. Prospective randomized trial of aspirin versus aspirin + heparin in pregnant women with a history of recurrent miscarriage in association with antiphospholipid antibodies. Human Reproduction 1996;11 (Suppl 1):25-7.

Rai RS, Regan L, Dave M, Cohen H. Prospective randomised trial of aspirin versus aspirin plus heparin in pregnant women with the antiphospholipid syndrome. British Journal of Haematology 1996;93 (Suppl 1):5; abstract 20.

\section{References to studies excluded from this review}

Anonymous 2010 \{published data only\}

Anticoagulation ineffective for recurrent miscarriage. Journal of the National Medical Association 2010;102(10):969-70.

\section{Arachchillage 2016 \{published data only\}}

Arachchillage DJ, Mackie IJ, Efthymiou M, Chitolie A, Hunt BJ, Isenberg D, et al. Rivaroxaban limits complement activation compared to warfarin in antiphospholipid syndrome patients with venous thromboembolism. Blood 2015;126:2328.

* Arachchillage DR, Mackie IJ, Efthymiou M, Chitolie A, Hunt BJ, Isenberg DA, et al. Rivaroxaban limits complement activation compared with warfarin in antiphospholipid syndrome patients with venous thromboembolism. Journal of Thrombosis and Haemostasis 2016;14(11):2177-86.

\section{Cohen 1996 \{published data only\}}

Cohen $\mathrm{H}$. Randomized trial of aspirin versus aspirin and heparin in pregnant women with the antiphospholipid syndrome. Annales de Medecine Interne 1996;147:44.

\section{Cohen 2016 \{published data only\}}

Cohen H, Dore C, Clawson S, Hunt BJ, Khamashta M, Machin SJ, et al. RAPS: a prospective randomised controlled phase II/ III clinical trial of rivaroxaban vs. warfarin in patients with thrombotic antiphospholipid syndrome, with or without SLE. Journal of Thrombosis and Haemostasis 2013;11 (Suppl 2):860.

Cohen H, Dore CJ, Clawson S, Hunt BJ, Isenberg D, Khamashta M, et al. Rivaroxaban in antiphospholipid syndrome (RAPS) protocol: a prospective, randomized controlled phase II/III clinical trial of rivaroxaban versus warfarin in patients with 
thrombotic antiphospholipid syndrome, with or without SLE. Lupus 2015;24(10):1087-94.

* Cohen H, Hunt BJ, Efthymiou M, Arachchillage DRJ, Mackie IJ, Clawson S, et al. Rivaroxaban versus warfarin to treat patients with thrombotic antiphospholipid syndrome, with or without systemic lupus erythematosus (RAPS): a randomised, controlled, open-label, phase $2 / 3$, non-inferiority trial. Lancet Haematology 2016;3(9):e426-36.

\section{Cowchock 1992 \{published data only\}}

Cowchock FS, Reece EA, Balaban D, Branch DW, Plouffe L. Repeated fetal losses associated with antiphospholipid antibodies: a collaborative randomized trial comparing prednisone with low-dose heparin treatment. American Journal of Obstetrics and Gynecology 1992;166:1318-23.

\section{Cowchock 1997 \{published data only\}}

Cowchock S, Reece EA. Do low-risk pregnant women with antiphospholipid antibodies need to be treated?. American Journal of Obstetrics and Gynecology 1997;176:1099-100.

\section{Crowther 2003 \{published data only\}}

Crowther MA, Ginsberg JS, Gent M, Julian J, Costantini L, Kovacs $M$, et al. A randomized trial of two intensities of warfarin (international normalized ratio of 2.0 to 3.0 versus 3.1 to 4.0 ) for the prevention of recurrent thrombosis in patients with antiphospholipid antibodies. Blood 2002; Vol. 100, issue 2:148aAbstract 555.

* Crowther MA, Ginsberg JS, Julian J, Denburg J, Hirsh J, Douketis J, et al. A comparison of two intensities of warfarin for the prevention of recurrent thrombosis in patients with the antiphospholipid antibody syndrome. New England Journal of Medicine 2003;349(12):1133-8.

\section{Douketis 1999 \{published data only\}}

Douketis JD, Crowther MA, Julian JA, Stewart K, Donovan D, Kaminska EA, et al. The effects of low-intensity warfarin on coagulation activation in patients with antiphospholipid antibodies and systemic lupus erythematosus. Thrombosis and Haemostasis 1999;82(3):1028-32.

\section{Finazzi 2005 \{published data only\}}

* Finazzi G, Brancaccio V, Schinco P, Wisloff F, Musial J, Baudo F, et al. A randomized clinical trial of high-intensity warfarin vs. conventional antithrombotic therapy for the prevention of recurrent thrombosis in patients with the antiphospholipid syndrome (WAPS). Journal of Thrombosis and Haemostasis 2005;3(5):848-53.

Finazzi G, Marchioli R, Barbui T. A randomized clinical trial of two intensities of oral anticoagulant therapy in patients with the antiphospholipid syndrome: final results of the WAPS study. Blood 2003;102(11 Part 1):16a-Abstract OC365.

\section{Goel 2006 \{published data only\}}

Goel N, Tuli A, Choudhry R. The role of aspirin versus aspirin and heparin in cases of recurrent abortions with raised anticardiolipin antibodies. Medical Science Monitor 2006;12:CR132-6.

\section{Kondrat'eva 2010 \{published data only\}}

Kondrat'eva LV, Patrusheva NL, Patrushev LI, Aleksandrova EN, Kovalenko TF, Ostriakova EV, et al. Recurrent thromboses and hemorrhagic complications in patients with antiphospholipid syndrome during therapy with warfarin plus aspirin. Terapevitcheskii Arkhiv 2010;82(5):33-9.

\section{Kutteh 1996 \{published data only\}}

Kutteh WH. Antiphospholipid antibody-associated recurrent pregnancy loss: treatment with heparin and low-dose aspirin is superior to low-dose aspirin alone. American Journal of Obstetrics and Gynecology 1996;174:1584-9.

\section{Lopez-Pedrera 2015 \{published data only\}}

Lopez-Pedrera C, Perez-Sanchez C, Aguirre M, Velasco F, Ruiz-Limon P, Barbarroja N, et al. Beneficial effects of in vivo ubiquinol supplementation on athero-thrombosis prevention in antiphospholipid syndrome patients. Preliminary results of a clinical trial. Annals of the Rheumatic Diseases 2015;74:340-1.

\section{Mohamed 2014 \{published data only\}}

Mohamed KA, Saad AS. Enoxaparin and aspirin therapy for recurrent pregnancy loss due to anti-phospholipid syndrome (APS). Middle East Fertility Society Journal 2014;19:176-82.

\section{Moreira da Costa 2015 \{published data only\}}

Moreira da Costa J, de Castro Pimenta M, Santana da Silva Antunes MI, Aparecida Costa M, Parreiras Martins MA. Implementation of an anticoagulation clinic at a teaching hospital: a descriptive study [Implantação de um ambulatório de anticoagulação em um hospital de ensino: estudo descritivo]. Revista de Atencao Primaria a Saude 2015;18(1):64-9.

\section{NCT02295475 \{published data only\}}

NCT02295475. Apixaban for the secondary prevention of thromboembolism among patients with the antiphospholipid syndrome (ASTRO-APS). clinicaltrials.gov/ct2/show/ NCT02295475 (first received 18 November 2014).

\section{NCT02926170 \{published data only\}}

NCT02926170. Rivaroxaban for patients with antiphospholipid syndrome. clinicaltrials.gov/ct2/show/NCT02926170 (first received 6 October 2016).

\section{Noble 2005 \{published data only\}}

Noble LS, Kutteh WH, Lashey N, Franklin RD, Herrada J. Antiphospholipid antibodies associated with recurrent pregnancy loss: prospective, multicenter, controlled pilot study comparing treatment with low-molecular-weight heparin versus unfractionated heparin. Fertility and Sterility 2005;83:684-90.

\section{O'Neil 2007 \{published data only\}}

O'Neil KM. Clinical trials report. Current Rheumatology Reports 2007;9:187-9.

\section{Pattison 2000 \{published data only\}}

Pattison NS, Chamley LW, Birdsall M, Zanderigo AM, Liddell HS, McDougall J. Does aspirin have a role in improving pregnancy outcome for women with the antiphospholipid syndrome? A 
randomized controlled trial. American Journal of Obstetrics and Gynecology 2000;183:1008-12.

\section{Pengo 2016 \{published data only\}}

Pengo V, Banzato A, Bison E, Zoppellaro G, Padayattil Jose S, Denas G. Efficacy and safety of rivaroxaban vs warfarin in high-risk patients with antiphospholipid syndrome: rationale and design of the Trial on Rivaroxaban in AntiPhospholipid Syndrome (TRAPS) trial. Lupus 2016;25(3):301-6.

\section{Roubey 2010 \{published data only\}}

Roubey RA. Heparin and aspirin versus aspirin alone for prevention of recurrent pregnancy loss. Current Rheumatology Reports 2010;12:1-3.

\section{Scarpellini 2009 \{published data only\}}

Scarpellini F, Sbracia M. Aspirin versus aspirin plus heparin in the treatment of women with habitual abortion and positive to anticardiolipin at low or moderate levels: a controlled trial. American Journal of Reproductive Immunology 2009;61:395.

\section{Stephenson 2004 \{published data only\}}

Stephenson MD, Ballem PJ, Tsang P, Purkiss S, Ensworth S, Houlihan E, et al. Treatment of antiphospholipid antibody syndrome (APS) in pregnancy: a randomized pilot trial comparing low molecular weight heparin to unfractionated heparin. Journal of Obstetrics and Gynaecology Canada 2004;26:729-34.

\section{Stern 2001 \{published data only\}}

Stern C, Norris H, Chamley L, Baker H. A randomized, doubleblind, placebo-controlled trial of heparin and aspirin for women with IVF-implantation failure and antiphospholipid or antinuclear antibodies. Human Reproduction (Oxford, England) 2001;16 (Suppl 1):74.

\section{Villamil 2016 \{published data only\}}

Villamil A, Bandi JC, Nunez F. Antiphospholipid antibodies associated vascular events are an underrecognized cause of morbidity and mortality after liver transplantation: benefit of plasmapheresis and anticoagulation in transplanted patients with high thrombotic risk. liverlearning.aasld.org/aasld/2016/thelivermeeting/143869/

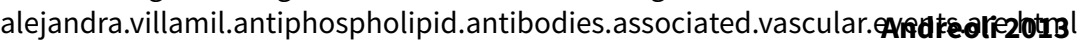
(accessed prior to 22 June 2018).

\section{Woller 2016 \{published data only\}}

Woller SC, Stevens SM, Kaplan DA, Branch DW, Aston VT, Wilson EL, et al. Apixaban for the secondary prevention of thrombosis among patients with antiphospholipid syndrome: study rationale and design (ASTRO-APS). Clinical and Applied Thrombosis/Hemostasis 2016;22(3):239-47.

\section{Yamazaki 2009 \{published data only\}}

Yamazaki M, Kadohira Y, Maekawa M, Hayashi T, Morishita E, Asakura $\mathrm{H}$, et al. Combined antiplatelet agents might help prevent arterial thromboses in antiphospholipid syndrome. Journal of Thrombosis and Haemostasis 2009;7 (Suppl 2):720-1.

\section{References to ongoing studies}

NCT03100123 \{unpublished data only\}

NCT03100123. Antiphospholipid syndrome low-molecularweight heparin pregnancy loss evaluation: the pilot study (APPLE). clinicaltrials.gov/ct2/show/NCT03100123 (first received 4 April 2017).

\section{Additional references}

\section{Abu-Shakra 1995}

Abu-Shakra M, Gladman DD, Urowitz MB, Farewell V. Anticardiolipin antibodies in systemic lupus erythematosus: clinical and laboratory correlations. American Journal of Medicine 1995;99(6):624-8.

\section{Ageno 2012}

Ageno W, Gallus AS, Wittkowsky A, Crowther M, Hylek EM, Palareti G, et al. Oral anticoagulant therapy: Antithrombotic Therapy and Prevention of Thrombosis, 9th ed: American College of Chest Physicians Evidence-Based Clinical Practice Guidelines. Chest 2012;141(2 Suppl):e44S-88S.

\section{Alikhan 2014}

Alikhan R, Bedenis R, Cohen AT. Heparin for the prevention of venous thromboembolism in acutely ill medical patients (excluding stroke and myocardial infarction). Cochrane Database of Systematic Reviews 2014, Issue 5. [DOI: 10.1002/14651858.CD003747.pub4]

\section{Alonso-Coello 2012}

Alonso-Coello P, Bellmunt S, McGorrian C, Anand SS, Guzman R, Criqui $\mathrm{MH}$, et al. Antithrombotic therapy in peripheral artery disease: Antithrombotic Therapy and Prevention of Thrombosis, 9th ed: American College of Chest Physicians Evidence-Based Clinical Practice Guidelines. Chest 2012;141(2 Suppl):e669S-90S.

\section{Amengual 2015}

Amengual O, Fujita D, Ota E, Carmona L, Oku K, SugiuraOgasawara M, et al. Primary prophylaxis to prevent obstetric complications in asymptomatic women with antiphospholipid antibodies: a systematic review. Lupus 2015;24(11):1135-42.

Andreoli L, Chighizola CB, Banzato A, Pons-Estel GJ, Ramire de Jezus G, Erkan D. Estimated frequency of antiphospholipid antibodies in patients with pregnancy morbidity, stroke, myocardial infarction, and deep vein thrombosis: a critical review of the literature. Arthritis Care and Research 2013;65(11):1869-73.

\section{Andreoli 2017}

Andreoli L, Bertsias GK, Agmon-Levin N, Brown S, Cervera R, Costedoat-Chalumeau N, et al. EULAR recommendations for women's health and the management of family planning, assisted reproduction, pregnancy and menopause in patients with systemic lupus erythematosus and/or antiphospholipid syndrome. Annals of the Rheumatic Diseases 2017;76(3):476-85. 


\section{Arnaud 2014}

Arnaud L, Mathian A, Ruffatti A, Erkan D, Tektonidou M, Cervera $\mathrm{R}$, et al. Efficacy of aspirin for the primary prevention of thrombosis in patients with antiphospholipid antibodies: an international and collaborative meta-analysis. Autoimmunity Reviews 2014;13(3):281-91.

\section{Arnaud 2015}

Arnaud L, Mathian A, Devilliers H, Ruffatti A, Tektonidou M, Forastiero R, et al. Patient-level analysis of five international cohorts further confirms the efficacy of aspirin for the primary prevention of thrombosis in patients with antiphospholipid antibodies. Autoimmunity Reviews 2015;14(3):192-200.

\section{Atkins 2004}

Atkins D, Best D, Briss PA, Eccles M, Falck-Ytter Y, Flottorp S, et al. Grading quality of evidence and strength of recommendations. BMJ 2004;328(7454):1490-4.

\section{Bala 2017a}

Bala MM, Celinska-Lowenhoff M, Szot W, Padjas A, Kaczmarczyk M, Swierz MJ, et al. Antiplatelet and anticoagulant agents for secondary prevention of stroke and other thromboembolic events in people with antiphospholipid syndrome. Cochrane Database of Systematic Reviews 2017, Issue 10. [DOI: 10.1002/14651858.CD012169.pub2]

\section{Bates 2012}

Bates SM, Greer IA, Middeldorp S, Veenstra DL, Prabulos AM, Vandvik PO, et al. VTE, thrombophilia, antithrombotic therapy, and pregnancy: Antithrombotic Therapy and Prevention of Thrombosis, 9th ed: American College of Chest Physicians Evidence-Based Clinical Practice Guidelines. Chest 2012;141(2 Suppl):e691S-736S.

\section{Chen 2010}

Chen PP, Giles I. Antibodies to serine proteases in the antiphospholipid syndrome. Current Rheumatology Reports 2010;12(1):45-52.

\section{Covidence 2017 [Computer program]}

Veritas Health Innovation. Covidence systematic review software, Available at www.covidence.org. Melbourne, Australia: Veritas Health Innovation, 2017.

\section{de Jong 2014}

de Jong PG, Kaandorp S, Di Nisio M, Goddijn M, Middeldorp S. Aspirin and/or heparin for women with unexplained recurrent miscarriage with or without inherited thrombophilia. Cochrane Database of Systematic Reviews 2014, Issue 7. [DOI: 10.1002/14651858.CD004734.pub4]

\section{Depta 2015}

Depta JP, Bhatt DL. New approaches to inhibiting platelets and coagulation. Annual Review of Pharmacology and Toxicology 2015;55:373-97.

\section{Douketis 2012}

Douketis JD, Spyropoulos AC, Spencer FA, Mayr M, Jaffer AK, Eckman $\mathrm{MH}$, et al. Perioperative management of antithrombotic therapy: Antithrombotic Therapy and Prevention of
Thrombosis, 9th ed: American College of Chest Physicians Evidence-Based Clinical Practice Guidelines. Chest 2012;141(2 Suppl):e326S-50S.

\section{Empson 2005}

Empson MB, Lassere M, Craig JC, Scott JR. Prevention of recurrent miscarriage for women with antiphospholipid antibody or lupus anticoagulant. Cochrane Database of Systematic Reviews 2005, Issue 2. [DOI: 10.1002/14651858.CD002859.pub2]

\section{Erkan 2014}

Erkan D, Aguiar CL, Andrade D, Cohen H, Cuadrado MJ, Danowskie A, et al. 14th International Congress on Antiphospholipid Antibodies: task force report on antiphospholipid syndrome treatment trends. Autoimmunity Reviews 2014;13(6):685-96.

\section{Farge 2016}

Farge D, Bounameaux $\mathrm{H}$, Brenner B, Cajfinger F, Debourdeau P, Khorana AA, et al. International clinical practice guidelines including guidance for direct oral anticoagulants in the treatment and prophylaxis of venous thromboembolism in patients with cancer. Lancet Oncology 2016;17(10):e452-66.

\section{Garcia 2012}

Garcia DA, Baglin TP, Weitz JI, Samama MM, American College of Chest Physicians. Parenteral anticoagulants: Antithrombotic Therapy and Prevention of Thrombosis, 9th ed: American College of Chest Physicians Evidence-Based Clinical Practice Guidelines. Chest 2012;141(2 Suppl):e24S-43S.

\section{Giannakopoulos 2007}

Giannakopoulos B, Passam F, Rahgozar S, Krilis SA. Current concepts on the pathogenesis of the antiphospholipid syndrome. Blood 2007;109(2):422-30.

\section{Giannakopoulos 2013}

Giannakopoulos B, Krilis S. The pathogenesis of the antiphospholipid syndrome. New England Journal of Medicine 2013;368(11):1033-44

\section{Gomez-Outes 2012}

Gómez-Outes A, Terleira-Fernández Al, Suárez-Gea ML, VargasCastrillón E. Dabigatran, rivaroxaban, or apixaban versus enoxaparin for thromboprophylaxis after total hip or knee replacement: systematic review, meta-analysis, and indirect treatment comparisons. BMJ 2012;344:e3675.

\section{Gomez-Puerta 2014}

Gómez-Puerta JA, Cervera R. Diagnosis and classification of the antiphospholipid syndrome. Journal of Autoimmunity 2014;48-9:20-5.

\section{GRADEpro GDT 2015 [Computer program]}

McMaster University (developed by Evidence Prime, Inc.). GRADEpro GDT: GRADEpro Guideline Development Tool. Version (accessed 22 January 2018). Hamilton (ON): McMaster University (developed by Evidence Prime, Inc.), 2015. 


\section{Guirguis-Blake 2016}

Guirguis-Blake JM, Evans CV, Senger CA, O'Connor EA, Whitlock EP. Aspirin for the primary prevention of cardiovascular events: a systematic evidence review for the U.S. Preventive Services Task Force. Annals of Internal Medicine 2016;164(12):804-13.

\section{Higgins 2011}

Higgins JP, Green S, editor(s). Cochrane Handbook for Systematic Reviews of Interventions Version 5.1.0 (updated March 2011). The Cochrane Collaboration, 2011. Available from handbook.cochrane.org.

\section{Islam 2016}

Islam MA, Alam F, Sasongko TH, Husin A, Abdullah S, Gan SH, et al. Antiplatelet and anticoagulant agents for preventing recurrence of peripheral vascular thrombosis in patients with Antiphospholipid syndrome. Cochrane Database of Systematic Reviews 2016, Issue 5. [DOI: 10.1002/14651858.CD012198]

\section{Junqueira 2012}

Junqueira DR, Zorzela LM, Perini E. Unfractionated heparin versus low molecular weight heparin for avoiding heparininduced thrombocytopenia in postoperative patients. Cochrane Database of Systematic Reviews 2012, Issue 4. [DOI: 10.1002/14651858.CD007557.pub3]

\section{Kahn 2012}

Kahn SR, Lim W, Dunn AS, Cushman M, Dentali F, Akl EA, et al. Prevention of VTE in nonsurgical patients: Antithrombotic Therapy and Prevention of Thrombosis, 9th ed: American College of Chest Physicians Evidence-Based Clinical Practice Guidelines. Chest 2012;141(2 Suppl):e195S-226S.

\section{Kearon 2016}

Kearon C, Akl EA, Ornelas J, Blaivas A, Jimenez D, Bounameaux $\mathrm{H}$, et al. Antithrombotic therapy for VTE disease: CHEST Guideline and Expert Panel Report. Chest 2016;149(2):315-52. [DOI: 10.1016/j.chest.2015.11.026]

\section{Linkins 2012}

Linkins LA, Dans AL, Moores LK, Bona R, Davidson BL, Schulman S, et al. Treatment and prevention of heparininduced thrombocytopenia: Antithrombotic Therapy and Prevention of Thrombosis, 9th ed: American College of Chest Physicians Evidence-Based Clinical Practice Guidelines. Chest 2012;141(2 Suppl):e495S-530S.

\section{Lip 2014}

Lip GY, Windecker S, Huber K, Kirchhof P, Marin F, Ten Berg JM, et al. Management of antithrombotic therapy in atrial fibrillation patients presenting with acute coronary syndrome and/or undergoing percutaneous coronary or valve interventions: a joint consensus document of the European Society of Cardiology Working Group on Thrombosis, European Heart Rhythm Association (EHRA), European Association of Percutaneous Cardiovascular Interventions (EAPCI) and European Association of Acute Cardiac Care (ACCA) endorsed by the Heart Rhythm Society (HRS) and Asia-Pacific Heart Rhythm Society (APHRS). European Heart Journal 2014;35(45):3155-79.

\section{Marchetti 2013}

Marchetti T, Cohen M, de Moerloose P. Obstetrical antiphospholipid syndrome: from the pathogenesis to the clinical and therapeutic implications. Clinical \& Developmental Immunology 2013 Jul 30 [Epub ahead of print]. [DOI: $10.1155 / 2013 / 159124]$

\section{Martel 2005}

Martel N, Lee J, Wells PS. Risk for heparin-induced thrombocytopenia with unfractionated and low-molecularweight heparin thromboprophylaxis: a meta-analysis. Blood 2005;106(8):2710-5.

\section{Meroni 2011}

Meroni PL, Borghi MO, Raschi E, Tedesco F. Pathogenesis of antiphospholipid syndrome: understanding the antibodies. Nature Reviews. Rheumatology 2011;7(6):330-9.

\section{Miyakis 2006}

Miyakis S, Lockshin MD, Atsumi T, Branch DW, Brey RL, Cervera $\mathrm{R}$, et al. International consensus statement on an update of the classification criteria for definite antiphospholipid syndrome (APS). Journal of Thrombosis and Haemostasis 2006;4(2):295-306.

\section{Montalescot 2013}

Montalescot G, Sechtem U, Achenbach S, Andreotti F, Arden C, Budaj A, et al. 2013 guidelines on the management of stable coronary artery disease: the Task Force on the management of stable coronary artery disease of the European Society of Cardiology. European Heart Journal 2013;34(38):2949-3003.

\section{MRCGPRF 1998}

The Medical Research Council's General Practice Research Framework. Thrombosis prevention trial: randomised trial of low-intensity oral anticoagulation with warfarin and low-dose aspirin in the primary prevention of ischaemic heart disease in men at increased risk. Lancet 1998;351:233-41.

\section{Qushmaq 2014}

Qushmaq NA, Al-Emadi SA. Review on effectiveness of primary prophylaxis in aPLs with and without risk factors for thrombosis: efficacy and safety. ISRN Rheumatology 2014;2014:348726. [DOI: 10.1155/2014/348726]

\section{Rajgopal 2008}

Rajgopal R, Bear M, Butcher M, Shaughnessy S. The effects of heparin and low molecular weight heparins on bone. Thrombosis Research 2008;122:293-8.

\section{Rand 2008}

Rand JH, Wu XX, Quinn AS, Taatjes DJ. Resistance to annexin A5 anticoagulant activity: a thrombogenic mechanism for the antiphospholipid syndrome. Lupus 2008;17(10):922-30.

\section{Rasmussen 2012}

Rasmussen LH, Larsen TB, Graungaard T, Skjøth F, Lip GY. Primary and secondary prevention with new oral anticoagulant drugs for stroke prevention in atrial fibrillation: indirect comparison analysis. BMJ 2012;345:e7097. 


\section{RevMan 2014 [Computer program]}

Nordic Cochrane Centre, The Cochrane Collaboration. Review Manager (RevMan). Version 5.3. Copenhagen: Nordic Cochrane Centre, The Cochrane Collaboration, 2014.

\section{Roffi 2016}

Roffi M, Patrono C, Collet JP, Mueller C, Valgimigli M, Andreotti F, et al. 2015 ESC Guidelines for the management of acute coronary syndromes in patients presenting without persistent ST-segment elevation. European Heart Journal 2016;37(3):267-315.

\section{Ruiz-Irastorza 2011}

Ruiz-Irastorza G, Cuadrado MJ, Ruiz-Arruza I, Brey R, Crowther M, Derksen R, et al. Evidence-based recommendations for the prevention and long-term management of thrombosis in antiphospholipid antibody-positive patients: report of a task force at the 13th International Congress on antiphospholipid antibodies. Lupus 2011;20(2):206-18.

\section{Schulman 2005}

Schulman S, Kearon C, Subcommittee on Control of Anticoagulation of the Scientific and Standardization Committee of the International Society on Thrombosis and Haemostasis. Definition of major bleeding in clinical investigations of antihemostatic medicinal products in nonsurgical patients. Journal of Thrombosis and Haemostasis 2005;3(4):692-4.

\section{Sebastiani 1999}

Sebastiani GD, Galeazzi M, Tincani A, Piette JC, Font J, Allegri F, et al. Anticardiolipin and anti-beta2GPI antibodies in a large series of European patients with systemic lupus erythematosus. Prevalence and clinical associations. European concerted action on the Immunogenetics of SLE. Scandinavian Journal of Rheumatology 1999;28(6):344-51.

\section{Sebire 2002}

Sebire NJ, Fox H, Backos M, Rai R, Paterson C, Regan L. Defective endovascular trophoblast invasion in primary antiphospholipid antibody syndrome-associated early pregnancy failure. Human Reproduction 2002;17(4):1067-71.

\section{Shamonki 2007}

Shamonki JM, Salmon JE, Hyjek E, Baergen RN. Excessive complement activation is associated with placental injury in patients with antiphospholipid antibodies. American Journal of Obstetrics and Gynecology 2007;196(2):167.e1-5.

\section{Skrzypczak 2011}

Skrzypczak J, Jasiński P, Wirstlein P, Goździewicz T, Rajewski M. Histologic changes in placenta and chorion of women with antiphospholipid syndrome and inherited thrombophilia [Histologiczne zmiany w łożyskach i kosmówkach u kobiet z zespołem antyfosfolipidowym i trombofilią wrodzoną]. Ginekologia Polska 2011;82(9):652-63.

\section{Torbicki 2008}

Torbicki A, Perrier A, Konstantinides S, Agnelli G, Galiè N, Pruszczyk $P$, et al. Guidelines on the diagnosis and management of acute pulmonary embolism: the Task Force for the Diagnosis and Management of Acute Pulmonary Embolism of the European Society of Cardiology (ESC). European Heart Journal 2008;29(18):2276-315.

\section{Vandvik 2012}

Vandvik PO, Lincoff AM, Gore JM, Gutterman DD, Sonnenberg FA, Alonso-Coello P, et al. Primary and secondary prevention of cardiovascular disease: Antithrombotic Therapy and Prevention of Thrombosis, 9th ed: American College of Chest Physicians Evidence-Based Clinical Practice Guidelines. Chest 2012;141(2 Suppl):e637S-68S.

\section{Warner 2011}

Warner TD, Nylander S, Whatling C. Anti-platelet therapy: cyclooxygenase inhibition and the use of aspirin with particular regard to dual anti-platelet therapy. British Journal of Clinical Pharmacology 2011;72(4):619-33.

\section{Weitz 2012}

Weitz JI, Eikelboom JW, Samama MM, American College of Chest Physicians. New antithrombotic drugs: Antithrombotic Therapy and Prevention of Thrombosis, 9th ed: American College of Chest Physicians Evidence-Based Clinical Practice Guidelines. Chest 2012;141(2 Suppl):e120S-51S.

\section{Weitz 2016}

Weitz $\mathrm{JI}$, Jaffer IH. Optimizing the safety of treatment for venous thromboembolism in the era of direct oral anticoagulants. Polskie Archiwum Medycyny Wewnetrznej 2016;126(9):688-96.

\section{Whitlock 2012}

Whitlock RP, Sun JC, Fremes SE, Rubens FD, Teoh KH, American College of Chest Physicians. Antithrombotic and thrombolytic therapy for valvular disease: Antithrombotic Therapy and Prevention of Thrombosis, 9th ed: American College of Chest Physicians Evidence-Based Clinical Practice Guidelines. Chest 2012;141(2 Suppl):e576S-600S

\section{Wijeyeratne 2011}

Wijeyeratne YD, Heptinstall S. Anti-platelet therapy: ADP receptor antagonists. British Journal of Clinical Pharmacology 2011;72(4):647-57.

\section{Wilson 1999}

Wilson WA, Gharavi AE, Koike T, Lockshin MD, Branch DW, Piette JC, et al. International consensus statement on preliminary classification criteria for definite antiphospholipid syndrome: report of an international workshop. Arthritis and Rheumatism 1999;42(7):1309-11.

\section{Windecker 2014}

Windecker S, Kolh P, Alfonso F, Collet JP, Cremer J, Falk V, et al. 2014 ESC/EACTS Guidelines on myocardial revascularization. The Task Force on Myocardial Revascularization of the European Society of Cardiology (ESC) and the European Association for Cardio-Thoracic Surgery (EACTS) developed with the special contribution of the European Association of Percutaneous Cardiovascular Interventions (EAPCI). European Heart Journal 2014;35(37):2541-619. 


\section{References to other published versions of this review}

\section{Bala 2017b}

Bala MM, Paszek EM, Wloch-Kopec D, Lesniak W, Undas A. Antiplatelet and anticoagulant agents for primary prevention of thrombosis in individuals with antiphospholipid antibodies.

\section{CHARACTERISTICS OFSTUDIES}

Characteristics of included studies [ordered by study ID]
Cochrane Database of Systematic Reviews 2017, Issue 2. [DOI: 10.1002/14651858.CD012534]

* Indicates the major publication for the study

Alalaf 2012

\begin{tabular}{ll}
\hline Study type: $\mathrm{RCT}$ \\
Location: Iraq \\
Time frame: September 2007 to July 2010 \\
Setting: maternity teaching hospital, Erbil city, Kurdistan region, North of Iraq \\
Number of centres: 1 \\
Follow-up: NR
\end{tabular}

Participants

Total number of participants: 141

Recruitment method: maternity teaching hospital patients

Informed consent: yes

Inclusion criteria: aged 18 to 42 years at the time of interview; a history of at least 2 unexplained consecutive pregnancy losses before 20 weeks gestation; persistent presence of aCL antibodies or LA or both on 2 occasions 8 weeks apart

Exclusion criteria: SLE, known peptic ulcer disease, sensitivity to ASA or heparin depending on patient's history report, previous venous thromboembolic disease requiring ongoing anticoagulant therapy, and failure to consent to participate

Age mean (SD): control: 30.61 (6.325), intervention: 31.44 (5.8)

Female: control 61 (100\%), intervention 80 (100\%)

SLE: NR

Cardiovascular risk factors: NR

Antibodies present: $L A, a C L$, anti- $\beta_{2} G P I$ (details NR)

Interventions

Treatment groups: control: ASA $100 \mathrm{mg}$ coated tablets, intervention: bemiparin $2500 \mathrm{IU}$ anti-Xa/0.2 mL solution for injection in prefilled syringes

Duration of interventions: up to 36 weeks of gestation

Concomitant treatment: yes - folic acid

Primary outcomes: live birth rate
Secondary outcomes: obstetric complications, foetal and maternal adverse events
Other outcomes: side effects

Notes

Funding: NR 
Alalaf 2012 (Continued)

Originally planned sample size: NR

\section{Risk of bias}

\begin{tabular}{lll}
\hline Bias & Authors' judgement & Support for judgement \\
\hline $\begin{array}{l}\text { Random sequence genera- } \\
\text { tion }\end{array}$ & High risk & $\begin{array}{l}\text { Quote: "1st case attained the hospital complaining from RM and proved to } \\
\text { have APS, was randomized to LDA group, the second case attained the hospital } \\
\text { and filled the inclusion criteria; LMWH was prescribed to her, sometimes two } \\
\text { cases of Heparin followed one case of LDA. All the cases received the drug ran- } \\
\text { domly." }\end{array}$ \\
& $\begin{array}{l}\text { Comment: women referred to the hospital were consecutively given LDA, then } \\
\text { LMWH, sometimes in a 2:1 ratio. }\end{array}$
\end{tabular}

\begin{tabular}{ll}
\hline Allocation concealment $\quad$ High risk & $\begin{array}{l}\text { Quote: "the 1st case attained the hospital complaining from RM and proved to } \\
\text { have APS, was randomized to LDA group, the second case attained the hospital } \\
\text { and filled the inclusion criteria" }\end{array}$ \\
Comment: no information about concealment
\end{tabular}

\begin{tabular}{|c|c|c|}
\hline $\begin{array}{l}\text { Blinding of participants } \\
\text { and personnel } \\
\text { All outcomes }\end{array}$ & Unclear risk & $\begin{array}{l}\text { Comment: no blinding, no clear definitions or methods of measurements of } \\
\text { outcomes, not possible to assess if lack of blinding could have influenced the } \\
\text { outcome }\end{array}$ \\
\hline
\end{tabular}

\begin{tabular}{lll}
\hline $\begin{array}{l}\text { Blinding of outcome as- } \\
\text { sessment } \\
\text { All outcomes }\end{array}$ & Unclear risk & $\begin{array}{l}\text { Comment: no blinding, no clear definitions or methods of measurements of } \\
\text { outcomes, not possible to assess if lack of blinding could have influenced the } \\
\text { outcome }\end{array}$ \\
\hline Incomplete outcome data & Low risk & Comment: no missing outcome data \\
\hline Selective reporting & High risk & $\begin{array}{l}\text { Comment: no protocol available, side effects described in methods section not } \\
\text { completely reported }\end{array}$ \\
\hline
\end{tabular}

Other sources of bias High risk Comment:
1. Low-dose aspirin given before pregnancy in the LDA group. Bemiparin group received treatment after pregnancy was diagnosed. No details on the structure of the groups in terms of diabetes.

2. No sample size calculation.

\section{Cuadrado 2014}

\section{Methods}

Study type: RCT, minimisation

Location: UK, other countries in Europe, Mexico

Time frame: February 2001 to June 2006

Setting: 5 tertiary referral centres in the UK, 8 tertiary referral centres and 1 district hospital in other European countries, 1 tertiary referral centre in Mexico

\section{Number of centres: 15}

Follow-up: control group: 37.2 months (median); intervention group: 32.4 months (median) 
Recruitment method: locally in 14 centres

Informed consent: yes

Inclusion criteria: (i) presence of aPLs (medium or high titres of aCL defined as IgG > $20 \mathrm{GPL}$ and/or IgM $>20 \mathrm{MPL}$ and/or LA positive) on at least 2 occasions, with an interval of 6 weeks, during the year previous to inclusion in the study; (ii) SLE patients meeting 4 or more ACR criteria for the classification of SLE and/or patients with a history of pregnancy morbidity as defined in the APS Sapporo classification criteria; and (iii) age between 18 and 65 years

Exclusion criteria: positive for aPLs but without SLE or obstetric APS, previous thrombotic events, uncontrolled hypertension, active gastric or duodenal ulceration, platelets $<50,000 / \mathrm{mm}^{3}$, hepatic failure, severe illness, allergy to ASA, warfarin, current pregnancy

Age mean (SD): control: 37.8 (10.7), intervention 37.8 (106)

Female: control 80 (96\%), intervention 80 (95\%)

SLE: control $62(75 \%)$, intervention $62(73 \%)$

\section{Cardiovascular risk factors:}

Control: hypertension $9(11 \%)$, hypercholesterolaemia $8(10 \%)$, hypertriglyceridaemia $0(0 \%)$, smoking $23(29 \%)$, obesity $6(7 \%)$

Intervention: hypertension 10 (12\%), hypercholesterolaemia 12 (14\%), hypertriglyceridaemia 4 (5\%), smoking $24(31 \%)$, obesity $12(14 \%)$

\section{Antibodies present:}

Control: LA 47/68 (69\%), aCL IgG 31/67 (46\%) IgM 11/66 (16\%), anti- $\beta_{2}$ GPI: IgG 10/57 (17.5\%) IgM 4/57 (7\%)

Intervention: LA 53/64 (83\%), aCL IgG 23/62 (37\%) IgM 13/61 (21\%), anti- $\beta_{2}$ GPI: IgG 13/58 (22.4\%) IgM $6 / 58(10 \%)$

Interventions

Treatment groups: control: ASA 75 to $125 \mathrm{mg}$, intervention: ASA 75 to $125 \mathrm{mg}$ and warfarin (target INR $=1.5$, range 1.3 to 1.7 ) (ASA dose depending on the preparation available in the participant country)

Duration of interventions: 37.2 (median months)

\section{Concomitant treatment: no}

Outcomes

Primary outcomes: thrombosis (objectively verified thrombotic events; the following investigations were performed in order to document the event: ultrasonography or venography for deep vein thrombosis, spiral CT scan or radionuclide lung scan or angiography for pulmonary embolism, MRI or angiography for thrombosis in intracerebral vessels, ophthalmological examination and fluorescein angiography (where possible) for retinal thrombosis, and arteriography for peripheral or mesenteric arterial thrombosis; for the diagnosis of myocardial infarction the World Health Organization (WHO) classification was followed, where two-thirds of the following criteria were required: (i) ECG characteristic changes ( $2 \mathrm{~mm}$ ST increase in ECG leads V4-V6 or $1 \mathrm{~mm}$ in I, II and aVF); (ii) ischaemic chest pain lasting $>30 \mathrm{~min}$; and (iii) increase in cardiac enzymes (at least twice their normal value), amaurosis fugax was defined as sudden monocular blindness lasting $<24 \mathrm{~h}$ and transient ischaemic attack as neurological symptoms or signs lasting $<24 \mathrm{~h}$ )

Secondary outcomes: clinical and serological risk factors for thrombosis, side effects of medications, death of any cause

Other outcomes: NR 
Cuadrado 2014 (Continued)

We attempted to contact Dr Cuadrado for results clarification but were unsuccessful.

\section{Risk of bias}

\begin{tabular}{|c|c|c|}
\hline Bias & Authors' judgement & Support for judgement \\
\hline $\begin{array}{l}\text { Random sequence genera- } \\
\text { tion }\end{array}$ & Low risk & Comment: randomisation carried out using minimisation protocol \\
\hline Allocation concealment & Low risk & $\begin{array}{l}\text { Comment: allocation by independent individual, explicit statement that treat- } \\
\text { ment allocation was concealed }\end{array}$ \\
\hline $\begin{array}{l}\text { Blinding of participants } \\
\text { and personnel } \\
\text { Death }\end{array}$ & Low risk & Comment: no blinding, outcome not likely to be influenced \\
\hline $\begin{array}{l}\text { Blinding of participants } \\
\text { and personnel } \\
\text { Bleeding }\end{array}$ & Unclear risk & Comment: no blinding, unclear outcome definition \\
\hline $\begin{array}{l}\text { Blinding of participants } \\
\text { and personnel } \\
\text { Thromboembolic events }\end{array}$ & Low risk & $\begin{array}{l}\text { Comment: no blinding, however outcome verified by objective methods, not } \\
\text { likely to be influenced }\end{array}$ \\
\hline $\begin{array}{l}\text { Blinding of participants } \\
\text { and personnel } \\
\text { Adverse events }\end{array}$ & High risk & $\begin{array}{l}\text { Comment: no blinding, outcome is not objectively verified and likely to be in- } \\
\text { fluenced }\end{array}$ \\
\hline $\begin{array}{l}\text { Blinding of outcome as- } \\
\text { sessment } \\
\text { Thromboembolic events }\end{array}$ & Low risk & $\begin{array}{l}\text { Comment: no blinding, however outcome verified by objective methods, not } \\
\text { likely to be influenced }\end{array}$ \\
\hline $\begin{array}{l}\text { Blinding of outcome as- } \\
\text { sessment } \\
\text { Death }\end{array}$ & Low risk & Comment: no blinding, outcome not likely to be influenced \\
\hline $\begin{array}{l}\text { Blinding of outcome as- } \\
\text { sessment } \\
\text { Bleeding }\end{array}$ & Unclear risk & Comment: no blinding, unclear outcome definition \\
\hline $\begin{array}{l}\text { Blinding of outcome as- } \\
\text { sessment } \\
\text { Adverse events }\end{array}$ & High risk & $\begin{array}{l}\text { Comment: no blinding, outcome is not objectively verified and likely to be in- } \\
\text { fluenced }\end{array}$ \\
\hline Incomplete outcome data & High risk & $\begin{array}{l}\text { Comment: approximately } 10 \% \text { more participants in the experimental group } \\
\text { than in the control group have follow-up shorter than } 1 \text { year }\end{array}$ \\
\hline Selective reporting & Low risk & Comment: all outcomes reported \\
\hline Other sources of bias & High risk & Comment: low recruitment rate, sample size not achieved \\
\hline
\end{tabular}

Dendrinos 2009

$\begin{array}{ll}\text { Methods } & \text { Study type: RCT } \\ & \text { Location: Greece }\end{array}$


Dendrinos 2009 (Continued)

Time frame: March 2002 to March 2006

Setting: university department

Number of centres: 1

Follow-up: up to 2 months postpartum

Participants

\section{Total number of participants: 85}

Recruitment method: patients referred to the authors' department

\section{Informed consent: yes}

Inclusion criteria: age 18 to 39 years; >= 3 consecutive spontaneous abortions before 10 weeks of gestation, and positive $\mathrm{aPL}$ antibodies ( $\mathrm{aCL}$ antibody of IgG and/or IgM isotype in blood, present in medium or high titres, or on 2 or more occasions at least 6 weeks apart; and LA present in plasma, on 2 or more occasions at least 6 weeks apart)

Exclusion criteria: SLE; ASA allergy or sensitivity to ASA; a chromosomal or anatomic abnormality or a luteal phase defect; confirmed peptic ulcer; previous thromboembolism, hypertension, or current treatment with antihypertensive drugs; previous prednisone therapy; an abnormal chest radiograph result; or a positive result of a tuberculin skin test

Age mean (SD): intervention $31.1(1)$, control $32(0.8)$

Female: intervention 40 (100\%), control 38 (100\%)

SLE: NR

Cardiovascular risk factors: NR

Antibodies present: LA, aPL, anti- $\beta_{2}$ GPI (details NR)

\section{Treatment groups:}

Control: IVIG $400 \mathrm{mg} / \mathrm{kg}$ as soon as positive pregnancy test every 28 days until 32 weeks of gestation Intervention: ASA $75 \mathrm{mg} / \mathrm{d}$ and $4500 \mathrm{IU}$ of heparin (Innohep) as soon as woman had a positive pregnancy test result (LMWH dose adapted so that factor Xa levels were within the recommended prophylactic range); ASA was discontinued at 32 weeks of gestation or at the time of an abortion, and heparin at 38 weeks of gestation or at the time of an abortion

Duration of interventions: until 32/38 weeks of gestation or abortion

Concomitant treatment: control group: calcium $500 \mathrm{mg} /$ day

Secondary outcomes: maternal adverse effects during pregnancy and postdelivery (haemorrhages, pregnancy-associated hypertension, fractures during pregnancy or up to 2 months postpartum, reduced maternal bone mineral density, and death)

Other outcomes: NR

Notes Funding: NR

Originally planned sample size: NR

\section{Risk of bias}


Dendrinos 2009 (Continued)

$\begin{array}{ll}\begin{array}{l}\text { Random sequence genera- } \\ \text { tion }\end{array} & \text { Low risk } \\ \text { number tables }\end{array}$

\begin{tabular}{lll}
\hline Allocation concealment & Unclear risk & Comment: no information about concealment \\
\hline $\begin{array}{l}\text { Blinding of participants } \\
\text { and personnel }\end{array}$ & Low risk & $\begin{array}{l}\text { Comment: no information, outcome not likely to be influenced by lack of } \\
\text { beath }\end{array}$
\end{tabular}

\begin{tabular}{|c|c|c|}
\hline $\begin{array}{l}\text { Blinding of participants } \\
\text { and personnel } \\
\text { Thromboembolic events }\end{array}$ & Unclear risk & $\begin{array}{l}\text { Comment: no information about blinding, not clear how the outcome was as- } \\
\text { sessed }\end{array}$ \\
\hline
\end{tabular}

\begin{tabular}{|c|c|c|}
\hline $\begin{array}{l}\text { Blinding of participants } \\
\text { and personnel } \\
\text { Adverse events }\end{array}$ & Unclear risk & $\begin{array}{l}\text { Comment: no information about blinding, not clear how the outcomes were } \\
\text { assessed, therefore not possible to assess the influence of lack of blinding }\end{array}$ \\
\hline $\begin{array}{l}\text { Blinding of outcome as- } \\
\text { sessment } \\
\text { Thromboembolic events }\end{array}$ & Unclear risk & $\begin{array}{l}\text { Comment: no information about blinding, not clear how the outcome was as- } \\
\text { sessed }\end{array}$ \\
\hline $\begin{array}{l}\text { Blinding of outcome as- } \\
\text { sessment } \\
\text { Death }\end{array}$ & Low risk & $\begin{array}{l}\text { Comment: no blinding, but lack of blinding probably did not influence the out- } \\
\text { come }\end{array}$ \\
\hline $\begin{array}{l}\text { Blinding of outcome as- } \\
\text { sessment } \\
\text { Adverse events }\end{array}$ & Unclear risk & $\begin{array}{l}\text { Comment: no information about blinding, no information about the assess- } \\
\text { ment of outcomes or their definition, therefore not possible to assess if lack of } \\
\text { blinding could have influenced outcome }\end{array}$ \\
\hline Incomplete outcome data & High risk & $\begin{array}{l}\text { Comment: participants excluded from the analysis after randomisation due to } \\
\text { non-compliance or discontinuations. Intention-to-treat analysis cited for pri- } \\
\text { mary outcome, but not explained. }\end{array}$ \\
\hline Selective reporting & Unclear risk & $\begin{array}{l}\text { Comment: no protocol available, all outcomes described in methods section } \\
\text { were reported }\end{array}$ \\
\hline Other sources of bias & Low risk & Comment: no other bias identified \\
\hline
\end{tabular}

\section{Erkan 2007}

\begin{tabular}{ll}
\hline Methods & Study type: RCT, double-blind \\
Location: NR \\
Time frame: June 2001 to April 2005 \\
Setting: NR \\
Number of centres: 3 \\
Follow-up: $2.30+/-0.95$ years \\
\hline
\end{tabular}

Participants

\section{Total number of participants: 98}

Recruitment method: patients from clinic and collaborative centres

Informed consent: yes 
Erkan 2007 (Continued)

Inclusion criteria: individuals who were $>=18$ years of age, with or without systemic autoimmune diseases, who fulfilled at least 1 of the following criteria: a positive LA test result, as defined by the International Society on Thrombosis and Haemostasis on $>=2$ occasions, at least 6 weeks apart, and/or positive $\mathrm{aCL}$ antibodies (IgG/IgM/IgA) >= 20 units on $>=2$ occasions at least 6 weeks apart

Exclusion criteria: diagnosis of APS based on the original Sapporo classification criteria; a history of thrombosis, pulmonary embolism, or transient ischaemic attack; use of regular-dose warfarin or an antiplatelet agent (including ASA); ASA allergy; history of bleeding within the last 5 years that required hospitalisation or blood transfusion or both; severe thrombocytopenia, active gastric/duodenal ulcer; active malignancy, chronic viral infection with HIV or hepatitis C; pregnancy

Age mean (SD): intervention 43.1 (12.8), control 42.7 (14)

Female: intervention 44 (92\%), control 44 (88\%)

SLE: intervention $30(63 \%)$, control $34(68 \%)$

\section{Cardiovascular risk factors:}

Intervention: hypertension 12 (25\%), diabetes 4 (8\%), hyperlipidaemia/dyslipidaemia 3 (6\%), smoking $10(21 \%)$

Control: hypertension 10 (20\%), diabetes 2 (4\%), hyperlipidaemia/dyslipidaemia 2 (4\%), smoking 4 $(8 \%)$

Antibodies present: information on high risk/low-risk antibodies only (the low-risk aPL profile was defined as IgG, IgM, or IgA 20 to 39 units; the high-risk aPL profile was defined as IgG, IgM, or IgA 40 units and/or positive LA test results)

Interventions

Treatment groups: intervention: ASA $81 \mathrm{mg}$ daily, control: placebo

Duration of interventions: $2.27+/-0.91$ (ASA) vs $2.33+/-0.99$ (control)

Concomitant treatment: $\mathrm{HCQ}$, steroids, NSAID (57\%, 33\%, 40\% respectively)

Outcomes

Primary outcomes: acute thrombosis (stroke confirmed by neuroimaging, deep vein thrombosis by Doppler ultrasonography, pulmonary embolism by CT scan (ventilation/perfusion or spiral)), acute MI confirmed by ECG and increased cardiac enzymes

Secondary outcomes: TIA (transient focal neurologic abnormalities with negative neuroimaging study)

Other outcomes: ASA-related adverse events (abdominal pain, nausea, vomiting, anorexia, heartburn, dyspepsia, any bleeding)

Notes

Funding: New York Chapter of the Arthiritis Foundation and New York Community Trust (Bayer Pharmaceutical provided ASA and placebo)

Originally planned sample size: 220

\section{Risk of bias}

\begin{tabular}{lll}
\hline Bias & Authors' judgement & Support for judgement \\
\hline $\begin{array}{l}\text { Random sequence genera- } \\
\text { tion }\end{array}$ & Low risk & Comment: computer-generated stratified randomisation \\
\hline Allocation concealment & Unclear risk & Comment: details not provided \\
\hline $\begin{array}{l}\text { Blinding of participants } \\
\begin{array}{l}\text { and personnel } \\
\text { All outcomes }\end{array}\end{array}$ & Low risk & Comment: investigators, co-ordinators, participants blinded \\
\hline
\end{tabular}


Erkan 2007 (Continued)

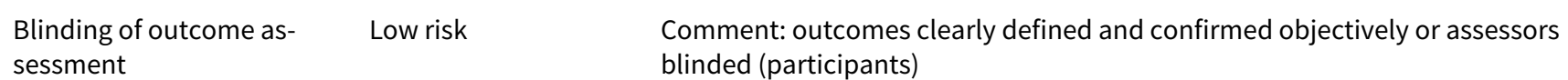

All outcomes

blinded (participants)

$\begin{array}{ll}\text { Incomplete outcome data Unclear risk } & \begin{array}{l}\text { Comment: insufficient information about analysis of data for participants lost } \\ \text { to follow-up }\end{array}\end{array}$

\begin{tabular}{lll}
\hline Selective reporting & Unclear risk & Comment: no protocol available \\
\hline Other sources of bias & High risk & $\begin{array}{l}\text { Comment: Bayer was the sponsor of the study - potential risk of favouring } \\
\text { the ASA group. Initially planned sample size was 110 per group, after interim } \\
\text { analysis it was estimated as 30,363 in each arm; the study included a total of } \\
98 \text { participants. }\end{array}$ \\
\end{tabular}

Farquharson 2002

\begin{tabular}{ll}
\hline Study type: $\mathrm{RCT}$ \\
Location: UK \\
Time frame: January 1997 to January 2000 \\
Setting: miscarriage clinic \\
Number of centres: 1 \\
Follow-up: NR
\end{tabular}

Participants

\section{Total number of participants: 98}

Recruitment method: miscarriage clinic patients

\section{Informed consent: NR}

Inclusion criteria: women, 18 to 41 years, at least 3 consecutive pregnancy losses or 2 consecutive losses with proven foetal death after 10 weeks' gestation; 2 positive tests for aPL antibody more than 6 weeks apart (with positive levels defined as $>9 \mathrm{U} / \mathrm{mL}$ for $\lg \mathrm{G}$ and $>5 \mathrm{U} / \mathrm{mL}$ for $\operatorname{lgM}$ )

Exclusion criteria: parental chromosomal abnormality, uterine anomaly, previous arterial or venous thrombosis, use of steroids during pregnancy, systemic lupus erythematosus requiring medication or complicated by nephritis, and other thrombophilia such as activated protein C resistance or protein C/ S deficiency

Age mean (SD): control 33 (4.9), intervention 33 (4.8)

Female: control 47 (100), intervention 51 (100)

SLE: NR

Cardiovascular risk factors: NR

\section{Antibodies present:}

Control: LA 18 (38\%), aCL 7 (15\%)

Intervention: LA 23 (45\%), aCL 9 (18\%)

Interventions

Treatment groups: control: ASA 75 mg/d, intervention: ASA 75 mg/d + LMWH 5000 U sc

Duration of interventions: from before 12 weeks' gestation until delivery 
Farquharson 2002 (Continued)

Concomitant treatment: NR

\begin{tabular}{|c|c|c|}
\hline Outcomes & \multicolumn{2}{|c|}{$\begin{array}{l}\text { Primary outcomes: live birth } \\
\text { Secondary outcomes: other pregnancy-related outcomes } \\
\text { Other outcomes: maternal thrombosis }\end{array}$} \\
\hline Notes & \multicolumn{2}{|c|}{$\begin{array}{l}\text { Funding: LUPUS UK and NHS R\&D (NWEST) } \\
\text { Originally planned sample size: } 220\end{array}$} \\
\hline \multicolumn{3}{|l|}{ Risk of bias } \\
\hline Bias & Authors' judgement & Support for judgement \\
\hline $\begin{array}{l}\text { Random sequence genera- } \\
\text { tion }\end{array}$ & Low risk & Comment: computer-generated randomisation, blocks of 20 \\
\hline Allocation concealment & Low risk & $\begin{array}{l}\text { Comment: telephone randomisation to the Trials Unit at the Centre for Cancer } \\
\text { Epidemiology at the University of Manchester }\end{array}$ \\
\hline $\begin{array}{l}\text { Blinding of participants } \\
\text { and personnel } \\
\text { Thromboembolic events }\end{array}$ & Unclear risk & $\begin{array}{l}\text { Comment: no information about blinding, not clear how the outcome was as- } \\
\text { sessed }\end{array}$ \\
\hline $\begin{array}{l}\text { Blinding of outcome as- } \\
\text { sessment } \\
\text { Thromboembolic events }\end{array}$ & Unclear risk & $\begin{array}{l}\text { Comment: no information about blinding, not clear how the outcome was as- } \\
\text { sessed }\end{array}$ \\
\hline Incomplete outcome data & Low risk & $\begin{array}{l}\text { Comment: no missing data, ITT analysis, } 24 \text { not adherent but included in the } \\
\text { analysis }\end{array}$ \\
\hline Selective reporting & Unclear risk & Comment: no protocol available \\
\hline Other sources of bias & High risk & $\begin{array}{l}\text { Comment: sample size calculated by the authors }(n=220) \text { not achieved; inter- } \\
\text { im analysis mentioned as planned, but not reported }\end{array}$ \\
\hline
\end{tabular}

Fouda 2010

Methods

Study type: RCT

Location: Egypt

Time frame: December 2008 to May 2010

Setting: Obstetrics and Gynecology Department, Cairo University Hospital, Egypt

Number of centres: 1

Follow-up: NR

Participants

Total number of participants: 60

Recruitment method: clinic patients

Informed consent: yes 
Fouda 2010 (Continued)

Inclusion criteria: minimum of 3 consecutive pregnancy losses before 10 weeks' gestation and positive LA and/or aCL antibodies (IgG and IgM) on at least 2 occasions at least 12 weeks apart

Exclusion criteria: paternal chromosomal abnormalities or uterine abnormalities (detected by hysterosalpingography, saline infusion sonography or office hysteroscopy), luteal phase defect, abnormal thyroid function tests, hyperprolactinaemia, polycystic ovary syndrome, SLE, previous thromboembolism, peptic ulcer, age $<19$ years or $>37$ years, $\mathrm{BMI}<19$ or $>30$, or sensitivity to ASA or heparin

Age mean (SD): intervention 27.13 (3.67), control 28.93 (4.18)

Female: intervention 30 (100\%), control 30 (100\%)

SLE: NR

Cardiovascular risk factors: NR

\section{Antibodies present:}

Intervention: LA 10 (33\%), aCL IgG 8 (27\%) IgM 4 (20\%)

Control: LA 9 (30\%), aCL IgG 6 (20\%) IgM 5 (17\%)

Interventions Treatment groups: intervention: enoxaparin $40 \mathrm{mg} /$ day + ASA 75 mg/day, control: enoxaparin 20 mg/ day + ASA $75 \mathrm{mg} /$ day

Duration of interventions: whole pregnancy

Concomitant treatment: prenatal vitamins, oral calcium (600 mg twice daily), vitamin D

Primary outcomes: live birth rate
Secondary outcomes: excessive bleeding, thrombocytopenia, IUGR; spontaneous osteoporotic frac-
tures; preterm delivery, pre-eclampsia; intrauterine foetal death; neonatal bleeding; congenital anom-
alies, thrombotic event

Other outcomes: NR

Notes Funding: NR

Originally planned sample size: calculated 410 , reduced to 60 due to time constraints

\section{Risk of bias}

\begin{tabular}{lll}
\hline Bias & Authors' judgement & Support for judgement \\
\hline $\begin{array}{l}\text { Random sequence genera- } \\
\text { tion }\end{array}$ & Low risk & Comment: computer-generated random numbers \\
\hline Allocation concealment & Low risk & Comment: concealed in opaque envelopes \\
\hline $\begin{array}{l}\text { Blinding of participants } \\
\text { and personnel } \\
\text { Bleeding }\end{array}$ & Unclear risk & Comment: no blinding, insufficient definition \\
\hline $\begin{array}{l}\text { Blinding of participants } \\
\text { and personnel } \\
\text { Thromboembolic events }\end{array}$ & Unclear risk & Comment: no blinding, no definition of thrombotic event is given \\
\hline $\begin{array}{l}\text { Blinding of participants } \\
\text { and personnel } \\
\text { Adverse events }\end{array}$ & Unclear risk & Comment: no blinding, insufficient definition \\
\hline
\end{tabular}


Fouda 2010 (Continued)

Blinding of outcome as- Unclear risk Comment: insufficient information to judge (no information about outcome sessment assessment)

Thromboembolic events

Blinding of outcome as- Unclear risk Comment: no blinding, insufficient definition
sessment

sessment

Bleeding

Blinding of outcome as- Unclear risk Comment: no blinding, insufficient definition

sessment

Adverse events

\begin{tabular}{lll}
\hline Incomplete outcome data & Low risk & Comment: no missing outcome data \\
\hline Selective reporting & Unclear risk & $\begin{array}{l}\text { Comment: no protocol available, most of the prespecified outcomes were re- } \\
\text { ported }\end{array}$ \\
\hline Other sources of bias & High risk & Comment: low recruitment rate, sample size not achieved \\
\hline
\end{tabular}

Fouda 2011

$\begin{array}{ll}\text { Methods } & \text { Study type: RCT } \\ \text { Location: Egypt } \\ \text { Time frame: June } 2006 \text { to December } 2009 \\ \text { Setting: Cairo University } \\ \text { Number of centres: } 2 \\ \text { Follow-up: NR }\end{array}$

Participants

Total number of participants: 60

Recruitment method: hospital patients

Informed consent: yes

Inclusion criteria: a history of 3 or more consecutive spontaneous abortions before 10 weeks of gestation, and positive LA and/or aCL antibodies (IgG and IgM) on 2 or more occasions at least 12 weeks apart; age between 18 and 37 years; and BMI between 19 and 29

Exclusion criteria: paternal chromosomal abnormalities; uterine malformation detected by hysterosalpingography or office hysteroscopy; cervical incompetence; luteal phase defect; abnormal thyroid function tests; hyperprolactinaemia; polycystic ovary syndrome; hereditary thrombophilia; SLE; previous venous or arterial thrombotic episodes; diabetes mellitus; kidney or liver disease; gastric ulcer; and sensitivity to ASA, UFH, or enoxaparin

Age mean (SD): intervention 27.47 (SD 3.2), control 28.57 (SD 3.48)

Female: intervention 30 (100\%), control 30 (100\%)

SLE: NR

Cardiovascular risk factors: NR

Antibodies present:

Intervention: LA 12 (40\%), aCL IgG 7 (23\%) IgM 5 (17\%) 
Fouda 2011 (Continued)

Control: LA 10 (33\%), aCL IgG 5 (17\%) IgM 8 (27\%)

Interventions Treatment groups: intervention: enoxaparin $40 \mathrm{mg} /$ day sc + ASA $75 \mathrm{mg} /$ day, control: heparin calcium $5000 \mathrm{IU}$ sc, twice daily + ASA $75 \mathrm{mg} /$ day

Duration of interventions: whole pregnancy

Concomitant treatment: prenatal vitamins, $600 \mathrm{mg}$ oral calcium twice daily, and $400 \mathrm{IU}$ vitamin $\mathrm{D}_{3}$ twice daily

$\begin{array}{ll}\text { Outcomes } & \text { Primary outcomes: live birth rate } \\ & \text { Secondary outcomes: excessive haemorrhage, thrombocytopenia, IUGR, intrauterine foetal death, } \\ \text { preterm delivery, neonatal bleeding, congenital anomalies, pre-eclampsia, spontaneous osteoporotic } \\ \text { fractures }\end{array}$

Other outcomes: NR

Notes Funding: NR

Originally planned sample size: calculated 1447 , reduced to 60

\section{Risk of bias}

\begin{tabular}{|c|c|c|}
\hline Bias & Authors' judgement & Support for judgement \\
\hline $\begin{array}{l}\text { Random sequence genera- } \\
\text { tion }\end{array}$ & Low risk & Comment: computer-generated randomisation list \\
\hline Allocation concealment & Low risk & Comment: opaque, sealed envelopes \\
\hline $\begin{array}{l}\text { Blinding of participants } \\
\text { and personnel } \\
\text { Bleeding }\end{array}$ & Low risk & $\begin{array}{l}\text { Comment: open-label study, but outcome clearly defined and objectively con- } \\
\text { firmed, so not likely to be influenced by lack of blinding }\end{array}$ \\
\hline $\begin{array}{l}\text { Blinding of participants } \\
\text { and personnel } \\
\text { Thromboembolic events }\end{array}$ & Unclear risk & $\begin{array}{l}\text { Comment: open-label study, no clear definition of the outcome and assess- } \\
\text { ment }\end{array}$ \\
\hline $\begin{array}{l}\text { Blinding of participants } \\
\text { and personnel } \\
\text { Adverse events }\end{array}$ & Unclear risk & $\begin{array}{l}\text { Comment: open-label study, no clear definition of the outcome and assess- } \\
\text { ment }\end{array}$ \\
\hline $\begin{array}{l}\text { Blinding of outcome as- } \\
\text { sessment } \\
\text { Thromboembolic events }\end{array}$ & Unclear risk & $\begin{array}{l}\text { Comment: open-label study, no clear definition of the outcome and assess- } \\
\text { ment }\end{array}$ \\
\hline $\begin{array}{l}\text { Blinding of outcome as- } \\
\text { sessment } \\
\text { Bleeding }\end{array}$ & Low risk & $\begin{array}{l}\text { Comment: open-label study, but outcome clearly defined and objectively con- } \\
\text { firmed, so not likely to be influenced by lack of blinding }\end{array}$ \\
\hline $\begin{array}{l}\text { Blinding of outcome as- } \\
\text { sessment } \\
\text { Adverse events }\end{array}$ & Unclear risk & $\begin{array}{l}\text { Comment: open-label study, no clear definition of the outcome and assess- } \\
\text { ment }\end{array}$ \\
\hline Incomplete outcome data & Low risk & Comment: no missing outcome data \\
\hline Selective reporting & Unclear risk & Comment: no protocol, all outcomes reported \\
\hline
\end{tabular}


Fouda 2011 (Continued)

Other sources of bias High risk Comment: low recruitment rate (estimated: 1447; recruited: 60)

Ismail 2016

Study type: $\mathrm{RCT}$
Location: Egypt
Time frame: January 2011 to June 2013
Setting: Women's Health Hospital, Assiut University, Egypt
Number of centres: 1
Follow-up: to 6 weeks after delivery

Participants

Total number of participants: 180

Recruitment method: gynaecology outpatient clinic patients

Informed consent: yes

Inclusion criteria: diagnosis of APS was made on the basis of 2 positive test results, at least 12 weeks apart, for the presence of either LA or aCL antibodies and a history of 3 or more consecutive firsttrimester ( $\leq 13$ weeks) spontaneous abortions, or 2 or more second-trimester spontaneous abortions (13 to 24 weeks) with the same partner

Exclusion criteria: history of thromboembolic events, bleeding tendencies, hypersensitivity to ASA or enoxaparin, congenital anomalies of the uterus, cervical insufficiency, uncontrolled diabetes mellitus, or chromosomal anomalies affecting either participants or their partners, pregnancy at study enrolment following the use of assisted reproductive techniques

Age mean (SD): intervention 25.5 (4.7), control 27.6 (4.8)

Female: intervention 90 (100\%), control 90 (100\%)

SLE: NR

Cardiovascular risk factors: NR

Antibodies present: NR

Interventions

Treatment groups: intervention: $40 \mathrm{mg}$ of enoxaparin sc daily + $81 \mathrm{mg}$ of ASA daily, control: placebo

Duration of interventions: from preconception to 6 weeks after delivery

Concomitant treatment: folic acid, calcium

Outcomes

Primary outcomes: rate of live birth after 24 weeks of pregnancy, clinical pregnancy rate at 0 to 6 months, clinical pregnancy rate at 6 to 12 months

Secondary outcomes: rate of first- and second-trimester spontaneous abortion, vaginal bleeding during pregnancy, pre-eclampsia, pregnancy-induced hypertension, abruptio placentae, preterm delivery, IUGR

Other outcomes: complications of enoxaparin use (maternal or neonatal bleeding or both, heparin-induced thrombocytopenia, pain and bruising at injection sites, hypersensitivity to heparin, teratogenicity), and thromboembolic events

Notes $\quad$ Funding: NR


Ismail 2016 (Continued)

\section{Originally planned sample size: 180}

We obtained additional information and clarification of results from Dr Ismail.

\section{Risk of bias}

\begin{tabular}{lll}
\hline Bias & Authors' judgement & Support for judgement \\
\hline $\begin{array}{l}\text { Random sequence genera- } \\
\text { tion }\end{array}$ & Low risk & $\begin{array}{l}\text { Quote: "Using a computer-generated sequence, participants were randomly } \\
\text { allocated in a 1:1 ratio to receive enoxaparin plus aspirin or placebo.(..) A min- } \\
\text { imization procedure employing a computer-based algorithm was applied to } \\
\text { avoid chance imbalances in important stratification variables" }\end{array}$ \\
\hline Allocation concealment & Low risk & $\begin{array}{l}\text { Quote: "To ensure allocation concealment, an independent secretary stored } \\
\text { all the sealed envelopes containing each participant's group assignment; all } \\
\text { envelopes were kept closed until data analysis was completed. Additionally, a } \\
\text { central telephone system was used whereby an independent secretary spoke } \\
\text { with patients to arrange all follow-up visits." }\end{array}$ \\
& Comment: allocation concealment properly implemented
\end{tabular}

Blinding of participants Low risk and personnel

All outcomes
Quote: "Study drugs and placebo were prepared by the pharmacy department of the study institution, with all placebo treatments manufactured to be identical to study medications. Study drugs and placebo were stored in identical ampoules and as tablets of identical size, shape, and colour; study treatments were distributed to participants by study institution staff without informing them of their treatment assignment. Clinicians, investigators, and data analysts were masked to the group assignments."

Comment: blinding implemented appropriately

\begin{tabular}{|c|c|c|}
\hline $\begin{array}{l}\text { Blinding of outcome as- } \\
\text { sessment } \\
\text { Thromboembolic events }\end{array}$ & Unclear risk & $\begin{array}{l}\text { Comment: no clear definition of outcome and assessment, no information } \\
\text { about blinding of outcome assessors }\end{array}$ \\
\hline $\begin{array}{l}\text { Blinding of outcome as- } \\
\text { sessment } \\
\text { Bleeding }\end{array}$ & Low risk & $\begin{array}{l}\text { Comment: no blinding but lack of blinding would not have influenced the out- } \\
\text { come, as clear definition of outcome provided }\end{array}$ \\
\hline $\begin{array}{l}\text { Blinding of outcome as- } \\
\text { sessment } \\
\text { Adverse events }\end{array}$ & Low risk & $\begin{array}{l}\text { Comment: participants, clinicians, and investigators were reported to be } \\
\text { blinded }\end{array}$ \\
\hline Incomplete outcome data & Low risk & Comment: similar percentage of participants lost to follow up, ITT analysis \\
\hline Selective reporting & Unclear risk & Comment: no protocol, no information about thrombotic events \\
\hline Other sources of bias & Low risk & Comment: no other sources of bias \\
\hline
\end{tabular}

\section{Rai 1997}

\section{Methods}

\section{Study type: RCT \\ Location: UK}

Time frame: April 1993 to July 1995

Setting: recurrent miscarriage clinic at St Mary's Hospital in London 
Rai 1997 (Continued)

\section{Number of centres: 1}

Follow-up: NR

Participants

Total number of participants: 90

Recruitment method: recurrent miscarriage clinic patients

Informed consent: yes

Inclusion criteria: a history of 3 or more consecutive miscarriages and positive results for aPL antibodies on at least 2 occasions more than 8 weeks apart before becoming pregnant

Exclusion criteria: previous thromboembolism, SLE, a uterine abnormality, hypersecretion of luteinising hormone, and multiple pregnancy, abnormal karyotype

Age mean (range): control 34 (22 to 44 ), intervention 32 (23 to 40 )

Female: control 45 (100\%), intervention 45 (100\%)

SLE: NR

Cardiovascular risk factors: NR

\section{Antibodies present:}

Control: LA 34 (76\%), aCL 5 (11\%)

Intervention: LA 40 (89\%), aCL 3 (7\%)

Interventions

Treatment groups: control: ASA 75 mg/day, intervention: ASA 75 mg/day + calcium heparin $5000 \mathrm{IU}$ sc daily

Duration of interventions: up to 34 weeks gestation

Concomitant treatment: NR

\begin{tabular}{|c|c|c|}
\hline Outcomes & \multicolumn{2}{|c|}{$\begin{array}{l}\text { Primary outcomes: live births } \\
\text { Secondary outcomes: premature delivery (before } 37 \text { weeks of gestation) } \\
\text { Other outcomes: safety, adverse events }\end{array}$} \\
\hline Notes & \multicolumn{2}{|c|}{$\begin{array}{l}\text { Funding: Arthritis and Rheumatism Council } \\
\text { Originally planned sample size: } 80 \text { to } 90\end{array}$} \\
\hline \multicolumn{3}{|l|}{ Risk of bias } \\
\hline Bias & Authors' judgement & Support for judgement \\
\hline $\begin{array}{l}\text { Random sequence genera- } \\
\text { tion }\end{array}$ & Low risk & $\begin{array}{l}\text { Quote: "Patients were randomly assigned in equal proportion to the two treat- } \\
\text { ment groups by means of a computer generated random number list (Systat } \\
\text { 5.2.1; Macintosh)." } \\
\text { Comment: computer-generated random number list }\end{array}$ \\
\hline Allocation concealment & Low risk & $\begin{array}{l}\text { Quote: "The randomisation list was kept by an independent member of staff } \\
\text { not involved in the trial." } \\
\text { Comment: only a person outside the study had access }\end{array}$ \\
\hline $\begin{array}{l}\text { Blinding of participants } \\
\text { and personnel }\end{array}$ & Unclear risk & $\begin{array}{l}\text { Comment: lack of blinding, definition of outcome unclear, therefore not possi- } \\
\text { ble to judge if lack of blinding could have influenced the outcomes }\end{array}$ \\
\hline
\end{tabular}

Antiplatelet and anticoagulant agents for primary prevention of thrombosis in individuals with antiphospholipid antibodies (Review) 
Rai 1997 (Continued)

All outcomes

\begin{tabular}{lll}
\hline $\begin{array}{l}\text { Blinding of outcome as- } \\
\text { sessment } \\
\text { All outcomes }\end{array}$ & Unclear risk & $\begin{array}{l}\text { Comment: lack of blinding, definition of outcome unclear, therefore not possi- } \\
\text { ble to judge if lack of blinding could have influenced the outcomes }\end{array}$ \\
\hline Incomplete outcome data & Low risk & Comment: no missing data \\
\hline Selective reporting & Unclear risk & Comment: no protocol available \\
\hline Other sources of bias & Low risk & Comment: no other sources of bias \\
\hline
\end{tabular}

aCL: anticardiolipin

ACR: American College of Rheumatology

anti- $\beta_{2}$ GPI: anti-beta2-glycoprotein I

aPL: antiphospholipid

APS: antiphospholipid syndrome

ASA: acetylsalicylic acid

BMI: body mass index

CT: computed tomography

ECG: electrocardiography

GPI: glycoprotein I

GPL: G phospholipids

HCQ: hydroxychloroquine

IgA: immunoglobulin A

IgG: immunoglobulin $\mathrm{G}$

IgM: immunoglobulin $M$

INR: international normalised ratio

ITT: intention-to-treat

IUGR: intrauterine growth restriction

LA: lupus anticoagulant

LDA: low-dose aspirin

LMWH: low molecular weight heparin

MI: myocardial infarction

MPL: M phospholipids

MRI: magnetic resonance imaging

NR: not reported

NSAID: non-steroidal anti-inflammatory drugs

$\mathrm{RCT}$ : randomised controlled trial

$\mathrm{RM}$ : recurrent miscarriage

sc: subcutaneously

SD: standard deviation

SLE: systemic lupus erythematosus

TIA: transient ischaemic attack

UFH: unfractionated heparin

Characteristics of excluded studies [ordered by study ID]

\begin{tabular}{ll}
\hline Study & Reason for exclusion \\
\hline Anonymous 2010 & Wrong patient population: aPL antibodies not confirmed \\
\hline Arachchillage 2016 & Wrong patient population: secondary prevention \\
\hline Cohen 1996 & Wrong outcomes: obstetric failure only \\
\hline Cohen 2016 & Wrong patient population: secondary prevention \\
\hline \hline
\end{tabular}

Antiplatelet and anticoagulant agents for primary prevention of thrombosis in individuals with antiphospholipid antibodies (Review) 


\begin{tabular}{|c|c|}
\hline Study & Reason for exclusion \\
\hline Cowchock 1992 & Wrong outcomes: only obstetric outcomes, thromboembolism not assessed \\
\hline Cowchock 1997 & Wrong outcomes: obstetric failure only \\
\hline Crowther 2003 & Wrong patient population: secondary prevention \\
\hline Douketis 1999 & $\begin{array}{l}\text { Wrong outcomes: prothrombin fragment } 1+2 \text { level }(F 1+2) \text {; thromboembolic events/bleeding not } \\
\text { assessed }\end{array}$ \\
\hline Finazzi 2005 & Wrong patient population: secondary prevention \\
\hline Goel 2006 & Wrong study design: non-RCT \\
\hline Kondrat'eva 2010 & Wrong patient population: secondary prevention \\
\hline Kutteh 1996 & Wrong study design: non-RCT \\
\hline Lopez-Pedrera 2015 & Wrong intervention: no anticoagulant/antiplatelet intervention \\
\hline Mohamed 2014 & Wrong study design: non-randomised comparative study \\
\hline Moreira da Costa 2015 & Wrong study design: non-RCT \\
\hline NCT02295475 & Wrong patient population: secondary prevention \\
\hline NCT02926170 & Wrong patient population: secondary prevention \\
\hline Noble 2005 & Wrong study design: non-randomised trial \\
\hline O'Neil 2007 & Wrong patient population: secondary prevention \\
\hline Pattison 2000 & Wrong outcomes: obstetric failure only \\
\hline Pengo 2016 & Wrong patient population: secondary prevention \\
\hline Roubey 2010 & $\begin{array}{l}\text { Wrong patient population: study group consisted of aPL-positive patients or people with other } \\
\text { thrombophilia }\end{array}$ \\
\hline Scarpellini 2009 & Wrong outcomes: only obstetric outcomes, thromboembolism not assessed \\
\hline Stephenson 2004 & Wrong outcomes: obstetric failure only \\
\hline Stern 2001 & Wrong outcomes: only effectiveness of implantation assessed \\
\hline Villamil 2016 & Wrong intervention: no antiplatelet/anticoagulant intervention \\
\hline Woller 2016 & Wrong patient population: secondary prevention \\
\hline Yamazaki 2009 & Wrong patient population: not primary prevention \\
\hline
\end{tabular}

aPL: antiphospholipid

RCT: randomised controlled trial 
Characteristics of ongoing studies [ordered by study ID]

\section{NCT03100123}

Trial name or title

A pilot study assessing the feasibility of a randomized controlled trial evaluating aspirin versus low-molecular-weight heparin (LMWH) and aspirin in women with antiphospholipid syndrome and pregnancy loss

Methods

Study type: multicentre, open-label, randomised controlled trial

Location: Canada

Number of centres: 2

Time frame of the study: November 2017 to November 2019

\begin{tabular}{|c|c|}
\hline Participants & $\begin{array}{l}\text { Inclusion criteria: } \\
\text { - confirmed pregnancy } \\
\text { - } 18 \text { years or older } \\
\text { - } 2 \text { or more unexplained pregnancy loss before the } 10 \text { th week of gestation and/or } 1 \text { or more unex- } \\
\text { plained pregnancy loss at or beyond the } 10 \text { th week of gestation } \\
\text { - } 1 \text { or more APS laboratory criteria present, according to revised Sapporo criteria } \\
\text { Exclusion criteria: } \\
\text { - greater than } 11 \text { weeks }+6 \text { days gestational age at time of randomisation } \\
\text { - indication(s) for prophylactic or therapeutic-dose anticoagulation } \\
\text { - contraindication to heparin or ASA } \\
\text { - received } 7 \text { or more doses of LMWH } \\
\text { - previous participation in the trial } \\
\text { - geographic inaccessibility } \\
\text { - refused consent }\end{array}$ \\
\hline Interventions & $\begin{array}{l}\text { - Experimental arm: ASA } 81 \mathrm{mg} \text { orally daily in tablet form } \\
\text { - Standard care arm: low molecular weight heparin: tinzaparin } 4500 \mathrm{IU} \text { sc daily until } 20 \text { weeks ges- } \\
\text { tation, and then } 4500 \mathrm{IU} \text { sc twice daily until } 37 \text { weeks gestation }\end{array}$ \\
\hline Outcomes & $\begin{array}{l}\text { Primary outcome: the primary feasibility outcome of the pilot trial is the mean recruitment rate per } \\
\text { centre per month. } \\
\text { Secondary outcomes: } \\
\text { - proportion of sites requiring more than } 18 \text { months to obtain all required approvals/contracts from } \\
\text { time of delivery of all study documents } \\
\text { - proportion of screened patients who meet eligibility criteria (i.e. patients who meet inclusion cri- } \\
\text { teria and are also eligible based on exclusion criteria) } \\
\text { - proportion of eligible participants who provide consent } \\
\text { - proportion of withdrawals/loss to follow-up among randomised participants } \\
\text { - cross-over rate between standard care and experimental study arms } \\
\text { - level of compliance with study drug through participant recall and participant medication diary } \\
\text { - reasons for physician and patient non-consent }\end{array}$ \\
\hline
\end{tabular}

Starting date

6 November 2017
Contact: Leslie Skeith, MD, Veronica Whitham, BSc

613-737-8899 ext 71068 Ottawa Hospital Research Institute

Notes

Funding: Ottawa Hospital Research Institute 
APS: antiphospholipid syndrome

ASA: acetylsalicylic acid

LMWH: low molecular weight heparin

sc: subcutaneously

\section{DATA AND ANALYSES}

Comparison 1. Anticoagulant with or without ASA versus ASA only

\begin{tabular}{lllll}
\hline $\begin{array}{l}\text { Outcome or subgroup } \\
\text { title }\end{array}$ & No. of studies & $\begin{array}{l}\text { No. of partici- } \\
\text { pants }\end{array}$ & Statistical method & Effect size \\
\hline 1 Thrombosis & 4 & 493 & Risk Ratio (M-H, Fixed, 95\% Cl) & $0.98[0.25,3.77]$ \\
\hline 2 Minor bleeding & 1 & & Risk Ratio (M-H, Fixed, 95\% Cl) & Totals not selected \\
\hline
\end{tabular}

Analysis 1.1. Comparison 1 Anticoagulant with or without ASA versus ASA only, Outcome 1 Thrombosis.

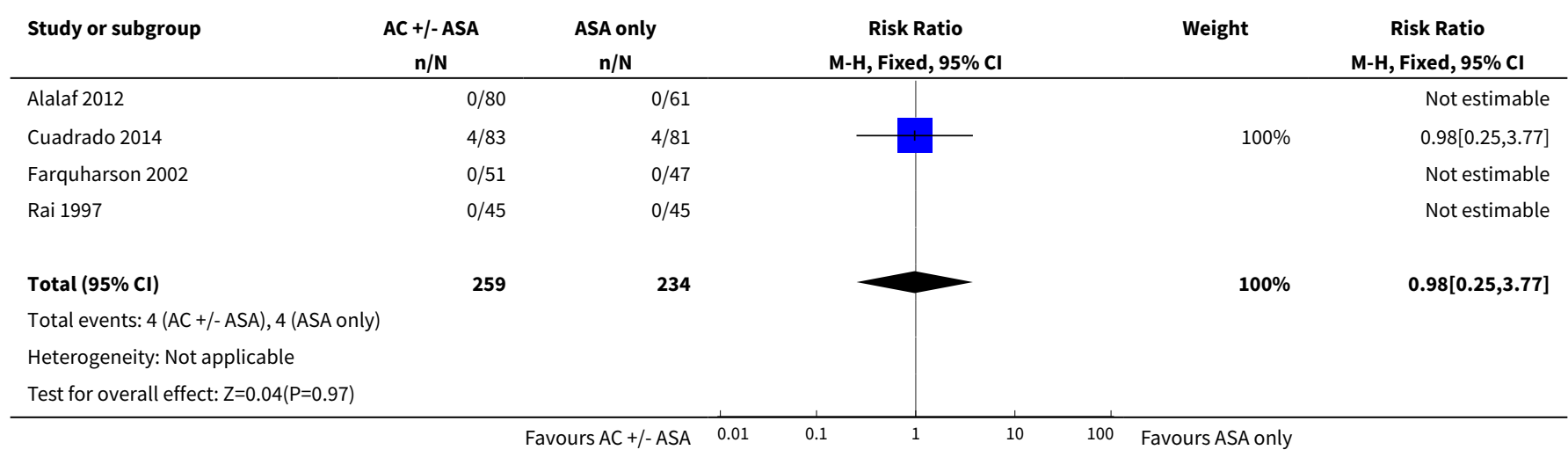

Analysis 1.2. Comparison 1 Anticoagulant with or without ASA versus ASA only, Outcome 2 Minor bleeding.

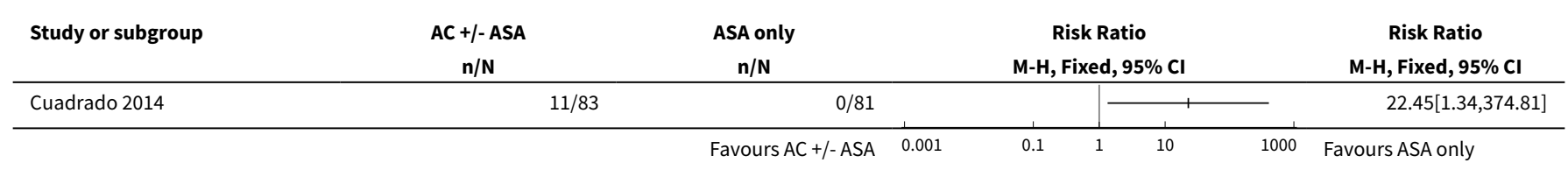


Comparison 2. ASA only versus placebo

\begin{tabular}{lllll}
\hline $\begin{array}{l}\text { Outcome or sub- } \\
\text { group title }\end{array}$ & No. of studies & $\begin{array}{l}\text { No. of partici- } \\
\text { pants }\end{array}$ & Statistical method & Effect size \\
\hline 1 Thrombosis & 1 & Risk Ratio (M-H, Fixed, 95\% Cl) & Totals not selected \\
\hline 2 Bleeding & 1 & Risk Ratio (M-H, Fixed, 95\% Cl) & Totals not selected \\
\hline
\end{tabular}

Analysis 2.1. Comparison 2 ASA only versus placebo, Outcome 1 Thrombosis.

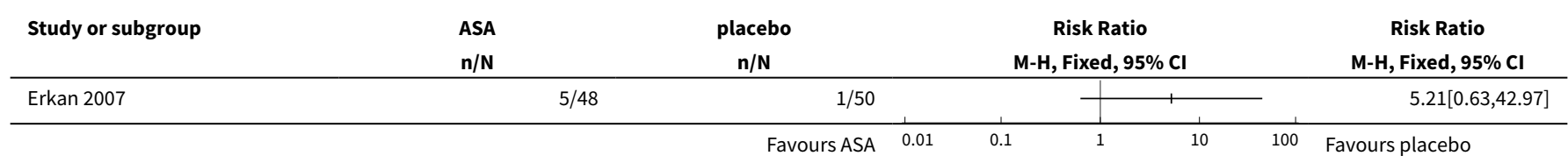

Analysis 2.2. Comparison 2 ASA only versus placebo, Outcome 2 Bleeding.

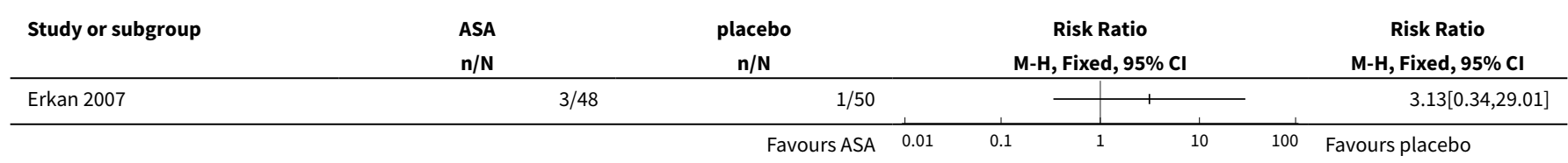

Comparison 3. ASA with LMWH versus placebo or IVIG

\begin{tabular}{lllll}
\hline Outcome or subgroup title & No. of studies & $\begin{array}{l}\text { No. of partici- } \\
\text { pants }\end{array}$ & Statistical method & Effect size \\
\hline 1 Thrombosis & 2 & & Risk Ratio (M-H, Fixed, 95\% Cl) & Subtotals only \\
\hline 2 Bleeding & 1 & Risk Ratio (M-H, Fixed, 95\% Cl) & Subtotals only \\
\hline $\begin{array}{l}2.1 \text { Bleeding requiring } \\
\text { transfusion }\end{array}$ & 1 & Risk Ratio (M-H, Fixed, 95\% Cl) & $9.0[0.49,164.76]$ \\
\hline $\begin{array}{l}2.2 \text { Bleeding during first } \\
\text { trimester }\end{array}$ & 1 & 180 & Risk Ratio (M-H, Fixed, 95\% Cl) & $0.89[0.50,1.61]$ \\
\hline $\begin{array}{l}2.3 \text { Postpartum haemor- } \\
\text { rhage }\end{array}$ & 1 & 180 & Risk Ratio $(\mathrm{M}-\mathrm{H}$, Fixed, 95\% Cl) & $1.3[0.60,2.81]$ \\
\hline
\end{tabular}


Analysis 3.1. Comparison 3 ASA with LMWH versus placebo or IVIG, Outcome 1 Thrombosis.

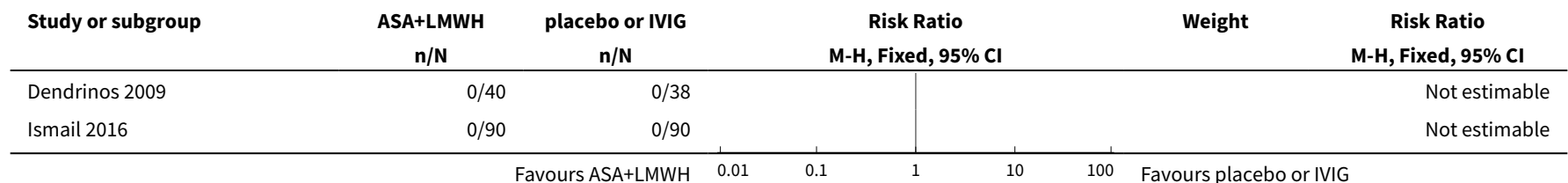

Analysis 3.2. Comparison 3 ASA with LMWH versus placebo or IVIG, Outcome 2 Bleeding.

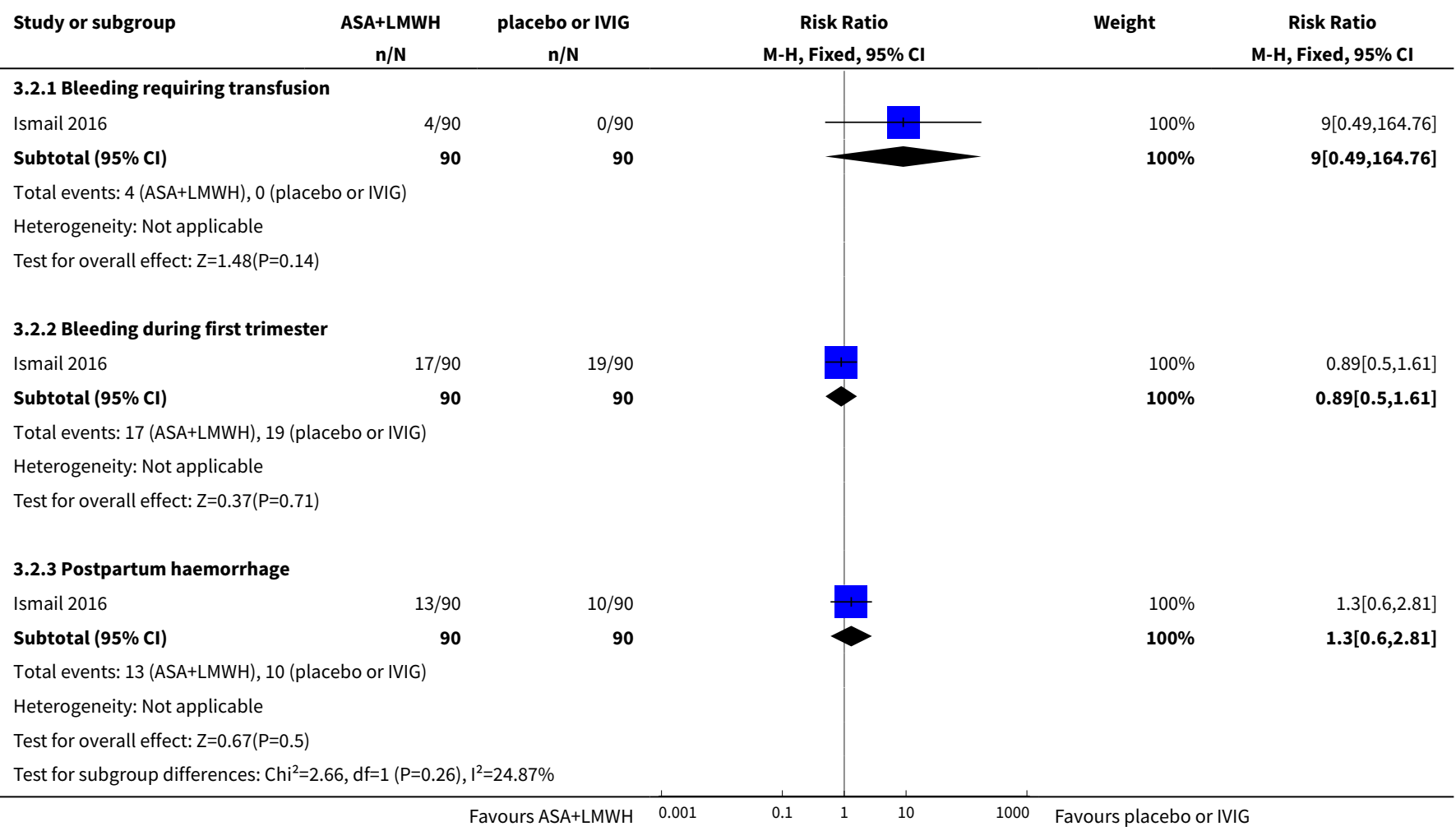

\section{Comparison 4. ASA + high-dose LMWH versus ASA + low-dose LMWH or UFH}

\begin{tabular}{llllll}
\hline Outcome or subgroup title & No. of studies & $\begin{array}{l}\text { No. of partici- } \\
\text { pants }\end{array}$ & Statistical method & Effect size \\
\hline 1 Thrombosis & 2 & 120 & Risk Ratio (M-H, Fixed, 95\% Cl) & $0.0[0.0,0.0]$ \\
\hline 2 Major/excessive bleeding & 2 & 120 & Risk Ratio (M-H, Fixed, 95\% Cl) & $0.0[0.0,0.0]$ \\
\hline 3 Subcutaneous bruises & 2 & 120 & Risk Ratio (M-H, Fixed, 95\% Cl) & $1.0[0.34,2.93]$ \\
\hline
\end{tabular}


Analysis 4.1. Comparison 4 ASA + high-dose LMWH versus ASA + low-dose LMWH or UFH, Outcome 1 Thrombosis.

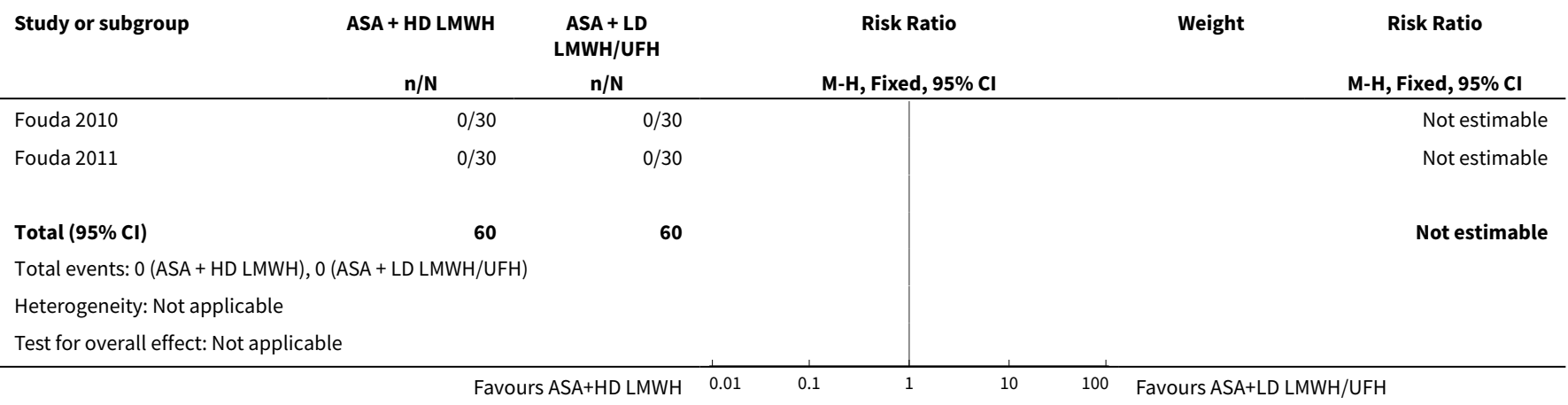

Analysis 4.2. Comparison 4 ASA + high-dose LMWH versus ASA

+ low-dose LMWH or UFH, Outcome 2 Major/excessive bleeding.

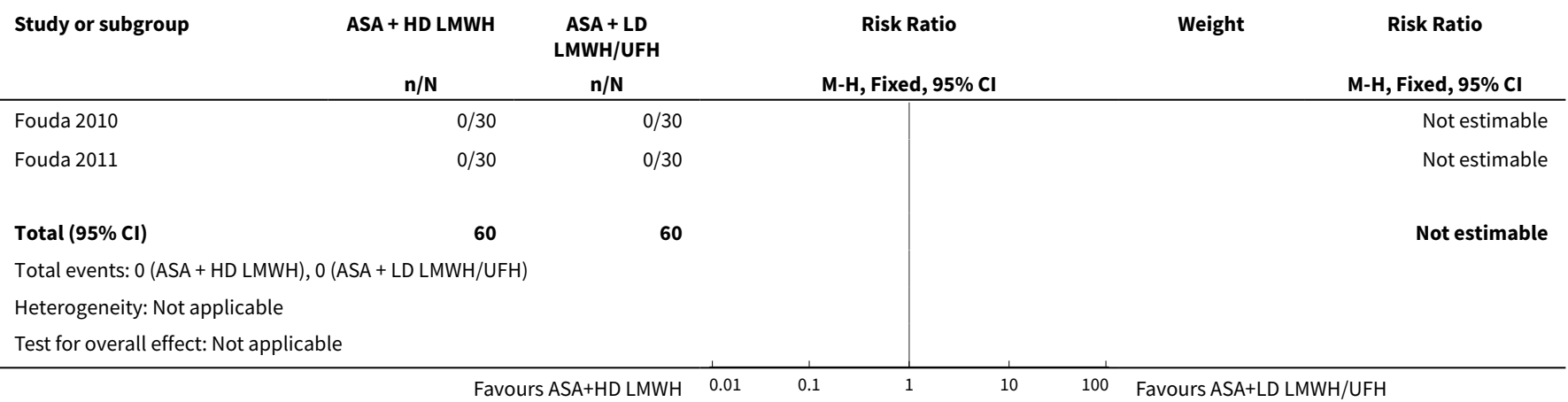

Analysis 4.3. Comparison 4 ASA + high-dose LMWH versus ASA

+ low-dose LMWH or UFH, Outcome 3 Subcutaneous bruises.

\begin{tabular}{|c|c|c|c|c|c|}
\hline \multirow[t]{2}{*}{ Study or subgroup } & ASA + HD LMWH & $\begin{array}{c}\text { ASA + LD } \\
\text { LMWH/UFH }\end{array}$ & Risk Ratio & \multirow[t]{2}{*}{ Weight } & \multirow{2}{*}{$\begin{array}{c}\text { Risk Ratio } \\
\text { M-H, Fixed, } 95 \% \mathrm{Cl}\end{array}$} \\
\hline & $\mathrm{n} / \mathrm{N}$ & $n / N$ & M-H, Fixed, 95\% Cl & & \\
\hline Fouda 2010 & $3 / 30$ & $3 / 30$ & - & $50 \%$ & $1[0.22,4.56]$ \\
\hline Fouda 2011 & $3 / 30$ & $3 / 30$ & & $50 \%$ & $1[0.22,4.56]$ \\
\hline Total $(95 \% \mathrm{Cl})$ & 60 & 60 & & $100 \%$ & $1[0.34,2.93]$ \\
\hline \multicolumn{6}{|c|}{ Heterogeneity: $\mathrm{Tau}^{2}=0 ; \mathrm{Chi}^{2}=0, \mathrm{df}=1(\mathrm{P}=1) ; \mathrm{I}^{2}=0 \%$} \\
\hline Test for overall effect & & & & & \\
\hline
\end{tabular}


Comparison 5. Sensitivity analyses anticoagulant with or without ASA versus ASA only

\begin{tabular}{llllll}
\hline Outcome or subgroup title & No. of studies & $\begin{array}{l}\text { No. of partici- } \\
\text { pants }\end{array}$ & Statistical method & Effect size \\
\hline 1 Thrombosis best-worst scenario & 4 & 493 & Risk Ratio (M-H, Fixed, 95\% Cl) & $0.39[0.13,1.19]$ \\
\hline 2 Thrombosis worst-best scenario & 4 & 493 & Risk Ratio (M-H, Fixed, 95\% Cl) & $4.39[1.55,12.42]$ \\
\hline
\end{tabular}

Analysis 5.1. Comparison 5 Sensitivity analyses anticoagulant with or without ASA versus ASA only, Outcome 1 Thrombosis best-worst scenario.

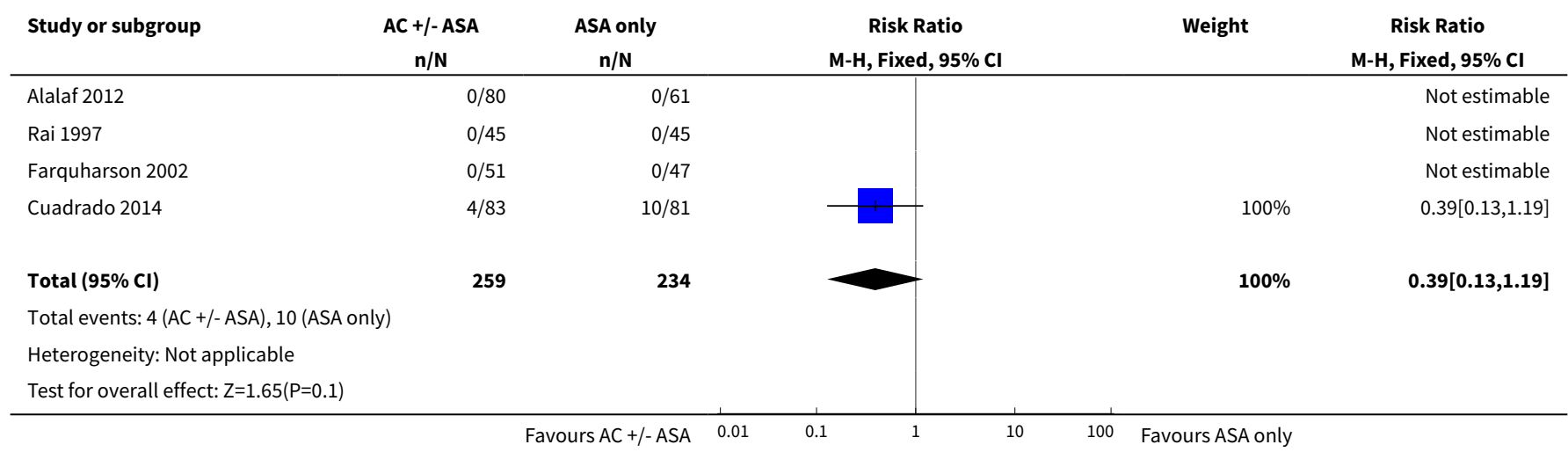

Analysis 5.2. Comparison 5 Sensitivity analyses anticoagulant with or without ASA versus ASA only, Outcome 2 Thrombosis worst-best scenario.

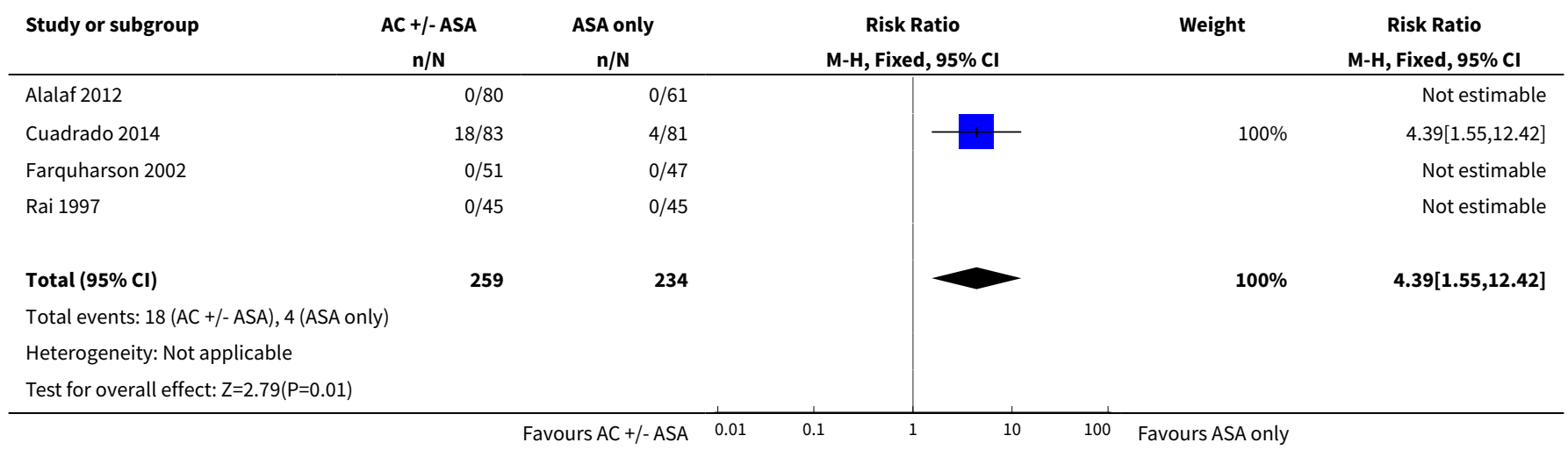

\section{Comparison 6. Sensitivity analyses ASA with LMWH versus placebo or IVIG}

\begin{tabular}{lllll}
\hline Outcome or subgroup title & No. of studies & $\begin{array}{l}\text { No. of partici- } \\
\text { pants }\end{array}$ & Statistical method & Effect size \\
\hline 1 Thrombosis best-worst scenario & 2 & 265 & Risk Ratio (M-H, Fixed, 95\% Cl) & $0.13[0.01,2.51]$ \\
\hline
\end{tabular}




\begin{tabular}{lllll}
\hline Outcome or subgroup title & No. of studies & $\begin{array}{l}\text { No. of partici- } \\
\text { pants }\end{array}$ & Statistical method & Effect size \\
\hline 2 Thrombosis worst-best scenario & 2 & 265 & Risk Ratio (M-H, Fixed, 95\% Cl) & $8.4[0.47,151.34]$ \\
\hline
\end{tabular}

Analysis 6.1. Comparison 6 Sensitivity analyses ASA with LMWH versus placebo or IVIG, Outcome 1 Thrombosis best-worst scenario.

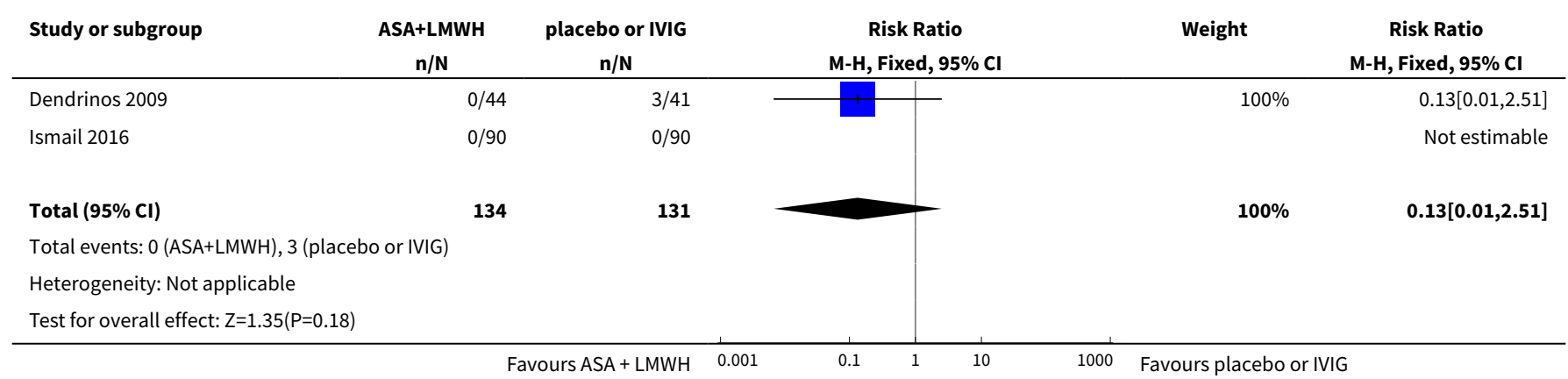

Analysis 6.2. Comparison 6 Sensitivity analyses ASA with LMWH versus placebo or IVIG, Outcome 2 Thrombosis worst-best scenario.

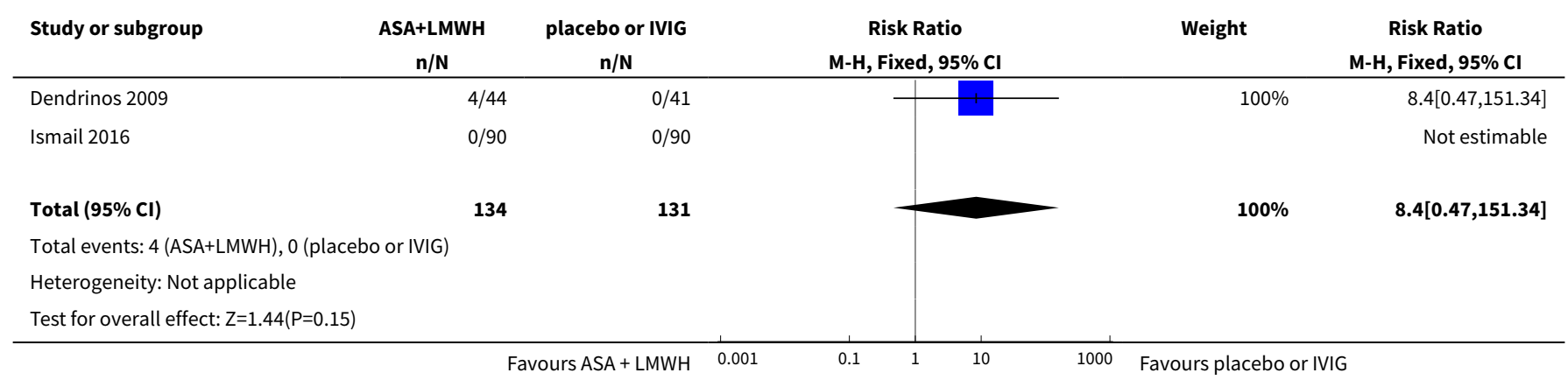

\section{APPENDICES}

\section{Appendix 1. CENTRAL search strategy 15 February 2017}

\begin{tabular}{llc}
\hline$\# 1$ & MESH DESCRIPTOR Antiphospholipid Syndrome & 52 \\
\hline$\# 2$ & MESH DESCRIPTOR Antibodies, Antiphospholipid EXPLODE ALL TREES & 90 \\
\hline
\end{tabular}


(Continued)

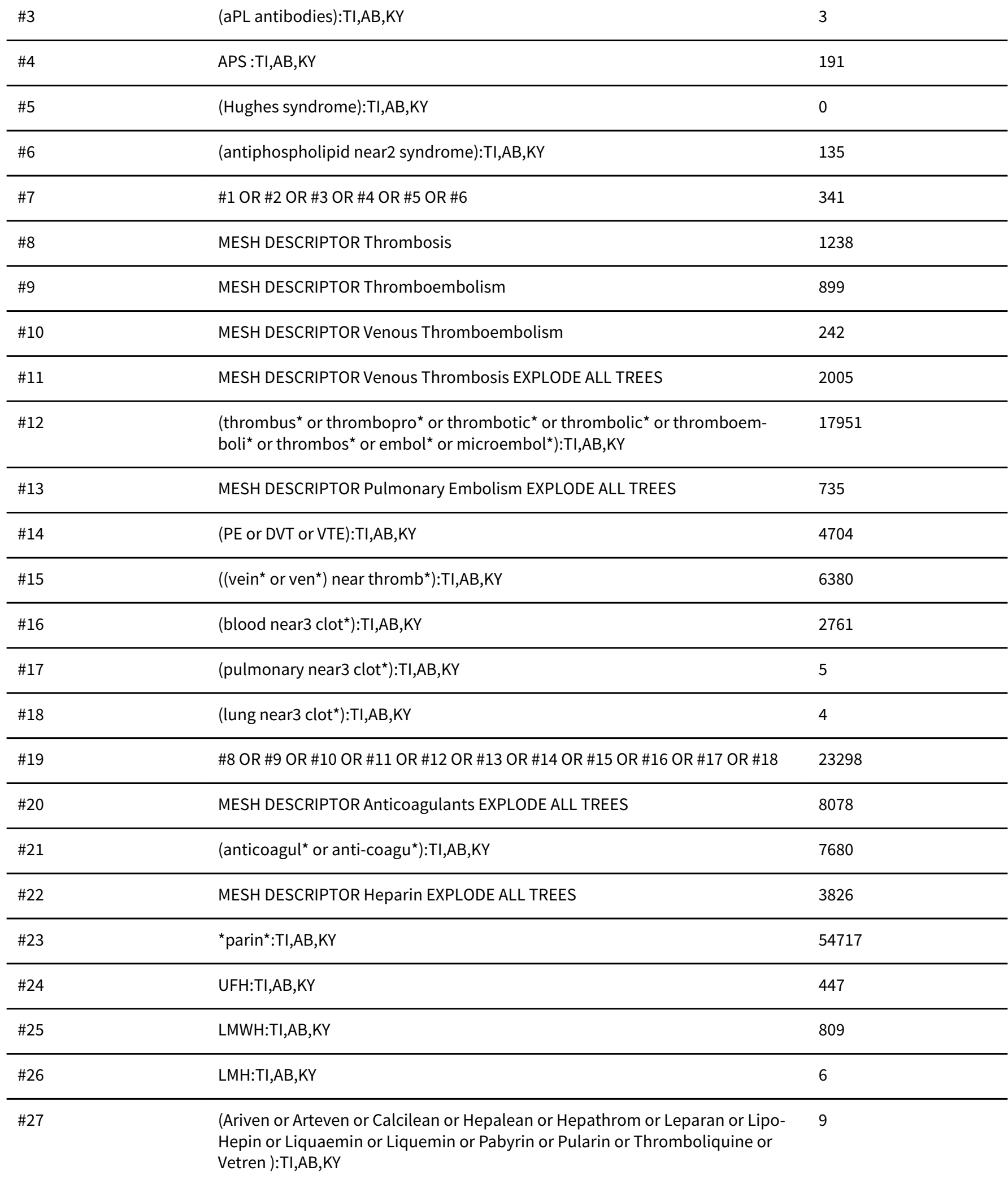

\begin{tabular}{lll}
\hline$\# 28$ & $($ Clexane or klexane or lovenox ):TI,AB,KY & 42 \\
\hline$\# 29$ & (Fragmin):TI,AB,KY & 178 \\
\hline
\end{tabular}


(Continued)

\begin{tabular}{|c|c|c|}
\hline \#30 & (Innohep):TI,AB,KY & 11 \\
\hline \#31 & clivarin $^{\star}: T I, A B, K Y$ & 20 \\
\hline \#32 & (danaproid or danaparoid):TI,AB,KY & 37 \\
\hline \#33 & (antixarin): $\mathrm{TI}, \mathrm{AB}, \mathrm{KY}$ & 2 \\
\hline \#34 & (Zibor or cy 222 or embolex or monoembolex):TI,AB,KY & 38 \\
\hline \#35 & (rd 11885 or RD1185):TI,AB,KY & 0 \\
\hline \#36 & (Kabi-2165 or Kabi 2165):TI,AB,KY & 39 \\
\hline \#37 & (emt-966 or emt966 or emt-967 or emt977 or pk-10169 or pk10169):TI,AB,KY & 8 \\
\hline \#38 & (fr-860 or fr860 or cy-216 or cy216):TI,AB,KY & 51 \\
\hline \#39 & (kb101 or lomoparan or orgaran ):TI,AB,KY & 28 \\
\hline$\# 40$ & (fluxum or lohepa or lowhepa):TI,AB,KY & 11 \\
\hline \#41 & (op 2123 or op2123):TI,AB,KY & 1 \\
\hline \#42 & (ave 5026 or ave 5026 ):TI,AB,KY & 2 \\
\hline$\# 43$ & (M118 or RO-1):TI,AB,KY & 9 \\
\hline \#44 & ${ }^{\star}$ coumar*:TI,AB,KY & 616 \\
\hline \#45 & $\left({ }^{\star}\right.$ warfarin or (vitamin near/3 antagonist $\left.\left.{ }^{\star}\right)\right): \mathrm{TI}, \mathrm{AB}, \mathrm{KY}$ & 2855 \\
\hline \#46 & $\begin{array}{l}\text { (VKA or phenindione or Sinthrome or nicoumalone or phenprocoumon or Mar- } \\
\text { coumar or Marcumar or Falithrom or AVK or phenprocoumon* or aldocumar } \\
\text { or carfin or jantoven or kumatox or lawarin or marevan or prothromadin or } \\
\text { sofarin or tedicumar or tintorane or waran or warfant or warfilone or warner- } \\
\text { in):TI,AB,KY }\end{array}$ & 389 \\
\hline$\# 47$ & MESH DESCRIPTOR Antithrombins EXPLODE ALL TREES & 1235 \\
\hline$\# 48$ & MESH DESCRIPTOR Hirudin Therapy & 75 \\
\hline \#49 & (thrombin near3 inhib*):TI,AB,KY & 506 \\
\hline$\# 50$ & hirudin*:TI,AB,KY & 364 \\
\hline \#51 & (dabigatran or Pradaxa or Rendix):TI,AB,KY & 393 \\
\hline \#52 & (BIBR-953* or BIBR953* or BIBR-1048 or BIBR1048):TI,AB,KY & 9 \\
\hline \#53 & (ximelagatran or Exanta or Exarta or melagatran):TI,AB,KY & 150 \\
\hline \#54 & (AZD0837 or AZD-0837):TI,AB,KY & 14 \\
\hline \#55 & (S35972 or S-35972):TI,AB,KY & 0 \\
\hline
\end{tabular}


(Continued)

\begin{tabular}{|c|c|c|}
\hline \#56 & MESH DESCRIPTOR Factor Xa Inhibitors & 295 \\
\hline \#57 & $\left(\right.$ Factor $X^{\star}$ near4 (antag ${ }^{\star}$ or inhib ${ }^{\star}$ or block $\left.\left.{ }^{\star}\right)\right): \mathrm{TI}, \mathrm{AB}, \mathrm{KY}$ & 584 \\
\hline \#58 & $\left(F^{\star}{ }^{\star}\right.$ near4 (antag ${ }^{\star}$ or inhib* or block $\left.\left.{ }^{\star}\right)\right): T I, A B, K Y$ & 48 \\
\hline \#59 & $\left(10^{\star}\right.$ near4 (antag* or inhib* or block $\left.\left.{ }^{\star}\right)\right): T I, A B, K Y$ & 1073 \\
\hline \#60 & (rivaroxaban or Xarelto):TI,AB,KY & 526 \\
\hline$\# 61$ & (Bay-597939 or Bay597939):TI,AB,KY & 0 \\
\hline \#62 & (betrixaban or PRT054021):TI,AB,KY & 19 \\
\hline \#63 & apixaban:TI,AB,KY & 300 \\
\hline \#64 & (BMS-562247 or BMS-562247 or ELIQUIS):TI,AB,KY & 0 \\
\hline \#65 & (DU-176b or DU176b):TI,AB,KY & 11 \\
\hline \#66 & (PRT-054021 or PRT054021):TI,AB,KY & 1 \\
\hline \#67 & (YM150 or YM-150 or LY517717 or LY-517717 or DU-176b or DU176*):TI,AB,KY & 39 \\
\hline \#68 & $\begin{array}{l}\text { (GW813893 or "Tak } 442 \text { " or TAK442 or PD0348292 or GSK-813893 or } \\
\text { GSK813893):TI,AB,KY }\end{array}$ & 3 \\
\hline \#69 & edoxaban or lixiana:TI,AB,KY & 157 \\
\hline$\# 70$ & *ixaban:TI,AB,KY & 326 \\
\hline$\# 71$ & ^axaban:TI,AB,KY & 6 \\
\hline$\# 72$ & *exaban:TI,AB,KY & 11 \\
\hline$\# 73$ & etexilate:TI,AB,KY & 126 \\
\hline$\# 74$ & agatroban:TI,AB,KY & 1 \\
\hline$\# 75$ & ${ }^{\star}$ parinux:TI,AB,KY & 303 \\
\hline$\# 76$ & MESH DESCRIPTOR Platelet Aggregation Inhibitors EXPLODE ALL TREES & 8396 \\
\hline$\# 77$ & MESH DESCRIPTOR Phosphodiesterase Inhibitors EXPLODE ALL TREES & 5495 \\
\hline$\# 78$ & MESH DESCRIPTOR Tetrazoles & 1823 \\
\hline$\# 79$ & (antiplatelet ${ }^{\star}$ or anti-platelet ${ }^{\star}$ or antiaggreg $^{\star}$ or anti-aggreg ${ }^{\star}$ ):TI,AB,KY & 3253 \\
\hline \#80 & $\begin{array}{l}(((\text { platelet or thromboxane or thrombocyte or cyclooxygenase or cyclo-oxy- } \\
\text { genase or phosphodiesterase or fibrinogen or PAR-1) near3 (antagonist or in- } \\
\text { hibitor }))): T I, A B, K Y\end{array}$ & 2349 \\
\hline \#81 & ((gp* or glycoprotein ${ }^{\star}$ or protease or $\mathrm{P} 2 \mathrm{Y} 12$ or TXA2) near3 inhibit $\left.{ }^{\star}\right): \mathrm{TI}, \mathrm{AB}, \mathrm{KY}$ & 3199 \\
\hline \#82 & thienopyridine:TI,AB,KY & 266 \\
\hline
\end{tabular}


(Continued)

\begin{tabular}{|c|c|c|}
\hline \#83 & (ticlopidine or Ticlid):TI,AB,KY & 1748 \\
\hline \#84 & (clopidogrel or Plavix):TI,AB,KY & 3014 \\
\hline \#85 & (Prasugrel or Effient or Efient or Prasita):TI,AB,KY & 501 \\
\hline \#86 & (ticagrelor or AZD6140 or Brilinta):TI,AB,KY & 436 \\
\hline \#87 & (elinogrel or PRT060128 or PRT-060128):TI,AB,KY & 8 \\
\hline \#88 & (cangrelor or AR-C6993* or ARC6993*):TI,AB,KY & 50 \\
\hline \#89 & (SCH530348 or SCH-530348):TI,AB,KY & 19 \\
\hline \#90 & E5555:TI,AB,KY & 5 \\
\hline \#91 & (terutroban or Triplion):TI,AB,KY & 14 \\
\hline \#92 & (aspirin* or nitroaspirin or $\mathrm{ASA}): \mathrm{TI}, \mathrm{AB}, \mathrm{KY}$ & 17036 \\
\hline \#93 & (acetylsalicylic acid):TI,AB,KY & 4935 \\
\hline \#94 & (acetyl salicylic acid*):TI,AB,KY & 109 \\
\hline \#95 & (triflusal or disgren):TI,AB,KY & 97 \\
\hline \#96 & (Cilostazol or Pletal or Pletaal):TI,AB,KY & 464 \\
\hline \#97 & (dipyridamol ${ }^{*}$ or Persantine):TI,AB,KY & 1129 \\
\hline \#99 & (picotamide or picotinamide):TI,AB,KY & 41 \\
\hline \#100 & satigrel:TI,AB,KY & 3 \\
\hline$\# 101$ & vorapaxar:TI,AB,KY & 84 \\
\hline \#102 & indobufen:TI,AB,KY & 82 \\
\hline \multirow[t]{8}{*}{ \#103 } & \#20 OR \#21 OR \#22 OR \#23 OR \#24 OR \#25 OR \#26 OR \#27 OR \#28 OR \#29 OR \#30 & 92582 \\
\hline & OR \#31 OR \#32 OR \#33 OR \#34 OR \#35 OR \#36 OR \#37 OR \#38 OR \#39 OR \#40 OR & \\
\hline & \#41 OR \#42 OR \#43 OR \#44 OR \#45 OR \#46 OR \#47 OR \#48 OR \#49 OR \#50 OR \#51 & \\
\hline & OR \#52 OR \#53 OR \#54 OR \#55 OR \#56 OR \#57 OR \#58 OR \#59 OR \#60 OR \#61 OR & \\
\hline & \#62 OR \#63 OR \#64 OR \#65 OR \#66 OR \#67 OR \#68 OR \#69 OR \#70 OR \#71 OR \#72 & \\
\hline & OR \#73 OR \#74 OR \#75 OR \#76 OR \#77 OR \#78 OR \#79 OR \#80 OR \#81 OR \#82 OR & \\
\hline & \#83 OR \#84 OR \#85 OR \#86 OR \#87 OR \#88 OR \#89 OR \#90 OR \#91 OR \#92 OR \#93 & \\
\hline & OR \#94 OR \#95 OR \#96 OR \#97 OR \#98 OR \#99 OR \#100 OR \#101 OR \#102 & \\
\hline \#104 & \#7 AND \#19 AND \#103 & 72 \\
\hline
\end{tabular}

\section{Appendix 2. Trials registries searches 15 February 2017}

ClinicalTrials.gov

73 studies found for: antiphospholipid 
World Health Organization International Clinical Trials Registry Platform

65 records for 57 trials found for: antiphospholipid

ISRCTN Register

21 results for: antiphospholipid

Appendix 3. Follow-up search strategies November/December 2017

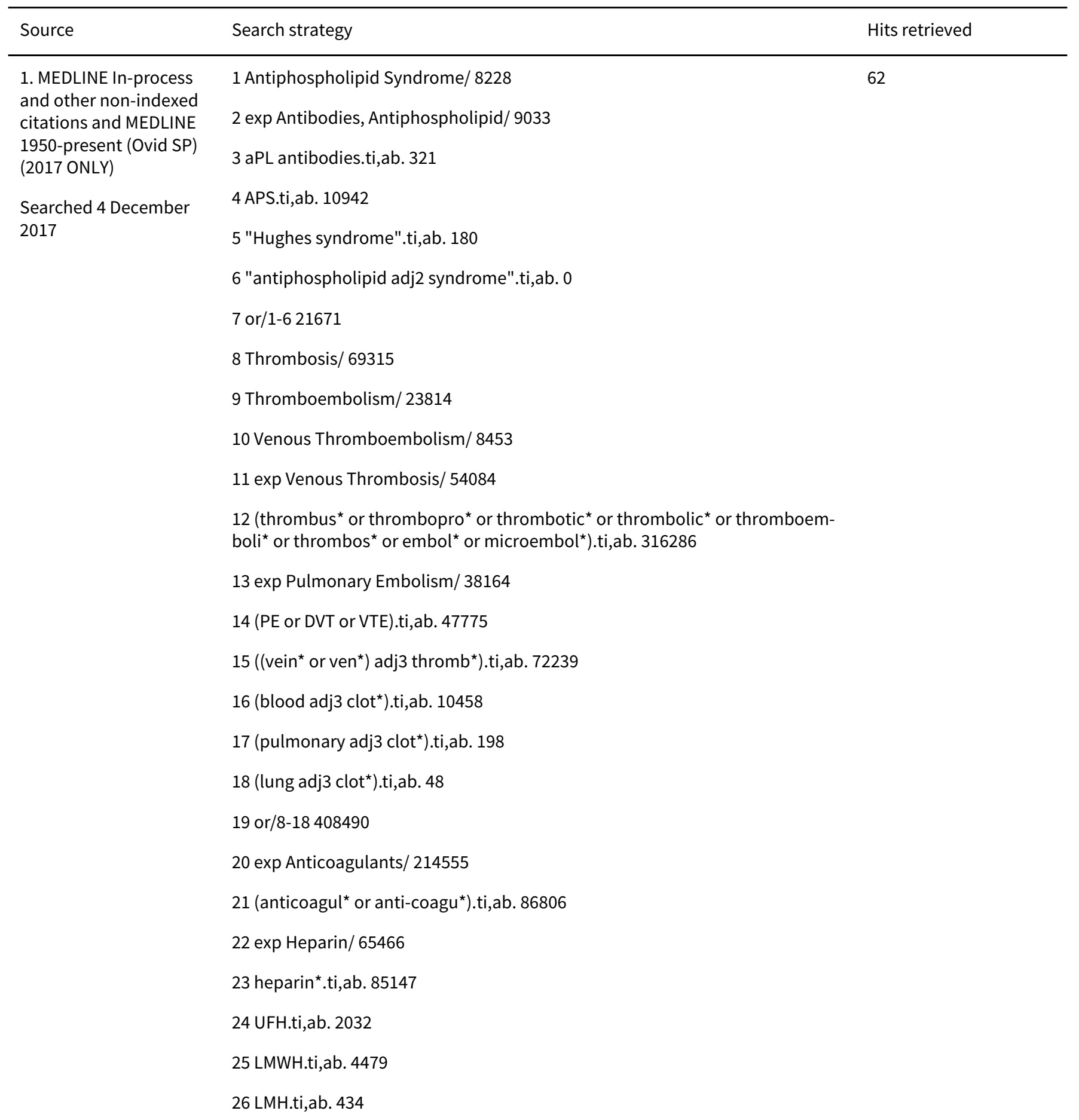


27 (Ariven or Arteven or Calcilean or Hepalean or Hepathrom or Leparan or Lipo-Hepin or Liquaemin or Liquemin or Pabyrin or Pularin or Thromboliquine or Vetren).ti,ab. 55

28 (Clexane or klexane or lovenox).ti,ab. 241

29 Fragmin.ti,ab. 384

30 Innohep.ti,ab. 21

31 clivarin*.ti,ab. 28

32 (danaproid or danaparoid).ti,ab. 449

33 antixarin.ti,ab. 1

34 (Zibor or cy 222 or embolex or monoembolex).ti,ab. 59

35 (rd 11885 or RD1185).ti,ab. 1

36 (Kabi-2165 or Kabi 2165).ti,ab. 41

37 (emt-966 or emt966 or emt-967 or emt977 or pk-10169 or pk10169).ti,ab. 43

38 (fr-860 or fr860 or cy-216 or cy216).ti,ab. 99

39 (kb101 or lomoparan or orgaran).ti,ab. 113

40 (fluxum or lohepa or lowhepa).ti,ab. 12

41 (op 2123 or op2123).ti,ab. 3

42 (ave 5026 or ave5026).ti,ab. 8

43 (M118 or RO-1).ti,ab. 140

44 coumar $^{\star}$.ti,ab. 16405

45 (warfarin or (vitamin adj3 antagonist*)).ti,ab. 26213

46 (VKA or phenindione or Sinthrome or nicoumalone or phenprocoumon or Marcoumar or Marcumar or Falithrom or AVK or phenprocoumon* or aldocumar or carfin or jantoven or kumatox or lawarin or marevan or prothromadin or sofarin or tedicumar or tintorane or waran or warfant or warfilone or warnerin).ti,ab. 2709

47 exp Antithrombins/ 20598

48 Hirudin Therapy/ 684

49 (thrombin adj3 inhib*).ti,ab. 10229

50 hirudin*.ti,ab. 3471

51 (dabigatran or Pradaxa or Rendix).ti,ab. 3811

52 (BIBR-953* or BIBR953* or BIBR-1048 or BIBR1048).ti,ab. 14

53 (ximelagatran or Exanta or Exarta or melagatran).ti,ab. 652

54 (AZD0837 or AZD-0837).ti,ab. 31

55 (S35972 or S-35972).ti,ab. 2

56 Factor Xa Inhibitors.ti,ab. 1086

57 (Factor $X^{\star}$ adj4 (antag* or inhib* or block*)).ti,ab. 4546 
$58\left(\mathrm{FX}^{\star}\right.$ adj4 (antag* or inhib* or block*)).ti,ab. 1654

$59\left(10^{\star}\right.$ adj4 (antag* or inhib* or block $)$ ).ti,ab. 81139

60 (rivaroxaban or Xarelto).ti,ab. 3487

61 (Bay-597939 or Bay597939).ti,ab. 2

62 apixaban.ti,ab. 2183

63 (BMS-562247 or BMS-562247 or ELIQUIS).ti,ab. 47

64 (DU-176b or DU176b).ti,ab. 26

65 (PRT-054021 or PRT054021).ti,ab. 4

66 (YM150 or YM-150 or LY517717 or LY-517717 or DU-176b or DU176*).ti,ab. 67

67 (GW813893 or "Tak 442" or TAK442 or PD0348292 or GSK-813893 or GSK813893).ti,ab. 16

68 (edoxaban or lixiana).ti,ab. 892

69 etexilate.ti,ab. 723

70 agatroban.ti,ab. 1

71 exp Platelet Aggregation Inhibitors/ 107579

72 exp Phosphodiesterase Inhibitors/ 85845

73 Tetrazoles/ 11647

74 (antiplatelet* or anti-platelet ${ }^{\star}$ or antiaggreg* or anti-aggreg ${ }^{\star}$ ).ti,ab. 31484

75 ((platelet or thromboxane or thrombocyte or cyclooxygenase or cyclo-oxygenase or phosphodiesterase or fibrinogen or PAR-1) adj3 (antagonist or inhibitor)).ti,ab. 20364

76 ((gp* or glycoprotein ${ }^{\star}$ or protease or P2Y12 or TXA2) adj3 inhibit*).ti,ab. 49431

77 thienopyridine.ti,ab. 983

78 (ticlopidine or Ticlid).ti,ab. 2653

79 (clopidogrel or Plavix).ti,ab. 11473

80 (Prasugrel or Effient or Efient or Prasita).ti,ab. 1828

81 (ticagrelor or AZD6140 or Brilinta).ti,ab. 1801

82 (elinogrel or PRT060128 or PRT-060128).ti,ab. 52

83 (cangrelor or AR-C6993* or ARC6993*).ti,ab. 456

84 (SCH530348 or SCH-530348).ti,ab. 68

85 E5555.ti,ab. 20

86 (terutroban or Triplion).ti,ab. 59

87 (aspirin* or nitroaspirin or ASA).ti,ab. 70039

88 acetylsalicylic acid.ti,ab. 8940

89 acetyl salicylic acid ${ }^{*}$.ti,ab. 802 
90 (triflusal or disgren).ti,ab. 183

91 (Cilostazol or Pletal or Pletaal).ti,ab. 1589

92 (dipyridamol* or Persantine).ti,ab. 8584

93 (OPC-13013 or OPC13013).ti,ab. 31

94 (picotamide or picotinamide).ti,ab. 111

95 satigrel.ti,ab. 4

96 vorapaxar.ti,ab. 230

97 indobufen.ti,ab. 174

98 or/20-97 654251

997 and 19 and 984435

100 randomized controlled trial.pt. 505457

101 controlled clinical trial.pt. 100426

102 randomized.ab. 442085

103 placebo.ab. 205331

104 drug therapy.fs. 2147127

105 randomly.ab. 305213

106 trial.ab. 465590

107 groups.ab. 1884917

108 or/100-107 4448119

109 exp animals/ not humans.sh. 4743197

110108 not 1093846919

11199 and 1101424

$1122017^{\star}$.ed. 954730

113111 and 11262

114 from 113 keep 1-62 62

2. EMBASE 1 Antiphospholipid Syndrome/ 13340

1974 to (2017 ONLY) 2 exp Antibodies, Antiphospholipid/ 10672

Searched 4 December 3 aPL antibodies.ti,ab. 450

2017

\author{
4 APS.ti,ab. 13550 \\ 5 "Hughes syndrome".ti,ab. 174 \\ 6 "antiphospholipid adj2 syndrome".ti,ab. 0 \\ 7 or/1-6 27751
}

8 Thrombosis/ 92570

9 Thromboembolism/ 48884 
10 Venous Thromboembolism/ 29859

11 exp Venous Thrombosis/ 93279

12 (thrombus* or thrombopro* or thrombotic ${ }^{\star}$ or thrombolic ${ }^{\star}$ or thromboemboli* $^{\star}$ or thrombos ${ }^{\star}$ or embol* or microembol*).ti,ab. 334991

13 exp Pulmonary Embolism/ 66110

14 (PE or DVT or VTE).ti,ab. 65140

$15\left(\left(\right.\right.$ vein $^{\star}$ or ven $\left.{ }^{\star}\right)$ adj3 thromb*).ti,ab. 82886

16 (blood adj3 clot ${ }^{\star}$ ).ti,ab. 9074

17 (pulmonary adj3 clot*).ti,ab. 218

18 (lung adj3 clot*$\left.^{\star}\right) . t i, a b .55$

19 or/8-18 474200

20 exp Anticoagulants/ 457874

21 (anticoagul $^{\star}$ or anti-coagu*).ti,ab. 99680

22 exp Heparin/ 92647

23 heparin*.ti,ab. 70674

24 UFH.ti,ab. 3144

25 LMWH.ti,ab. 7352

26 LMH.ti,ab. 505

27 (Ariven or Arteven or Calcilean or Hepalean or Hepathrom or Leparan or Lipo-Hepin or Liquaemin or Liquemin or Pabyrin or Pularin or Thromboliquine or Vetren).ti,ab. 27

28 (Clexane or klexane or lovenox).ti,ab. 542

29 Fragmin.ti,ab. 279

30 Innohep.ti,ab. 38

31 clivarin*.ti,ab. 24

32 (danaproid or danaparoid).ti,ab. 616

33 antixarin.ti,ab. 0

34 (Zibor or cy 222 or embolex or monoembolex).ti,ab. 12

35 (rd 11885 or RD1185).ti,ab. 0

36 (Kabi-2165 or Kabi 2165).ti,ab. 0

37 (emt-966 or emt966 or emt-967 or emt977 or pk-10169 or pk10169).ti,ab. 0

38 (fr-860 or fr860 or cy-216 or cy216).ti,ab. 4

39 (kb101 or lomoparan or orgaran).ti,ab. 107

40 (fluxum or lohepa or lowhepa).ti,ab. 11

41 (op 2123 or op2123).ti,ab. 2

42 (ave 5026 or ave5026).ti,ab. 13 


\section{3 (M118 or RO-1).ti,ab. 95}

44 coumar $^{\star}$.ti,ab. 16168

45 (warfarin or (vitamin adj3 antagonist*)).ti,ab. 34403

46 (VKA or phenindione or Sinthrome or nicoumalone or phenprocoumon or Marcoumar or Marcumar or Falithrom or AVK or phenprocoumon* or aldocumar or carfin or jantoven or kumatox or lawarin or marevan or prothromadin or sofarin or tedicumar or tintorane or waran or warfant or warfilone or warnerin).ti,ab. 3830

47 exp Antithrombins/ 7897

48 Hirudin Therapy/ 42908

49 (thrombin adj3 inhib*).ti,ab. 10057

50 hirudin*.ti,ab. 2574

51 (dabigatran or Pradaxa or Rendix).ti,ab. 6972

52 (BIBR-953* or BIBR953* or BIBR-1048 or BIBR1048).ti,ab. 18

53 (ximelagatran or Exanta or Exarta or melagatran).ti,ab. 804

54 (AZD0837 or AZD-0837).ti,ab. 43

55 (S35972 or S-35972).ti,ab. 6

56 Factor Xa Inhibitors.ti,ab. 1374

$57\left(\right.$ Factor $X^{\star}$ adj4 (antag* or inhib* or block $\left.\left.{ }^{\star}\right)\right) . t i, a b .5202$

$58\left(\mathrm{FX}^{\star}\right.$ adj4 (antag* or inhib* or block $\left.\left.{ }^{\star}\right)\right) . t i, a b .2626$

$59\left(10^{\star}\right.$ adj4 (antag* or inhib* or block $\left.)\right)$.ti,ab. 67594

60 (rivaroxaban or Xarelto).ti,ab. 6586

61 (Bay-597939 or Bay597939).ti,ab. 1

62 apixaban.ti,ab. 3945

63 (BMS-562247 or BMS-562247 or ELIQUIS).ti,ab. 90

64 (DU-176b or DU176b).ti,ab. 54

65 (PRT-054021 or PRT054021).ti,ab. 4

66 (YM150 or YM-150 or LY517717 or LY-517717 or DU-176b or DU176*).ti,ab. 119

67 (GW813893 or "Tak 442" or TAK442 or PD0348292 or GSK-813893 or GSK813893).ti,ab. 34

68 (edoxaban or lixiana).ti,ab. 1313

69 etexilate.ti,ab. 1267

70 agatroban.ti,ab. 1

71 exp Platelet Aggregation Inhibitors/ 239121

72 exp Phosphodiesterase Inhibitors/ 53488

73 Tetrazoles/ 2414 
74 (antiplatelet ${ }^{\star}$ or anti-platelet ${ }^{\star}$ or antiaggreg* ${ }^{\star}$ r anti-aggreg*).ti,ab. 41493

75 ((platelet or thromboxane or thrombocyte or cyclooxygenase or cyclo-oxygenase or phosphodiesterase or fibrinogen or PAR-1) adj3 (antagonist or inhibitor)).ti,ab. 15191

76 ((gp* or glycoprotein ${ }^{\star}$ or protease or P2Y12 or TXA2) adj3 inhibit $\left.{ }^{\star}\right)$.ti,ab. 50010

77 thienopyridine.ti,ab. 1504

78 (ticlopidine or Ticlid).ti,ab. 2396

79 (clopidogrel or Plavix).ti,ab. 20219

80 (Prasugrel or Effient or Efient or Prasita).ti,ab. 3255

81 (ticagrelor or AZD6140 or Brilinta).ti,ab. 3110

82 (elinogrel or PRT060128 or PRT-060128).ti,ab. 86

83 (cangrelor or AR-C6993* or ARC6993*).ti,ab. 643

84 (SCH530348 or SCH-530348).ti,ab. 94

85 E5555.ti,ab. 28

86 (terutroban or Triplion).ti,ab. 81

87 (aspirin* or nitroaspirin or ASA).ti,ab. 83196

88 acetylsalicylic acid.ti,ab. 6791

89 acetyl salicylic acid*.ti,ab. 771

90 (triflusal or disgren).ti,ab. 175

91 (Cilostazol or Pletal or Pletaal).ti,ab. 2322

92 (dipyridamol* or Persantine).ti,ab. 5207

93 (OPC-13013 or OPC13013).ti,ab. 5

94 (picotamide or picotinamide).ti,ab. 74

95 satigrel.ti,ab. 20

96 vorapaxar.ti,ab. 333

97 indobufen.ti,ab. 59

98 or/20-97 710273

997 and 19 and 987447

100 randomized controlled trial/ 437650

101 controlled clinical trial/ 408481

102 random\$.ti,ab. 1132164

103 randomization/ 68186

104 intermethod comparison/ 223714

105 placebo.ti,ab. 215213

106 (compare or compared or comparison).ti. 326736 
(Continued)

107 ((evaluated or evaluate or evaluating or assessed or assess) and (compare or compared or comparing or comparison)).ab. 1562487

108 (open adj label).ti,ab. 60147

109 ((double or single or doubly or singly) adj (blind or blinded or blind-

ly)).ti,ab. 153458

110 double blind procedure/ 119366

111 parallel group\$1.ti,ab. 18989

112 (crossover or cross over).ti,ab. 70151

113 ((assign\$ or match or matched or allocation) adj5 (alternate or group\$1 or intervention $\$ 1$ or patient $\$ 1$ or subject $\$ 1$ or participant $\$ 1)$ ).ti,ab. 241228

114 (assigned or allocated).ti,ab. 282341

115 (controlled adj7 (study or design or trial)).ti,ab. 252973

116 (volunteer or volunteers).ti,ab. 168202

117 trial.ti. 206175

118 or/100-117 3373917

$1192017^{\star}$.dc. 1694109

12099 and 118 and 11963

3. CINAHL (EBSCOhost) (2017 ONLY)

Searched 4 December 2017
S107 S98 AND S105 AND S106 6

S105 S99 OR S100 OR S101 OR S102 OR S103 OR S104 952,284

S104 TX randomly 41,763

S103 TX "treatment as usual" 709

S102 TX "double-blind" 755,656

S101 TX "single-blind*" 8,678

S100 TX trial 236,802

S99 MH "Clinical Trials" 90,899

S98 S7 AND S19 AND S97 231

S 97 S 20 OR S 21 OR S 22 OR S 23 OR S 24 OR S 25 OR S 26 OR S 27 OR S 28 OR S 29 OR S 30 OR S 31 OR S 32 OR S 33 OR S 34 OR S 35 OR S 36 OR S 37 OR S 38 OR S 39 OR S40 OR S41 OR S42 OR S43 OR S44 OR S45 OR S46 OR S47 OR S48 OR S49 OR S50 OR S 51 OR S52 OR S53 OR S54 OR S55 OR S56 OR S57 OR S58 OR S59 OR S60 OR S61 OR S62 OR S63 OR S64 OR S65 OR S66 OR S67 OR S68 OR S69 OR S70 OR S71 OR S72 OR S73 OR S74 OR S75 OR S76 OR S77 OR S78 OR S79 OR S80 OR S81 OR S 82 OR S 83 OR S84 OR S 85 OR S86 OR S87 OR S88 OR S89 OR S90 OR S91 ... 51,427

S96 TX indobufen 6

S95 TX vorapaxar 48

S94 TX satigrel 0 
S93 TX picotamide or picotinamide 8

S92 TX OPC-13013 or OPC13013 0

S91 TX Cilostazol or Pletal or Pletaal 204

S90 TX triflusal or disgren 23

S89 TX acetylsalicylic acid 408

S88 TX terutroban or Triplion 12

S87 TX E5555 4

S86 TX SCH530348 or SCH-530348 12

S85 TX cangrelor or AR-C6993* or ARC6993* 60

S84 TX elinogrel or PRT060128 or PRT-060128 2

S83 TX ticagrelor or AZD6140 or Brilinta 391

S82 TX Prasugrel or Effient or Efient or Prasita 360

S81 TX clopidogrel or Plavix 2,595

S80 TX ticlopidine or Ticlid 1,020

S79 TX thienopyridine 193

S78 TX gp* or glycoprotein ${ }^{\star}$ or protease or P2Y12 or TXA2) n3 inhibit* $): 4,288$

S77 TX platelet or thromboxane or thrombocyte or cyclooxygenase or cyclo-oxygenase or phosphodiesterase or fibrinogen or PAR-1) n3 (antagonist or inhibitor 6,893

S76 TX antiplatelet ${ }^{\star}$ or anti-platelet* or antiaggreg ${ }^{\star}$ or anti-aggreg ${ }^{\star} 3,535$

S75 (MH "Phosphodiesterase Inhibitors+") 1,834

S74 (MH "Platelet Aggregation Inhibitors+") 11,567

S73 * parinux 0

S72 argatroban 195

S71 etexilate 325

$\mathrm{S} 70$ *exaban 0

S69 *axaban 0

S68 *ixaban 0

S67 edoxaban or lixiana 136

S66 GW813893 or "Tak 442" or TAK442 or PD0348292 or GSK-813893 or GSK813893 24

S65 GW813893 or "Tak 442" or TAK442 or PD0348292 or GSK-813893 or GSK813893 0

S64 YM150 or YM-150 or LY517717 or LY-517717 or DU-176b or DU176 5

S63 PRT-054021 or PRT054021 0

S62 DU-176b or DU176b 3 
S61 BMS-562247 or BMS-562247 or ELIQUIS 15

S60 apixaban 387

S59 betrixaban or PRT054021 15

S58 Bay-597939 or Bay597939 0

S57 rivaroxaban or Xarelto 693

S56 (10* n4 (antag* or inhib* or block $\left.{ }^{\star}\right)$ ) 1,798

S55 (FX n4 (antag* or inhib* or block $\left.\left.{ }^{\star}\right)\right) 43$

S54 (Factor X* n4 (antag* or inhib* or block $\left.\left.{ }^{\star}\right)\right)$ 9,042

S53 TX S35972 or S-35972 0

S52 TX AZD0837 or AZD-0837 0

S51 TX ximelagatran or Exanta or Exarta or melagatran 89

S50 TX BIBR-953* or BIBR953* or BIBR-1048 or BIBR1048 2

S49 TX dabigatran or Pradaxa or Rendix 883

S48 TX hirudin* 283

S47 TX thrombin n3 inhib* 656

S46 (MH "Hirudin") 237

S45 TX VKA or phenindione or Sinthrome or nicoumalone or phenprocoumon or Marcoumar or Marcumar or Falithrom or AVK or phenprocoumon* or aldocumar or carfin or jantoven or kumatox or lawarin or marevan or prothromadin or sofarin or tedicumar or tintorane or waran or warfant or warfilone or warnerin 233

S44 TX (* warfarin or (vitamin n3 antagonist $\left.\left.{ }^{\star}\right)\right)$ 6,298

S43 TX M118 or RO-1 4,530

S42 TX ave 5026 or ave 50260

S41 TX op 2123 or op21230

S40 TX fluxum or lohepa or lowhepa 1

S39 TX kb101 or lomoparan or orgaran 2

S38 TX fr-860 or fr860 or cy-216 or cy216 0

S37 TX emt-966 or emt966 or emt-967 or emt977 or pk-10169 or pk10169 0

S36 TX Kabi-2165 or Kabi 21650

S35 TX rd 11885 or RD1185 0

S34 TX Zibor or cy 222 or embolex or monoembolex 3

S33 TX antixarin 0

S32 TX danaproid or danaparoid 34

S31 TX clivarin* 1

S30 TX Innohep 3 


\section{S29 TX Fragmin 19}

S28 TX Clexane or klexane or lovenox 28

S27 TX Ariven or Arteven or Calcilean or Hepalean or Hepathrom or Leparan or Lipo-Hepin or Liquaemin or Liquemin or Pabyrin or Pularin or Thromboliquine or Vetren 1

\section{S26 TX LMH 55}

S25 TX LMWH 463

S24 TX UFH 235

S23 TX *parin* 270

S22 (MH "Heparin+") 5,527

S21 TX anticoagul ${ }^{*}$ or anti-coagu* 13,627

S20 (MH "Anticoagulants+") 15,828

S19 S8 OR S9 OR S10 OR S11 OR S12 OR S13 OR S14 OR S15 OR S16 OR S17 OR S18 44,186

S18 lung n3 $\operatorname{clot}^{\star} 11$

S17 pulmonary $\mathrm{n} 3$ clot $^{\star} 19$

S16 (blood n3 clot*) 699

S15 TX ((vein* or ven*) n thromb*) 140

S14 TX PE or DVT or VTE 11,499

S13 (MH "Pulmonary Embolism") 4,591

S12 TX thrombus* or thrombopro* or thrombotic ${ }^{*}$ or thrombolic* or throm-

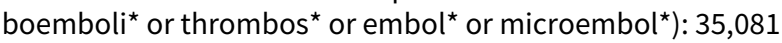

S11 (MH "Venous Thrombosis+") 6,154

S10 (MH "Venous Thromboembolism") 2,904

S9 (MH "Thromboembolism") 3,174

S8 (MH "Thrombosis") 4,493

S7 S1 OR S2 OR S3 OR S4 OR S5 OR S6 2,647

S6 TX antiphospholipid $\mathrm{n} 2$ syndrome 865

S5 TX "Hughes syndrome" 11

S4 TX APS 1,946

S3 TX aPL antibodies 105

S2 (MH "Antiphospholipid Syndrome") 699

S1 (MH "Antiphospholipid Syndrome") 699

$\begin{array}{lll}\text { 4. AMED (2017 ONLY) } & \text { 1 APS.ti,ab. 31 } & 0 \\ \begin{array}{l}\text { Searched 4 December } \\ 2017\end{array} & 2 \text { Thrombosis/195 } \\ & 3 \text { Thromboembolism/71 }\end{array}$

Antiplatelet and anticoagulant agents for primary prevention of thrombosis in individuals with antiphospholipid antibodies (Review) 
4 (thrombus $^{\star}$ or thrombopro* or thrombotic ${ }^{\star}$ or thrombolic* or thromboem-

boli* $^{\star}$ or thrombos ${ }^{\star}$ or embol* or microembol $\left.{ }^{\star}\right)$.ti,ab. 640

5 exp Pulmonary Embolism/ 53

6 (PE or DVT or VTE).ti,ab. 242

$7\left(\left(\right.\right.$ vein $^{\star}$ or ven $\left.{ }^{\star}\right)$ adj3 thromb*).ti,ab. 318

8 (blood adj3 clot $^{\star}$ ).ti,ab. 34

$9 \exp$ Anticoagulants/ 148

10 (anticoagul $^{\star}$ or anti-coagu ${ }^{\star}$ ).ti,ab. 189

11 exp Heparin/ 26

12 heparin $^{\star} . \mathrm{ti}, \mathrm{ab} .93$

13 UFH.ti,ab. 1

14 LMWH.ti,ab. 12

15 LMH.ti,ab. 1

16 coumar $^{\star}$.ti,ab. 347

17 (warfarin or (vitamin adj3 antagonist*)).ti,ab. 84

18 (VKA or phenindione or Sinthrome or nicoumalone or phenprocoumon or Marcoumar or Marcumar or Falithrom or AVK or phenprocoumon* or aldocumar or carfin or jantoven or kumatox or lawarin or marevan or prothromadin or sofarin or tedicumar or tintorane or waran or warfant or warfilone or warnerin).ti,ab. 1

19 (thrombin adj3 inhib*).ti,ab. 14

20 hirudin ${ }^{\star} . t i, a b .4$

21 (dabigatran or Pradaxa or Rendix).ti,ab. 1

22 (ximelagatran or Exanta or Exarta or melagatran).ti,ab. 4

$23\left(\right.$ Factor $X^{\star}$ adj4 (antag* or inhib* or block $\left.{ }^{\star}\right)$ ).ti,ab. 2

$24\left(\mathrm{FX}^{\star}\right.$ adj4 (antag* or inhib* or block $\left.\left.{ }^{\star}\right)\right) . t i, a b .3$

$25\left(10^{\star}\right.$ adj4 (antag* or inhib* or block*)).ti,ab. 574

26 (rivaroxaban or Xarelto).ti,ab. 1

27 exp Platelet Aggregation Inhibitors/ 8

28 Tetrazoles/ 0

29 (antiplatelet* ${ }^{\star}$ anti-platelet ${ }^{\star}$ or antiaggreg ${ }^{\star}$ or anti-aggreg*).ti,ab. 150

30 ((platelet or thromboxane or thrombocyte or cyclooxygenase or cyclo-oxygenase or phosphodiesterase or fibrinogen or PAR-1) adj3 (antagonist or inhibitor)).ti,ab. 55

31 ((gp* or glycoprotein* or protease or P2Y12 or TXA2) adj3 inhibit*).ti,ab. 107

32 (ticlopidine or Ticlid).ti,ab. 4

33 (clopidogrel or Plavix).ti,ab. 11 
34 (aspirin* or nitroaspirin or ASA).ti,ab. 261

35 acetylsalicylic acid.ti,ab. 39

36 acetyl salicylic acid ${ }^{\star}$.ti,ab. 5

37 (Cilostazol or Pletal or Pletaal).ti,ab. 4

38 (dipyridamol* or Persantine).ti,ab. 12

39 Antiphospholipid.mp. [mp=abstract, heading words, title] 9

401 or 3940

41 or $/ 2-8862$

42 or/9-38 1758

4340 and 41 and 422

$442017^{\star}$.up. 6951

4543 and 440

4639 and 440

5. VASCULAR
SPECIALISED REGISTER
Searched 4 December
2017

\#1 thrombosis AND INREGISTER

6

\# 22017 AND INREGISTER

\#3 1 AND 2

\section{CENTRAL}

\#1 MESH DESCRIPTOR Antiphospholipid Syndrome 54

Searched 29 November 2017

\#2 MESH DESCRIPTOR Antibodies, Antiphospholipid EXPLODE ALL TREES 90

\#3 (aPL antibodies):TI,AB,KY 5

\#4 APS :TI,AB,KY 258

\#5 (Hughes syndrome):TI,AB,KY 0

\#6 (antiphospholipid near2 syndrome):TI,AB,KY 193

\#7 \#1 OR \#2 OR \#3 OR \#4 OR \#5 OR \#6 443

\#8 MESH DESCRIPTOR Thrombosis 1303

\#9 MESH DESCRIPTOR Thromboembolism 943

\#10 MESH DESCRIPTOR Venous Thromboembolism 294

\#11 MESH DESCRIPTOR Venous Thrombosis EXPLODE ALL TREES 2085

\#12 ((thrombus* or thrombopro* or thrombotic* or thrombolic* or throm-

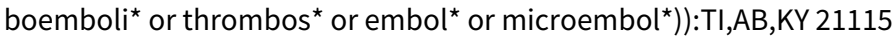

\#13 MESH DESCRIPTOR Pulmonary Embolism EXPLODE ALL TREES 769

\#14 (PE or DVT or VTE):TI,AB,KY 5562

\#15 (((vein* or ven*) near thromb*)):TI,AB,KY 7332

\#16 ((blood near3 clot $\left.\left.{ }^{\star}\right)\right): T I, A B, K Y 3497$

\#17 (pulmonary near3 clot*):TI,AB,KY 6 


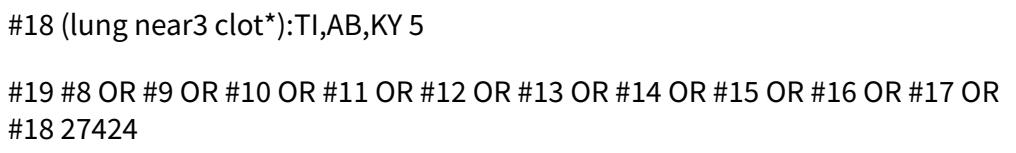

\#27 (Ariven or Arteven or Calcilean or Hepalean or Hepathrom or Leparan or Lipo-Hepin or Liquaemin or Liquemin or Pabyrin or Pularin or Thromboliquine or Vetren ):TI,AB,KY 9

\#28 (Clexane or klexane or lovenox ):TI,AB,KY 46

\#29 Fragmin:TI,AB,KY 182

\#30 Innohep:TI,AB,KY 12

\#31 clivarin*:TI,AB,KY 20

\#32 (danaproid or danaparoid):TI,AB,KY 46

\#33 antixarin:TI,AB,KY 2

\#34 (Zibor or cy 222 or embolex or monoembolex):TI,AB,KY 38

\#35 (rd 11885 or RD1185):TI,AB,KY 0

\#36 (Kabi-2165 or Kabi 2165):TI,AB,KY 39

\#37 (emt-966 or emt966 or emt-967 or emt977 or pk-10169 or pk10169):TI,AB,KY 8

\#38 (fr-860 or fr860 or cy-216 or cy216):TI,AB,KY 51

\#39 (kb101 or lomoparan or orgaran ):TI,AB,KY 28

\#40 (fluxum or lohepa or lowhepa):TI,AB,KY 11

\#41 (op 2123 or op2123):TI,AB,KY 1

\#42 (ave 5026 or ave5026):TI,AB,KY 2

\#43 (M118 or RO-1):TI,AB,KY 9

\#44 * ${ }^{*}{ }^{*}$ :TI,AB, KY 664

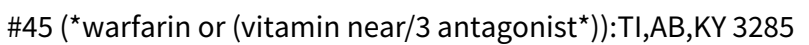

\#46 (VKA or phenindione or Sinthrome or nicoumalone or phenprocoumon or Marcoumar or Marcumar or Falithrom or AVK or phenprocoumon* or aldocumar or carfin or jantoven or kumatox or lawarin or marevan or prothromadin or sofarin or tedicumar or tintorane or waran or warfant or warfilone or warnerin):TI,AB,KY 476

\#47 MESH DESCRIPTOR Antithrombins 277 


\author{
\#48 MESH DESCRIPTOR Antithrombins EXPLODE ALL TREES 1354 \\ \#49 MESH DESCRIPTOR Hirudin Therapy 75 \\ \#50 (thrombin near3 inhib*):TI,AB,KY 559 \\ \#51 hirudin*:TI,AB,KY 383 \\ \#52 (BIBR-953* or BIBR953* or BIBR-1048 or BIBR1048):TI,AB,KY 9 \\ \#53 (ximelagatran or Exanta or Exarta or melagatran):TI,AB,KY 154 \\ \#54 (AZD0837 or AZD-0837):TI,AB,KY 14 \\ \#55 (S35972 or S-35972):TI,AB,KY 0 \\ \#56 MESH DESCRIPTOR Factor Xa Inhibitors 358 \\ \#57 (Factor $X^{\star}$ near4 (antag* or inhib* or block $\left.{ }^{\star}\right)$ ):TI,AB,KY 708 \\ \#58 (FX* near4 (antag* or inhib ${ }^{\star}$ or block $\left.\left.{ }^{\star}\right)\right): T I, A B, K Y 56$ \\ \#59 $\left(10^{\star}\right.$ near4 (antag* or inhib* or block*) ):TI,AB,KY 1226 \\ \#60 (rivaroxaban or Xarelto):TI,AB,KY 767 \\ \#61 (Bay-597939 or Bay597939):TI,AB,KY 0 \\ \#62 (betrixaban or PRT054021):TI,AB,KY 38 \\ \#63 apixaban:TI,AB,KY 457 \\ \#64 (BMS-562247 or BMS-562247 or ELIQUIS):TI,AB,KY 0 \\ \#65 (DU-176b or DU176b):TI,AB,KY 12 \\ \#66 (PRT-054021 or PRT054021):TI,AB,KY 1 \\ \#67 (YM150 or YM-150 or LY517717 or LY-517717 or DU-176b or
} DU176*):TI,AB,KY 44

\#68 (GW813893 or "Tak 442" or TAK442 or PD0348292 or GSK-813893 or GSK813893):TI,AB,KY 3

\#69 (edoxaban or lixiana):TI,AB,KY 254

\#70 *ixaban:TI,AB,KY 495

\#71 *axaban:TI,AB,KY 8

\#72 *exaban:TI,AB,KY 17

\#73 etexilate:TI,AB,KY 162

\#74 agatroban:TI,AB,KY 1

\#75 * parinux:TI,AB,KY 340

\#76 MESH DESCRIPTOR Platelet Aggregation Inhibitors EXPLODE ALL TREES 8757

\#77 MESH DESCRIPTOR Phosphodiesterase Inhibitors EXPLODE ALL TREES 5673

\#78 MESH DESCRIPTOR Tetrazoles EXPLODE ALL TREES 2866 
\#79 (antiplatelet* ${ }^{\star}$ r anti-platelet* ${ }^{\star}$ or antiaggreg* ${ }^{\star}$ or anti-aggreg ${ }^{\star}$ ):TI,AB,KY 3916

\#80 (((platelet or thromboxane or thrombocyte or cyclooxygenase or cyclo-oxygenase or phosphodiesterase or fibrinogen or PAR-1) near3 (antagonist or inhibitor))):TI,AB,KY 2589

\#81 (((gp* or glycoprotein* or protease or P2Y12 or TXA2) near3 inhibit $\left.\left.{ }^{\star}\right)\right): T I, A B, K Y 3512$

\#82 thienopyridine:TI,AB,KY 309

\#83 (ticlopidine or Ticlid):TI,AB,KY 1909

\#84 (clopidogrel or Plavix):TI,AB,KY 3552

\#85 (Prasugrel or Effient or Efient or Prasita):TI,AB,KY 648

\#86 (ticagrelor or AZD6140 or Brilinta):TI,AB,KY 647

\#87 (elinogrel or PRT060128 or PRT-060128):TI,AB,KY 8

\#88 (cangrelor or AR-C6993* or ARC6993*):TI,AB,KY 66

\#89 (SCH530348 or SCH-530348):TI,AB,KY 24

\#90 E5555:TI,AB,KY 6

\#91 (terutroban or Triplion):TI,AB,KY 17

\#92 (aspirin* or nitroaspirin or ASA):TI,AB,KY 18368

\#93 (acetylsalicylic acid):TI,AB,KY 5734

\#94 (acetyl salicylic acid*):TI,AB,KY 117

\#95 (triflusal or disgren):TI,AB,KY 103

\#96 (Cilostazol or Pletal or Pletaal):TI,AB,KY 520

\#97 (dipyridamol* or Persantine):TI,AB,KY 1165

\#98 (OPC-13013 or OPC13013):TI,AB,KY 5

\#99 (picotamide or picotinamide):TI,AB,KY 41

\#100 satigrel:TI,AB,KY 3

\#101 vorapaxar:TI,AB,KY 103

\#102 indobufen:TI,AB,KY 82

\#103 \#20 OR \#21 OR \#22 OR \#23 OR \#24 OR \#25 OR \#26 OR \#27 OR \#28 OR \#29 OR \#30 OR \#31 OR \#32 OR \#33 OR \#34 OR \#35 OR \#36 OR \#37 OR \#38 OR \#39 OR \#40 OR \#41 OR \#42 OR \#43 OR \#44 OR \#45 OR \#46 OR \#47 OR \#48 OR \#49 OR \#50 OR \#51 OR \#52 OR \#53 OR \#54 OR \#55 OR \#56 OR \#57 OR \#58 OR \#59 OR \#60 OR \#61 OR \#62 OR \#63 OR \#64 OR \#65 OR \#66 OR \#67 OR \#68 OR \#69 OR \#70 OR \#71 OR \#72 OR \#73 OR \#74 OR \#75 OR \#76 OR \#77 OR \#78 OR \#79 OR \#80 OR \#81 OR \#82 OR \#83 OR \#84 OR \#85 OR \#86 OR \#87 OR \#88 OR \#89 OR \#90 OR \#91 OR \#92 OR \#93 OR \#94 OR \#95 OR \#96 OR \#97 OR \#98 OR \#99 OR \#100 OR \#101 OR \#102 104894

\#104 \#7 AND \#19 AND \#103 100

\#105 01/01/2017 TO 29/11/2017:CD 109501 
(Continued)

\#106 \#104 AND \#105 28

7. ClinicalTrials.gov

antiphospholipid

10

(www.clinicaltrials.gov)

Searched 29 November

2017

8. ICTRP

antiphospholipid

1

Searched 29 November

2017

\section{CONTRIBUTIONS OF AUTHORS}

MMB developed the concept of the study, contributed to the preparation of this review and agreed upon this final version.

EP developed the concept of the study, contributed to the preparation of this review and agreed upon this final version.

WL contributed to the preparation of this review and agreed upon this final version.

DWK contributed to the preparation of this review and agreed upon this final version.

$\mathrm{KJ}$ contributed to the preparation of this review and agreed upon this final version.

$\mathrm{AU}$ developed the concept of the study, contributed to the preparation of this review and agreed upon this final version.

\section{DECLARATIONS OF INTEREST}

MMB receives honoraria as freelancer from a systematic review company that also works for pharmaceutical companies (Kleijnen Systematic Reviews Ltd). I am not aware of any direct conflict of interest.

EP: Abbott Vascular paid for her registration fee for the 20th International Congress of the Polish Cardiac Society.

WL has no known conflicts of interest.

DWK is an investigator in a clinical trial on drug-resistant epilepsy conducted by UCB Pharma.

KJ has no known conflicts of interest.

$\mathrm{AU}$ received honoraria for lectures relating to anticoagulant therapy in Poland and had travel expenses covered by Bayer, Boehringer Ingelheim, Pfizer, and Sanofi-Aventis.

\section{SOURCES OF SUPPORT}

\section{Internal sources}

- Jagiellonian University Medical College, Poland.

\section{External sources}

- Ministry of Science and Higher Education, Poland.

K/ZDS/007162; Core funding for statutory R\&D activities

- Chief Scientist Office, Scottish Government Health Directorates, The Scottish Government, UK.

The Cochrane Vascular editorial base is supported by the Chief Scientist Office.

\section{DIFFERENCES BETWEEN PROTOCOLAND REVIEW}

In our protocol we planned to analyse obstetric failure among thrombotic events, but as this outcome was thoroughly addressed by other Cochrane Reviews, de Jong 2014; Empson 2005, we did not analyse it in this review.

\section{NOTES}

We have based parts of the Methods section on a standard template established by Cochrane Vascular. 


\section{N D EX TERMS}

\section{Medical Subject Headings (MeSH)}

*Antibodies, Antiphospholipid; ${ }^{*}$ Primary Prevention; Anticoagulants [ ${ }^{\star}$ therapeutic use]; Antiphospholipid Syndrome [ ${ }^{\star}$ complications]; Platelet Aggregation Inhibitors [*therapeutic use]; Randomized Controlled Trials as Topic; Thrombosis [ ${ }^{*}$ prevention \& control]

\section{MeSH check words}

Humans 